US Army Corps

of Engineers ${ }_{\circledast}$

Engineer Research and

Development Center

Shallow Water Seakeeping Tests with

Columbia Class Submarine for Integration into the Environmental Monitoring and Operator Guidance System

Abigail L. Stehno and Jeffrey A. Melby

August 2020 
The US Army Engineer Research and Development Center (ERDC) solves the nation's toughest engineering and environmental challenges. ERDC develops innovative solutions in civil and military engineering, geospatial sciences, water resources, and environmental sciences for the Army, the Department of Defense, civilian agencies, and our nation's public good. Find out more at www.erdc.usace.army.mil.

To search for other technical reports published by ERDC, visit the ERDC online library at https://erdclibrary.on.worldcat.org/discovery. 


\section{Shallow Water Seakeeping Tests with Columbia Class Submarine for Integration into the Environmental Monitoring and Operator Guidance System}

Abigail L. Stehno and Jeffrey A. Melby

Coastal and Hydraulics Laboratory

US Army Engineer Research and Development Center

3909 Halls Ferry Road

Vicksburg, MS 39180-6199

Final report

Approved for public release; distribution is unlimited

Prepared for US Naval Surface Warfare Center Carderock Division

West Bethesda, MD 20817-5700

Under MIPR N0002418MP00414 


\section{Abstract}

The Environmental Monitoring and Operation Guidance System (EMOGS) tool was developed in 1989 to provide a real-time risk analysis for underkeel clearance for the Ohio class submarine while in transit to the Naval Submarine Base at Kings Bay, Georgia. The program computes expected submarine response for input water level, depth, speed, wave, and other input conditions using shallow-water motion transfer functions generated by the strip theory tool, Large Amplitude Motion Program (LAMP). The integration of the new Columbia class submarine into EMOGS required that new transfer functions be developed using LAMP. The LAMP results are to be validated using measured motions from physical model laboratory testing. This report summarizes a laboratory study of the Columbia class submarine response in shallow-water waves. The study was conducted at the US Army Engineer Research and Development Center, Coastal and Hydraulics Laboratory, and was done in direct support of the Naval Surface Warfare Center, Carderock Division. These seakeeping tests were performed in a shallow basin with a multidirectional wave generator, with measured still water vessel motions and measured vessel motion in regular and irregular waves of varying height, period, and direction.

DISCLAIMER: The contents of this report are not to be used for advertising, publication, or promotional purposes. Citation of trade names does not constitute an official endorsement or approval of the use of such commercial products. All product names and trademarks cited are the property of their respective owners. The findings of this report are not to be construed as an official Department of the Army position unless so designated by other authorized documents. 


\section{Contents}

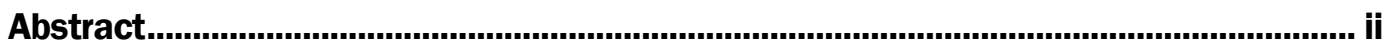

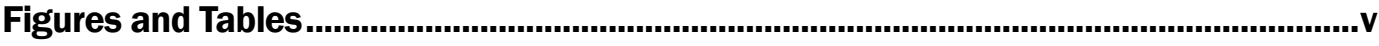

Preface

1 Introduction

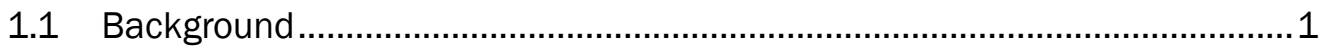

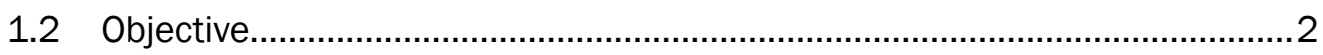

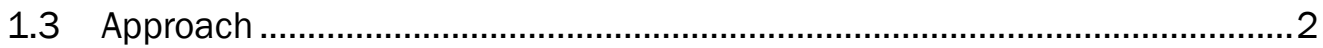

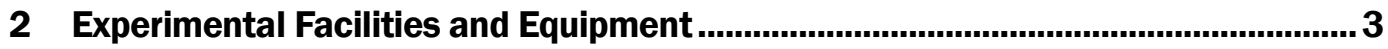

2.1 Directional Spectral Wave Generator (DSWG) .............................................

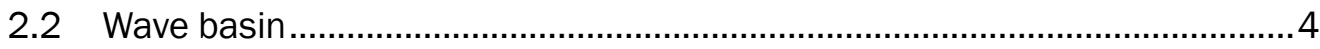

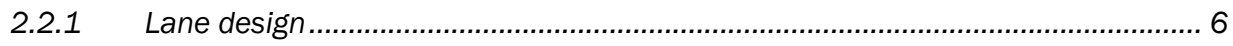

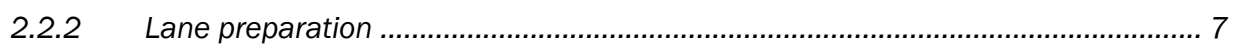

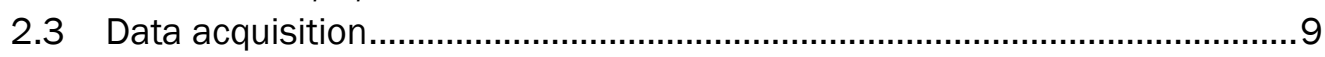

2.3.1 Senix ultrasonic sensors........................................................................ 9

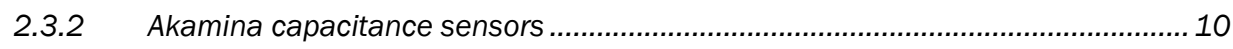

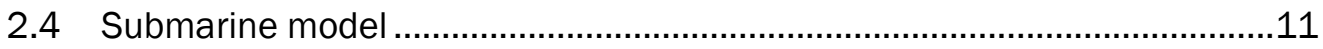

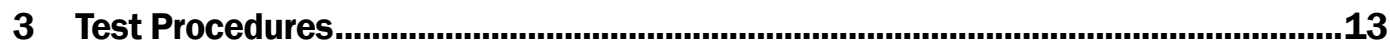

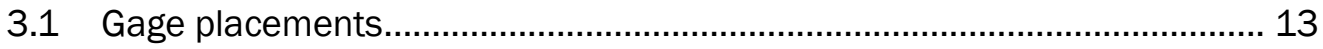

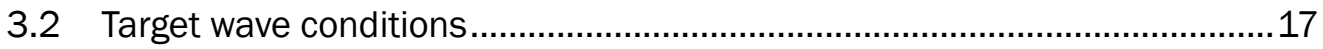

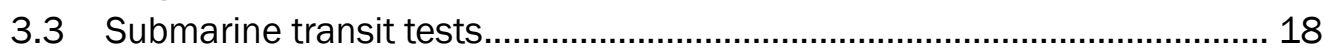

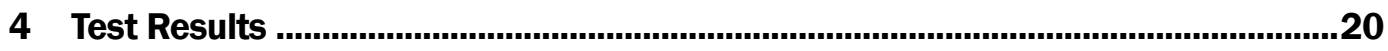

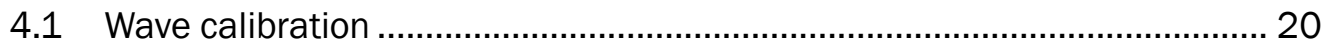

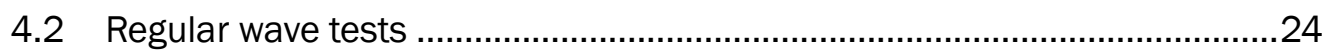

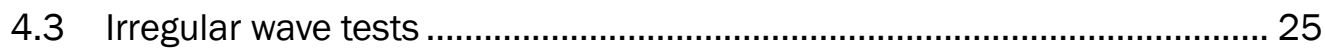

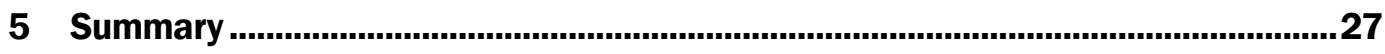

References............................................................................................................28

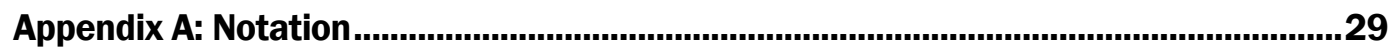

Appendix B: Gage Calibration Factors ........................................................................30

Appendix C: Calibration Results ............................................................................. 31

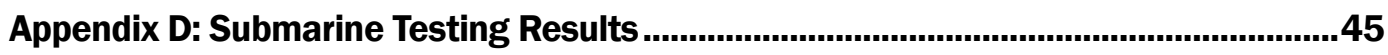

Unit Conversion Factors.................................................................................................... 72 


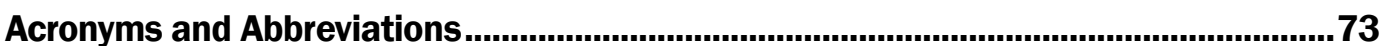

Report Documentation Page 


\section{Figures and Tables}

\section{Figures}

Figure 1. Plan view drawing of the shallow-water basin at ERDC with the DSWG at the east end (bottom), gate in red at the west end. Blue rectangles on the perimeter are wave absorbers, and green rectangles near the DSWG are guide vanes. The circles are the roof support poles. Length dimensions are in feet. 5

Figure 2. The upright wave absorber panels were placed along the walls of the basin, with the least porous panel closest to the wall.

Figure 3. The triangular absorbers at the transect lane ends that absorbed waves with the remnant waves reflect to the unused portion of the basin

Figure 4. Plan view drawing of the transit lane locations in the shallow-water basin, depicted by light green rectangles in the basin. Length dimensions are in feet.

Figure 5. Divots filled with concrete and mounds removed................................................. 8

Figure 6. Oblique lane with blue edging, facing east (left) and facing west (right).............. 8

Figure 7. Vertical lane with visible patches, facing east. DSWG is in the background.

Figure 8. Gage locations for layout 1 during wave calibration, shown as squares.............14

Figure 9. Gage locations for layout 2 wave calibration, shown as circles. .15

Figure 10. Gage locations during submarine testing, where triangles are Senix gages and circles are Akamina gages.

Figure 11. Target and measured wave spectra for gage 4 in sea state 3 calibrations.

\section{Tables}

Table 1. DSWG segment specifications (Rexroth 2003)...................................................... 3

Table 2. Wave operating requirements at $1 \mathrm{~m}$ water depth (Rexroth 2003)........................ 4

Table 3. Senix sensor specifications (Senix 2015). ............................................................10

Table 4. Akamina wave gage specifications (Akamina 2014)..............................................10

Table 5. Submarine model specifications for shallow water testing (Temple et al.

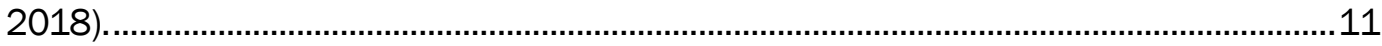

Table 6. Target regular wave parameters at a $1.927 \mathrm{ft}$ water depth................................17

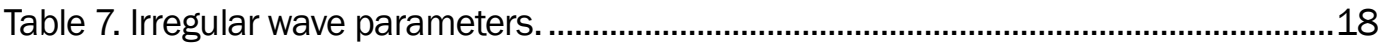

Table 8. Accuracy metrics for regular wave heights for gage location 9...........................21

Table 9. Accuracy metrics for regular wave periods for gage location 9...........................21

Table 10. Accuracy metrics for capacitance (C) gages 4, 8, and 13 in sea state 3

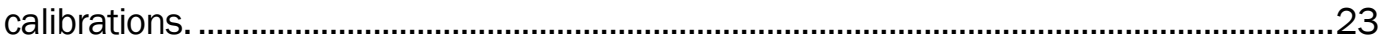

Table 11. The zero deg wave heights $H$ (inch) for the HS, FS, and BS. ..............................24

Table 12. The 5 deg wave heights $H$ (inch) for the BQ, SQ, and BQ-R.................................24 
Table 13. The zero deg wave period $T$ (second) for the HS, FS, and BS. ..........................25

Table 14. The 5 deg wave period $T$ (second) for the BQ, SQ, and BQ-R...........................25

Table 15. Sea state 3, BQ wave results for the capacitance (C) gages 5, 6, 7, and

9.

Table 16. Sea state 3, SQ wave results for the capacitance (C) gages 5, 6, 7, and

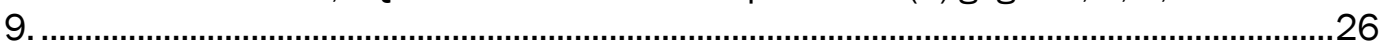

Table 17. Sea state 4, BQ wave results for capacitance (C) gages 5, 6, 7, and 9. .............26

Table 18. Sea state 4, SQ wave results for capacitance $(C)$ gages $5,6,7$, and $9 . \ldots \ldots \ldots . . . . .26$

Table B-1. Gage calibration factors. ................................................................................30

Table C-1. Wave heights (inch) for zero deg waves during wave calibration, setup

1.

Table C-2. Wave height RMSE (inch) for zero deg waves during wave calibration, setup 1.

Table C-3. Wave height standard deviations (inch) for zero deg waves during wave calibration, setup 1 .

Table C-4. Wave periods (second) for zero deg waves during wave calibration, setup 1.

Table C-5. Wave period RMSE (second) for zero deg waves during wave

calibration, setup 1 .

Table C-6. Wave heights (inch) for 5 deg waves during wave calibration, setup 1............34

Table C-7. Wave height RMSE (inch) for 5 deg waves during wave calibration, setup 1.

Table C-8. Wave height standard deviations (inch) for 5 deg waves during wave calibration, setup 1.

Table C-9. Wave periods (second) for 5 deg waves during wave calibration, setup

1.

Table C-10. Wave period RMSE (second) for 5 deg waves during wave calibration, setup 1.

Table C-11. Wave heights (inch) for zero deg waves during wave calibration, setup

2 , gages 1-10.

Table C-12. Wave heights (inch) for zero deg waves during wave calibration, setup

2 , gages 11-19.

Table C-13. Wave height RMSE (inch) for zero deg waves during wave calibration, setup 2, gages $1-10$.

Table C-14. Wave height RMSE (inch) for zero deg waves during wave calibration, setup 2, gages 11-19.

Table C-15. Wave height standard deviations (inch) for zero deg waves during wave calibration, setup 2, gages 1-10.

Table C-16. Wave height standard deviations (inch) for zero deg waves during wave calibration, setup 2, gages 11-19.

Table C-17. Wave periods (second) for zero deg waves during wave calibration, setup 2, gages $1-10$. 
Table C-18. Wave periods (second) for zero deg waves during wave calibration, setup 2, gages 11-19.

Table C-19. Wave period RMSE (second) for zero deg waves during wave calibration, setup 2, gages 1-10.

Table C-20. Wave period RMSE (second) for zero deg waves during wave calibration, setup 2, gages 11-19.

Table C-21. Wave heights (inch) for 5 deg waves during wave calibration, setup 2.

Table C-22. Wave height RMSE (inch) for 5 deg waves during wave calibration, setup 2.

Table C-23. Wave height standard deviations (inch) for 5 deg waves during wave calibration, setup 2 .

Table C-24. Wave periods (second) for 5 deg waves during wave calibration, setup 2.

Table C-25. Wave period RMSE (second) for 5 deg waves during wave calibration, setup 2.

Table C-26. Sea state 3 irregular wave characteristic statistics.

Table D-1. Wave heights (inch) by heading for wave M1. . .46

Table D-2. Wave periods (second) by heading for wave M1. 47

Table D-3. Wave heights (inch) by heading for wave M2 . .48

Table D-4. Wave periods (second) by heading for wave M2. .49

Table D-5. Wave heights (inch) by heading for wave M3. .50

Table D-6. Wave periods (second) by heading for wave M3 .51

Table D-7. Wave heights (inch) by heading for wave M4. . .52

Table D-8. Wave periods (second) by heading for wave M4. .53

Table D-9. Wave heights (inch) by heading for wave M5 . .54

Table D-10. Wave periods (second) by heading for wave M5.............................................55

Table D-11. Wave heights (inch) by heading for wave M6.................................................57

Table D-12. Wave periods (second) by heading for wave M6...........................................59

Table D-13. Wave heights (inch) by heading for wave M7...............................................61

Table D-14. Wave periods (second) by heading for wave M7. ..........................................63

Table D-15. Wave heights (inch) by heading for wave M8 ......................................................65

Table D-16. Wave periods (second) by heading for wave M8 ............................................66

Table D-17. Wave heights (inch) by heading for wave M9.................................................68

Table D-18. Wave periods (second) by heading for wave M9...........................................69

Table D-19. Irregular wave condition statistics for sea state 3 for SQ................................ 71

Table D-20. Irregular wave condition statistics for sea state 4 for SQ................................71

Table D-21. Irregular wave condition statistics for sea state 3 for BQ................................ 71

Table D-22. Irregular wave condition statistics for sea state 4 for BQ................................ 71 


\section{Preface}

The study summarized in this report was conducted at the request of the Naval Surface Warfare Center, Carderock Division (NSWCCD), under MIPR Noo02418MPo0414. Mr. Dylan Temple was the primary engineering point of contact at NSWCCD, and Mr. Andrew Silver was the project lead. The portion of the study reported herein was funded by NSWCCD and primarily conducted at the US Army Engineer Research and Development Center (ERDC), Coastal and Hydraulics Laboratory (CHL), Vicksburg, MS, during the period January 2018-September 2018.

Work was conducted through the Harbors, Entrances, and Structures Branch, CHL. Messrs. Raymond R. Reed, Cody M. Bryant, De'Arius Christmas, Gregory P. Mitchell, and William C. Gatlin provided technical assistance.

Appreciation is expressed to Mr. Glenn B. Myrick for his valuable contributions to this effort.

The study was performed under the general supervision of Mr. Jim Gutshall, Chief, Harbors, Entrances, and Structures Branch, and Dr. Jackie Pettway, Chief, Navigation Division. At the time of publication of this report, Mr. Jeffrey R. Eckstein was the Deputy Director of CHL, and Dr. Ty V. Wamsley was the Director.

COL Teresa A Schlosser was the Commander of ERDC, and the Director was Dr. David W. Pittman. 


\section{Introduction}

This report summarizes a laboratory study of the Columbia class submarine response in shallow-water waves. The study was conducted at the US Army Engineer Research and Development Center (ERDC), Coastal and Hydraulics Laboratory (CHL), and was performed in direct support of the Naval Surface Warfare Center, Carderock Division (NSWCCD). Final results of the submarine response observations were intended to integrate the Columbia class submarine into the Environmental Monitoring and Operator Guidance System (EMOGS). These seakeeping tests were performed in a shallow basin with a multi-directional wave generator, operated by CHL.

\subsection{Background}

The EMOGS tool was developed in 1989 to provide real-time risk analysis for underkeel clearance for the Ohio class submarine while in transit to the Naval Submarine Base (NSB) at Kings Bay, Georgia. The controlled dredge depth at the entrance channel is $46 \mathrm{ft}^{*}$ mean lower low water. While this depth is sufficient for calm sea navigation, vessel motions induced by wave conditions create a risk of grounding. Additional dredging was cost prohibitive; therefore, the EMOGS tool was created to calculate the risk based on the current atmospheric and ocean conditions during transit to the NSB.

The Columbia class submarine has been under development to replace the Ohio class submarine, which is nearing the end of its 42-year service life. The integration of a vessel into EMOGS requires knowledge of the vessel motion in shallow water. Channel depth, roll motion, and vessel design components will affect vessel motions under wave forcing. For risk assessment, the shallow-water motion transfer functions were generated by the strip theory tool, Large Amplitude Motion Program (LAMP). The

\footnotetext{
* For a full list of the spelled-out forms of the units of measure used in this document, please refer to US Government Publishing Office Style Manual, 31st ed. (Washington, DC: US Government Publishing Office 2016), 248-52, https://www.govinfo.gov/content/pkg/GPO-STYLEMANUAL-2016/pdf/GPOSTYLEMANUAL-2016.pdf.
} 
LAMP results were validated using measured motions from physical model testing, accounting for effects due to vessel motion in waves.

\subsection{Objective}

ERDC was tasked with facilitating the shallow-water seakeeping study for integrating the Columbia class submarine into EMOGS. A shallow-water basin was prepared, and wave conditions corresponding to those measured near the NSB entrance channel were generated using a directional spectral wave generator.

\subsection{Approach}

Prior to the shallow-water testing described herein, deep-water physical model testing was performed at the Maneuvering and Seakeeping Basin at NSWCCD. Surface testing for deep-water waves was performed to calibrate instruments, measure roll decay, perform sinkage and trim tests, and analyze vessel performance under a limited set of regular and irregular wave conditions. Shallow-water testing at CHL was conducted in a shallow basin with a multi-directional wave generator to investigate the seakeeping characteristics of the Columbia class submarine in shallowwater waves and to characterize calm water sinkage, trim decay, and roll decay of the surfaced vessel.

The model was tested at $8 \mathrm{kt}$ and $12 \mathrm{kt}$ prototype speeds at following, head, beam, bow quartering, and stern quartering headings, each in nine regular wave conditions. Additionally, the model was tested at both speeds at bow quartering and stern quartering headings in irregular waves. The irregular wave conditions are sea state 3 and sea state 4 , which correspond to the historical data collected at the wave buoy stationed at the Kings Bay Channel. The motion response of the surfaced submarine under regular and irregular wave conditions was used by NSWCCD to validate the LAMP model for shallow-water wave conditions. 


\section{Experimental Facilities and Equipment}

The shallow-water basin at ERDC was graded to a uniform flat bottom and included a new directional spectral wave generator that is capable of generating multi-directional regular and irregular wave conditions that the Columbia class submarine may experience near the seaward entrance of the NSB at Kings Bay, Georgia. ERDC facilities allowed NSWCCD to accurately measure underkeel clearance of the submarine model for EMOGS integration.

\subsection{Directional Spectral Wave Generator (DSWG)}

The DSWG is a wet-back piston-type segmented wave generator consisting of 48 segment wave boards, producing a $76 \mathrm{ft}$ long multidirectional wave front. The segment specifications are found in Table 1.

Table 1. DSWG segment specifications (Rexroth 2003).

\begin{tabular}{|r|l|}
\hline Segment height $(\mathrm{ft})$ & 4.92 \\
\hline Centerline to centerline distance $(\mathrm{ft})$ & 1.62 \\
\hline Amplitude of motion $(\mathrm{ft})$ & 1.64 \\
\hline Drive force (normal operation) (lbf) & 494.58 \\
\hline Maximum still water level (ft) & 3.28 \\
\hline Velocity (normal operation) (fps) & 3.28 \\
\hline
\end{tabular}

The operational limits of the DSWG for regular and irregular waves are presented in Table 2. Segment movements are computed though GEDAP software on a personal computer to generate soliton, regular long crested, irregular long crested, and short crested waves, JONSWAP ${ }^{*}, \mathrm{TMA}^{\dagger}$, and Pierson-Moskowitz spectra, in perpendicular and oblique directions. Additionally, the segments may be controlled individually in "manual mode" to produce customizable paddle motions. Individual paddle accuracy is $\pm 0.5 \%$ for amplitude, velocity, and acceleration, and is $\pm 0.1 \%$ for frequency between 0.2 and $2.0 \mathrm{~Hz}$. Irregular waves produce a $\pm 1 \%$ deviation of amplitude from the command signal (Rexroth 2003).

\footnotetext{
* Joint North Sea Wave Project spectrum

† Texel, Marsen, and Arsole Spectrum
} 
Table 2. Wave operating requirements at $1 \mathrm{~m}$ water depth (Rexroth 2003).

\begin{tabular}{|l|l|}
\hline \multicolumn{2}{|c|}{ Regular Wave Operation } \\
\hline Period Range (s) & 0.5 to 5 \\
\hline Angle of propagation (deg) & 0 to 75 \\
\hline Wave height at 1.5 s period (ft) & 1.31 \\
\hline Wave height at 2.4 s period (ft) & 1.94 \\
\hline Wave height at 3.0 s period (ft) & 1.64 \\
\hline Wave height at 5.0 s period (ft) & 1.31 \\
\hline \multicolumn{2}{|c|}{ Irregular Wave Operation } \\
\hline Angle of propagation (deg) & 0 to 75 \\
\hline Significant wave height at peak period of 3.0 s (ft) & 0.98 \\
\hline Significant wave height at peak period of $2.3 \mathrm{~s}(\mathrm{ft})$ & 1.19 \\
\hline
\end{tabular}

\subsection{Wave basin}

The shallow water basin is an indoor concrete basin $191 \mathrm{ft}$ long and $149 \mathrm{ft}$ wide with a maximum depth of $3 \mathrm{ft}$ (Figure 1). Four roof support poles, each $8 \mathrm{in}$. in diameter, are aligned in the north-south direction $94 \mathrm{ft}$ from the east wall of the basin and spaced $39 \mathrm{ft}$ apart. The DSWG is located on the east end of the basin, and a sealed door is located on the west end of the basin.

The inner perimeter of the basin was lined with upright wave absorbers to reduce wave reflections from the sidewalls during testing (Figure 2). Additional upright wave absorbers were placed behind the DSWG to minimize sloshing effects during operation. The upright wave absorbers measure $10 \mathrm{ft}$ long, $7 \mathrm{ft}$ wide, and $4 \mathrm{ft}$ high. They are composed of 14 rows of perforated vertical expanded metal sheets wired to a frame. The porosity of the array decreases from the front to back of the frame. The design results in an average wave reflection coefficient of $3.2 \%$ and maximum wave reflection coefficient of 11.2\% (Jamieson and Mogridge 2000). Smaller, triangular absorbers were placed at the ends of the transit lanes to absorb and reflect waves to the unused portion of the basin (Figure 3). Guide vanes were placed adjacent to the side of the DSWG to prevent waves generated behind the machine from transmitting into the testing area. Each guide vane was $9 \mathrm{ft}$ long, $2 \mathrm{ft}$ wide, and $4 \mathrm{ft}$ high. 
Figure 1. Plan view drawing of the shallow-water basin at ERDC with the DSWG at the east end (bottom), gate in red at the west end. Blue rectangles on the perimeter are wave absorbers, and green rectangles near the DSWG are guide vanes. The circles are the roof support poles. Length dimensions are in feet.

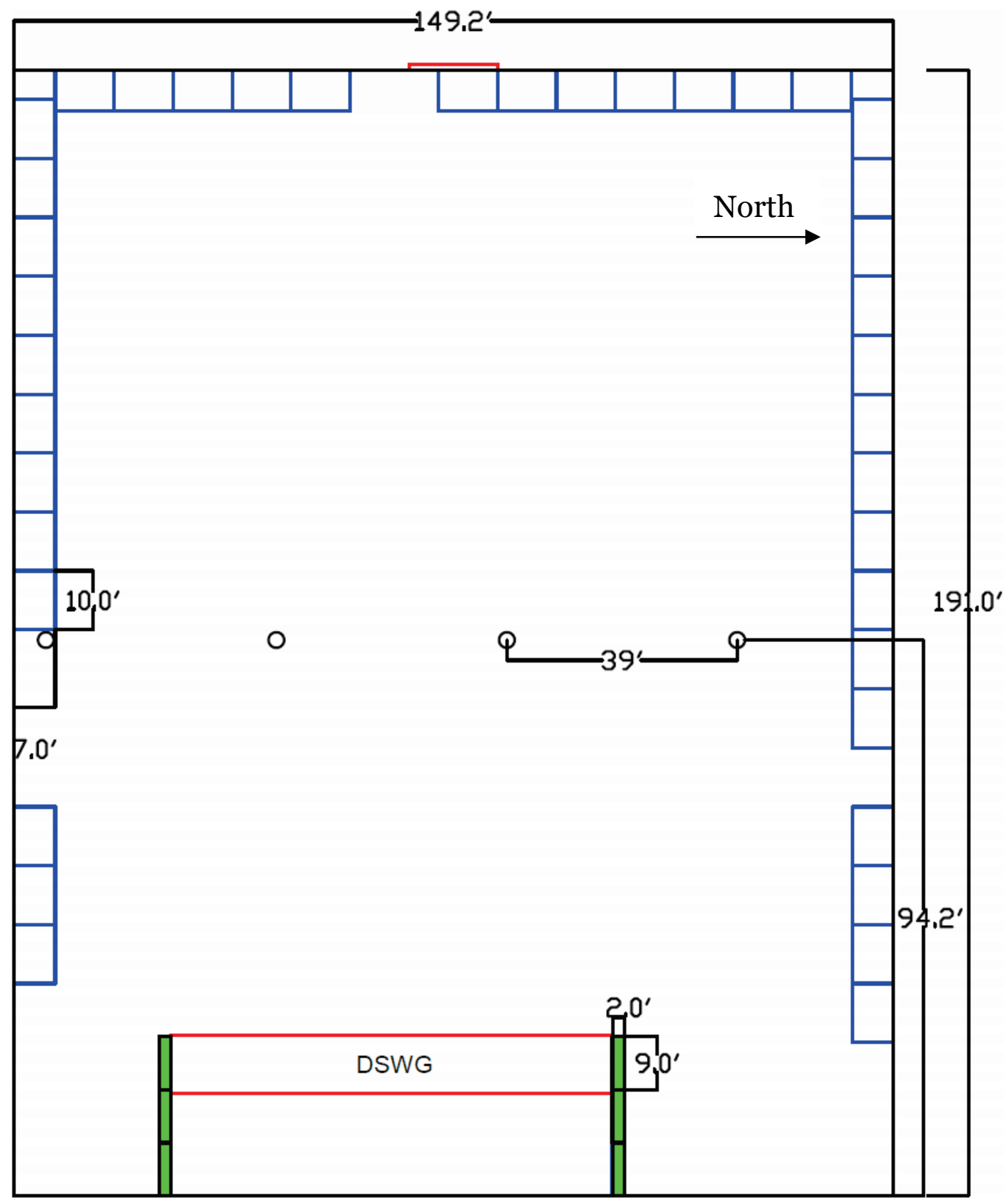


Figure 2. The upright wave absorber panels were placed along the walls of the basin, with the least porous panel closest to the wall.

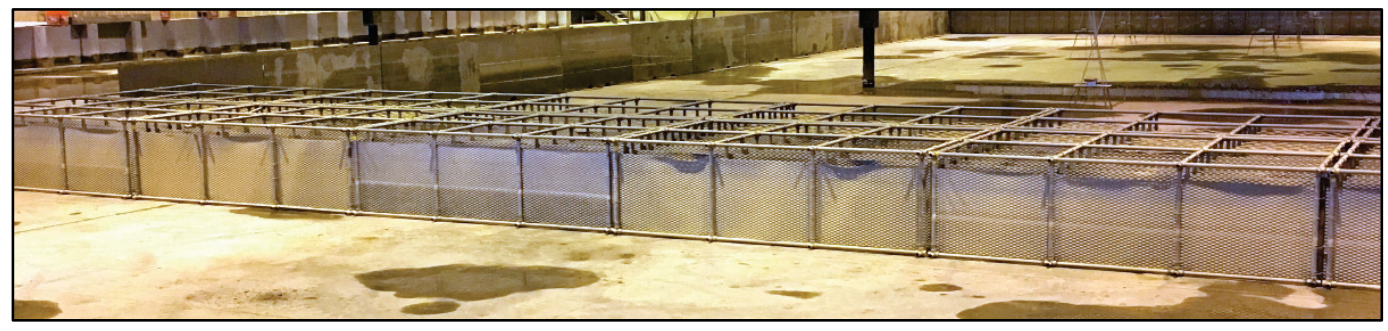

Figure 3. The triangular absorbers at the transect lane ends that absorbed waves with the remnant waves reflect to the unused portion of the basin.

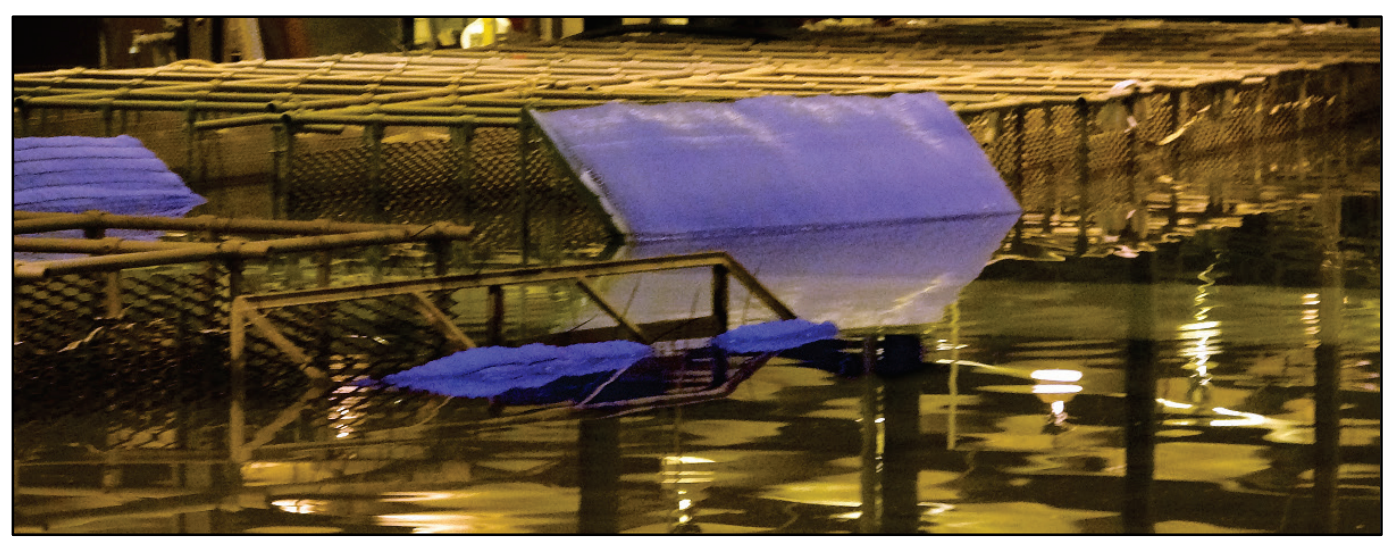

\subsubsection{Lane design}

The experiment was configured so that individual submarine transits were confined to transit lanes (Figure 4). The lane layout for the 2018 EMOGS experiment was based on the experiment conducted in 1988 for $\mathrm{NSWCCD}^{*}$. Three $8 \mathrm{ft}$ wide lanes were required for the model submarine to be exposed to the five relative wave directions used for EMOGS calibration. Lanes were delineated by marks on the floor. A $150 \mathrm{ft}$ long vertical lane was perpendicular to the wave generator and was offset from the centerline of the DSWG by $1 \mathrm{ft}$ to the south. The vertical lane was used for head and following seas. A $140 \mathrm{ft}$ horizontal lane was aligned with the north-south direction and located $39.8 \mathrm{ft}$ from the face of the DSWG. The horizontal lane was used for beam seas. A $205.5 \mathrm{ft}$ oblique lane was rotated 40 deg to the north of the vertical lane and was used for quartering stern and quartering bow seas.

* Outlaw, D. G., D. L. Green, L. A. Barnes, M. J. Briggs, and D. A. Daily. 1988 (unpublished). David Taylor Submarine Seakeeping Study. Miscellaneous Paper CERC-88-nn. Vicksburg, MS: Department of the Army, Waterways Experiment Station, Corps of Engineers, Coastal Engineering Research Facility. 
Figure 4. Plan view drawing of the transit lane locations in the shallow-water basin, depicted by light green rectangles in the basin. Length dimensions are in feet.

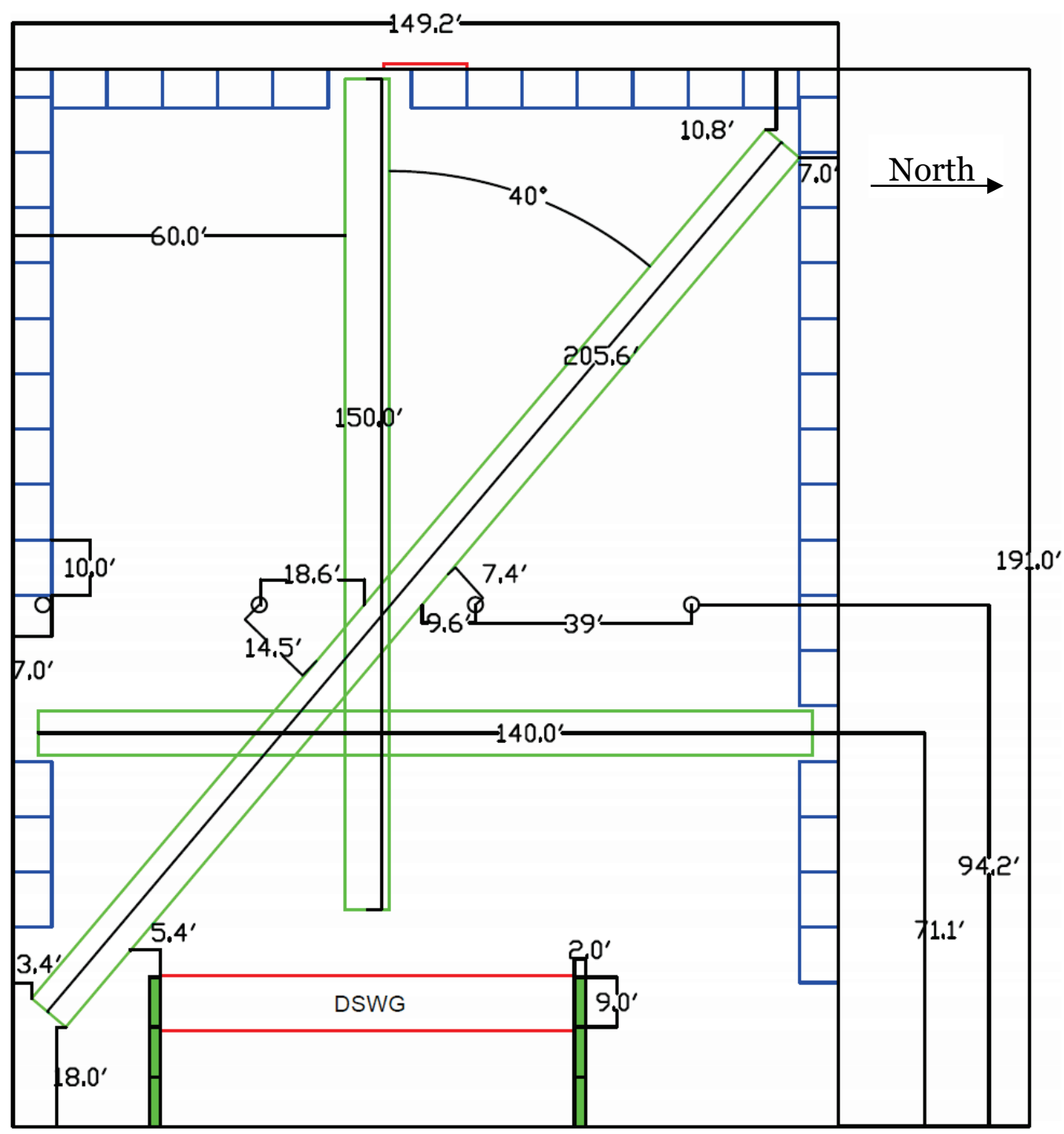

\subsubsection{Lane preparation}

The lane bottoms required a uniform depth within a $\pm 0.01 \mathrm{ft}$ tolerance for accurate measurements from the onboard ultrasonic sensors. An initial LIDAR scan was taken of the basin floor, which measured a $0.0242 \mathrm{ft}$ difference between the highest and lowest points in the basin prior to lane preparations. Floor low spots were filled with a sand and concrete mixture, and the high spots were ground down to the required tolerance (Figure 5). A second LIDAR scan was taken after basin preparations to ensure floor variations were within tolerance within the transit lanes. 
Figure 5. Divots filled with concrete and mounds removed.

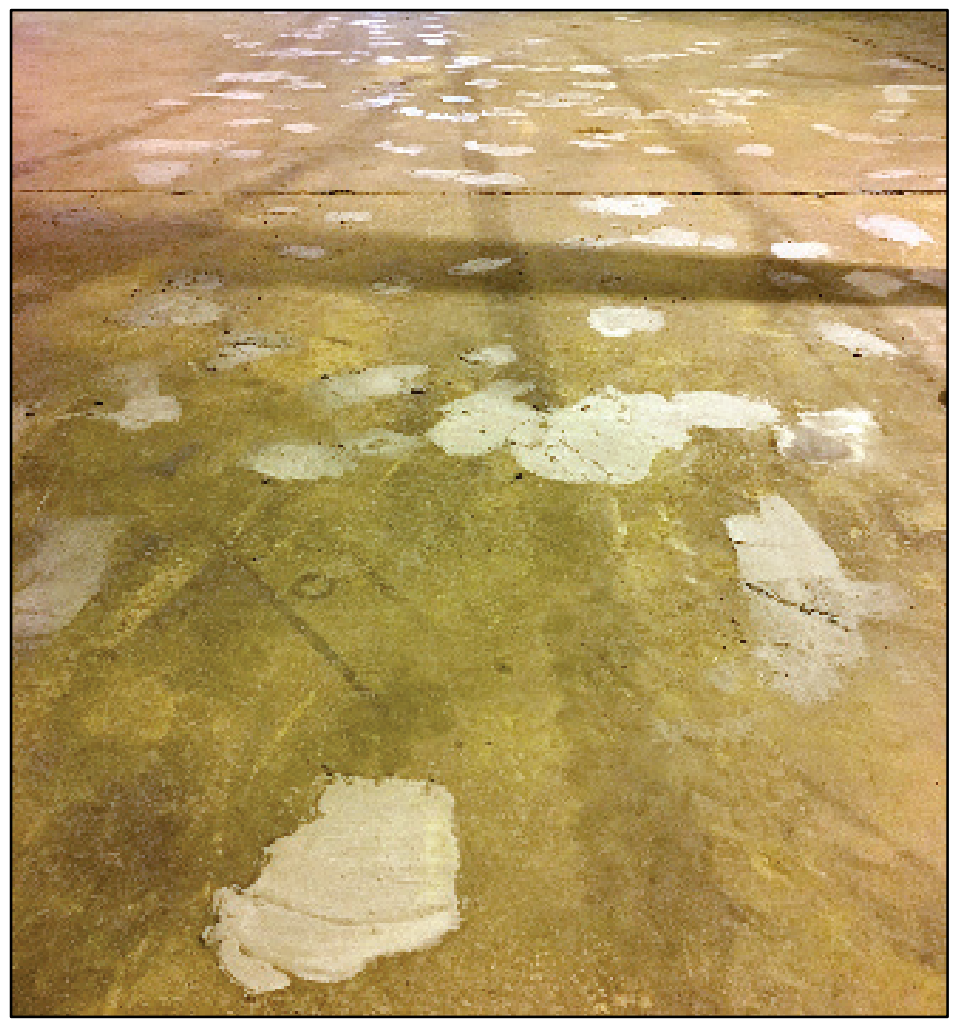

Each lane was painted a safety yellow to create a visual contrast between the floor and the submarine during testing. A blue border was added alongside the lanes to create a distinct lane edge for the submarine operator to view during testing (Figure 6). Additional floor deviations were filled with quick-drying epoxy filler (Figure 7).

Figure 6. Oblique lane with blue edging, facing east (left) and facing west (right).

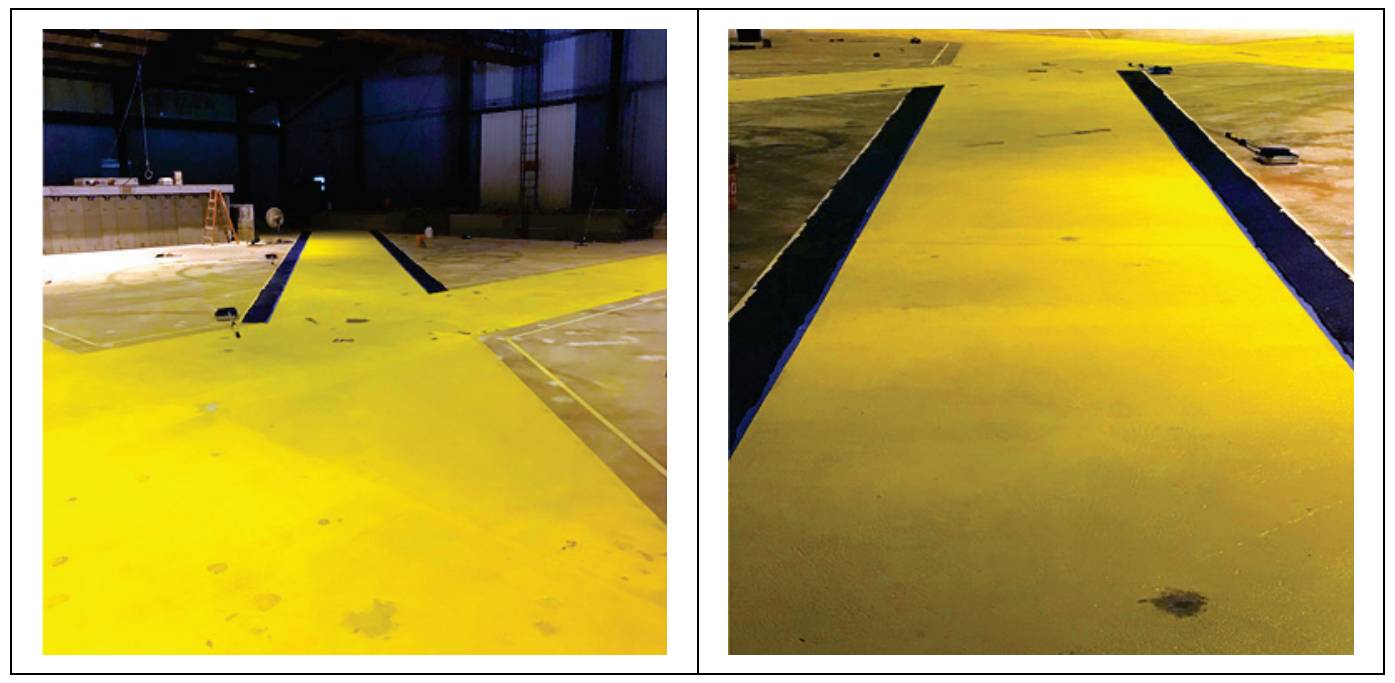


Figure 7. Vertical lane with visible patches, facing east. DSWG is in the background.

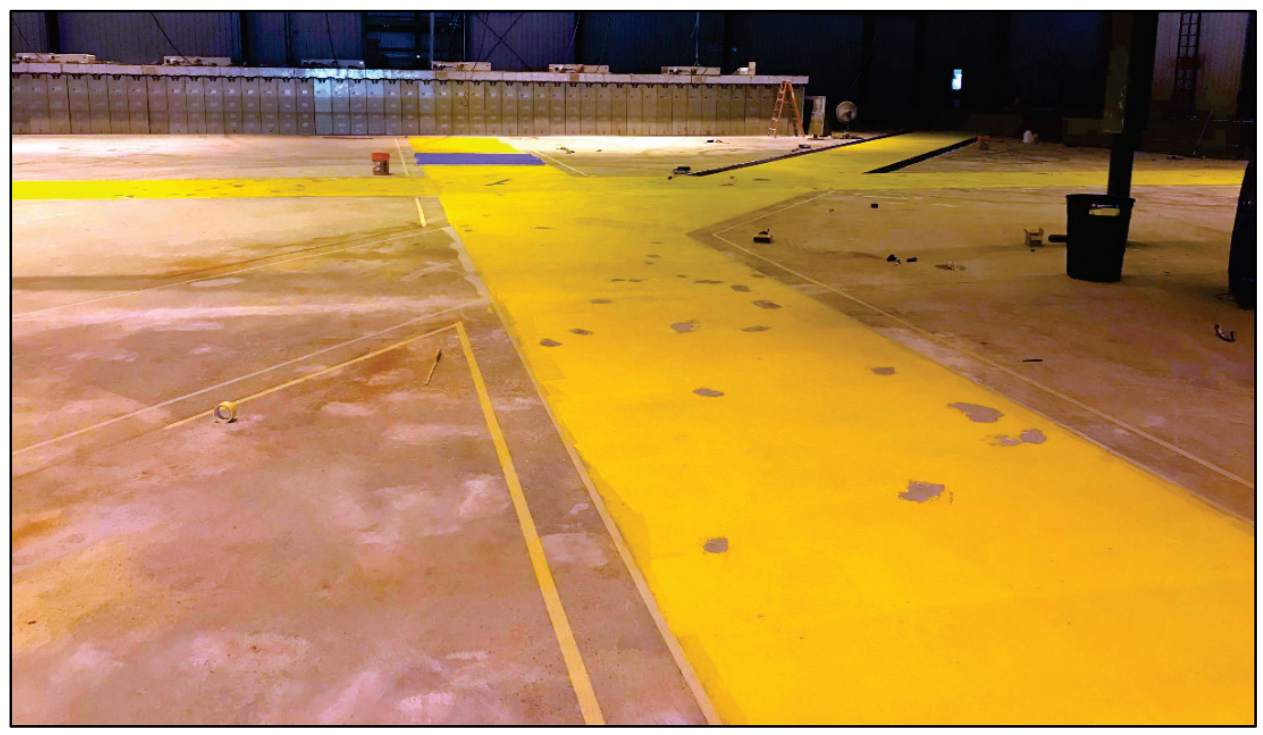

\subsection{Data acquisition}

Water surface elevations were measured during wave calibration and submarine testing with ultrasonic sensors and capacitance gages. These instruments were mounted on tripods, where the ultrasonic sensors were 13 in. above the still water level (SWL) and the capacitance gages were positioned with approximately half of the capacitance wire below the SWL. Instrumentation placement within the basin is discussed in Section 3 .

A multiplexing box was located on a roof support near the center of the basin. Data from the sensors and gages were transmitted to the multiplexing box through a double-shielded, twisted-pair cable. Power was also supplied from the multiplexing box to the sensors through this cable. The data were transferred to the control room over an Ethernet cord to be recorded by the data acquisition (DAQ) software, Laboratory Virtual Instrumentation Engineering Workbench (LabVIEW).

\subsubsection{Senix ultrasonic sensors}

Two Senix ToughSonic 14 sensors were placed in the basin during testing. These sensors produce ultrasonic pulses and record the time required for the sound wave to travel the distance from emitter to the water level and return. These high-resolution, noncontact, temperature-compensated instruments output voltage loops to a DAQ system for recording. The Senix sensors were mounted 13 in. above the water level to allow 
measurement of water surface variations up to 12 in. from SWL. Sensor specifications from the manufacturer are presented in Table 3.

Table 3. Senix sensor specifications (Senix 2015).

\begin{tabular}{|l|l|}
\hline Accuracy & Better than 0.5\% of target distance \\
\hline Resolution & $0.0034 \mathrm{in}$. \\
\hline Minimum Range & $4 \mathrm{in}$. \\
\hline Maximum Range & $168 \mathrm{in}$. \\
\hline Measurement Update Rate & Between $20 \mathrm{~Hz}$ and $200 \mathrm{~Hz}$ \\
\hline
\end{tabular}

Configuration and calibration of the Senix sensors were done at Carderock prior to testing. Results from the calibration are presented in Appendix B. The sensors automatically compensate for temperature changes and therefore do not require recalibration over the course of the testing period. The sonar gages sampled at $50 \mathrm{~Hz}$.

\subsubsection{Akamina capacitance sensors}

During wave calibration, water level variations were measured with 19 Akamina Technologies AWP-24-3 gages. These gages measure capacitance using digital techniques, which is then converted to an analogue voltage (proportional to the level of water variation from SWL), offset adjusted, amplified, and filtered to be sent to a DAQ system for recording. The Akamina gages were mounted to ensure the calibrated section of the probe was submerged to accurately record the full range of water levels under all anticipated wave conditions. Gage specifications from the manufacturer are presented in Table 4 .

Table 4. Akamina wave gage specifications (Akamina 2014).

\begin{tabular}{|l|l|}
\hline Linearity & $0.15 \%$ of full scale \\
\hline Accuracy & $0.15 \%$ of full scale \\
\hline Air Temperature Coefficient & $0.03 \%$ of full scale $/{ }^{\circ} \mathrm{C}$ \\
\hline Water Temperature Coefficient & $0.03 \%$ of full scale $/{ }^{\circ} \mathrm{C}$ \\
\hline Measurement Update Rate & $200 \mathrm{~Hz}$ \\
\hline
\end{tabular}

The Akamina gages were configured and calibrated at ERDC prior to wave calibration and testing. The configuration procedure in the Akamina Technologies AWP-24-3 Wave Height Gage User's Guide (2014) was 
applied. The linear relationship between water depth and gage output voltage was determined through calibration. The resultant calibration coefficients are presented in Appendix B.

The Akamina Technologies AWP-24-3 wave gages are highly linear (0.15\%) and highly accurate (0.15\%) (Akamina 2014). These gages also remain stable through large air and water temperature changes and therefore only require the initial calibration prior to water level measurements. The capacitance gages sampled at $50 \mathrm{~Hz}$.

\subsection{Submarine model}

The model of the Columbia class submarine and hydraulic basin model was scaled according to Froude similitude with a geometrically undistorted length scale of $\mathrm{N}_{\mathrm{L}}=23.8751$ and time and speed scaled according to $\mathrm{N}_{\mathrm{T}}=\left(\mathrm{N}_{\mathrm{L}}\right)^{0.5}=4.886$. The model submarine operated at the surface draft of the full-scale Columbia, ballasted to match the center of gravity and moments of inertia of the full-scale model. Model length and speed specifications are defined in Table 5. Additional specifications are defined in Temple et al. (2018).

Table 5. Submarine model specifications for shallow water testing (Temple et al. 2018).

\begin{tabular}{|l|l|l|}
\hline Parameter & Model \#5763 $(\lambda:$ 23.8751) & Columbia \\
\hline Length overall & $23.46 \mathrm{ft}$ & $560.05 \mathrm{ft}$ \\
\hline Diameter & $21.78 \mathrm{in}$. & $43.33 \mathrm{ft}$ \\
\hline $\begin{array}{l}\text { Surfaced } \\
\text { displacement }\end{array}$ & $2976.3 \mathrm{lb}$ (fresh water) & $\begin{array}{l}18535 \mathrm{LT} \\
\text { (saltwater) }\end{array}$ \\
\hline Surfaced draft @ FP & $18.31 \mathrm{in}$. & $36.42 \mathrm{ft}$ \\
\hline Surfaced draft @ AP & $18.51 \mathrm{in}$. & $36.83 \mathrm{ft}$ \\
\hline Slow transit speed & $2.8 \mathrm{ft} / \mathrm{s}$ & $8.0 \mathrm{kt}$ \\
\hline Fast transit speed & $4.1 \mathrm{ft} / \mathrm{s}$ & $12.0 \mathrm{kt}$ \\
\hline
\end{tabular}

The model was controlled remotely using control surfaces on the X-stern for steering and an unclassified propeller for propulsion. The X-stern configuration on the model consisted of fixed stabilizers and a trailing edge flap to control motions, representative of the full-scale design. The propeller operated at known rotations per minute for the respective transit 
speeds. The model required approximately $40 \mathrm{ft}$ of spin-up distance to obtain full speed and approximately $20 \mathrm{ft}$ to stop by reversing propellers.

Instruments operated by NSWCCD were fitted to the model to measure vessel motions and underkeel clearance. These data were transmitted in real time to the operator to monitor the motions and safety of the submarine during testing. Additionally, the model was fitted with two Senix ultrasonic sensors, one mounted on booms forward at the bow and one outward to stern port. These sensors were used to measure the incident wave, as described in Temple et al. (2018). Underwater sonic sensors were used in the shallow-water testing to determine sinkage. All onboard probes and sensors were sampled and recorded by NSWCCD personnel with their computer equipment and programs and are not reported herein. Vessel motion and underkeel clearance data processing was completed by NSWCCD and is not discussed further in this report. 


\section{Test Procedures}

Wave calibrations were completed prior to the submarine testing to ensure the DSWG was producing the expected wave conditions. Wave gages were placed into the basin in and around the lanes during wave calibration. After wave conditions were calibrated, submarine transit tests occurred. Twelve wave gages remained in the basin during the submarine testing, allowing a cross-check of the wave conditions with the calibrated wave. Measurements of the submarine motions were completed by NSWCCD.

\subsection{Gage placements}

Three gage layout patterns were used, two during wave calibration and one during testing. The two layouts used during wave calibration ensured that the desired wave heights were generated within the lanes. Gage locations during the wave calibration are shown in Figure 8 and Figure 9, where the squares are the locations for the first layout pattern and the circles are the locations for the second layout pattern. Multiple layout patterns were used to fully capture the wave condition variations in the basin with a limited set of gages. The final layout resulted in an array, with the first row parallel to the wave machine starting $12 \mathrm{ft}$ away from the face of the DSWG and succeeding rows parallel to the wave machine spaced $16 \mathrm{ft}$ from each other. In the first layout, the rows perpendicular to the wave machine created by the array were spaced $20 \mathrm{ft}$ apart, with the center rows perpendicular to the wave machine being aligned with the center of the vertical lane. The second layout continued to follow this pattern; however, additional rows perpendicular to the wave machine were spaced $10 \mathrm{ft}$ on each side from the original array and additional gages were located within the lanes.

A third layout combined gage locations completely outside of the lanes from the first two layouts. This arrangement allowed for measured wave conditions during submarine testing to be compared to the measured wave conditions from the wave calibration. Gage locations during the testing are shown in Figure 10, where the circles are Akamina wave gages and the triangles are the Senix sensors. 
Figure 8. Gage locations for layout 1 during wave calibration, shown as squares.

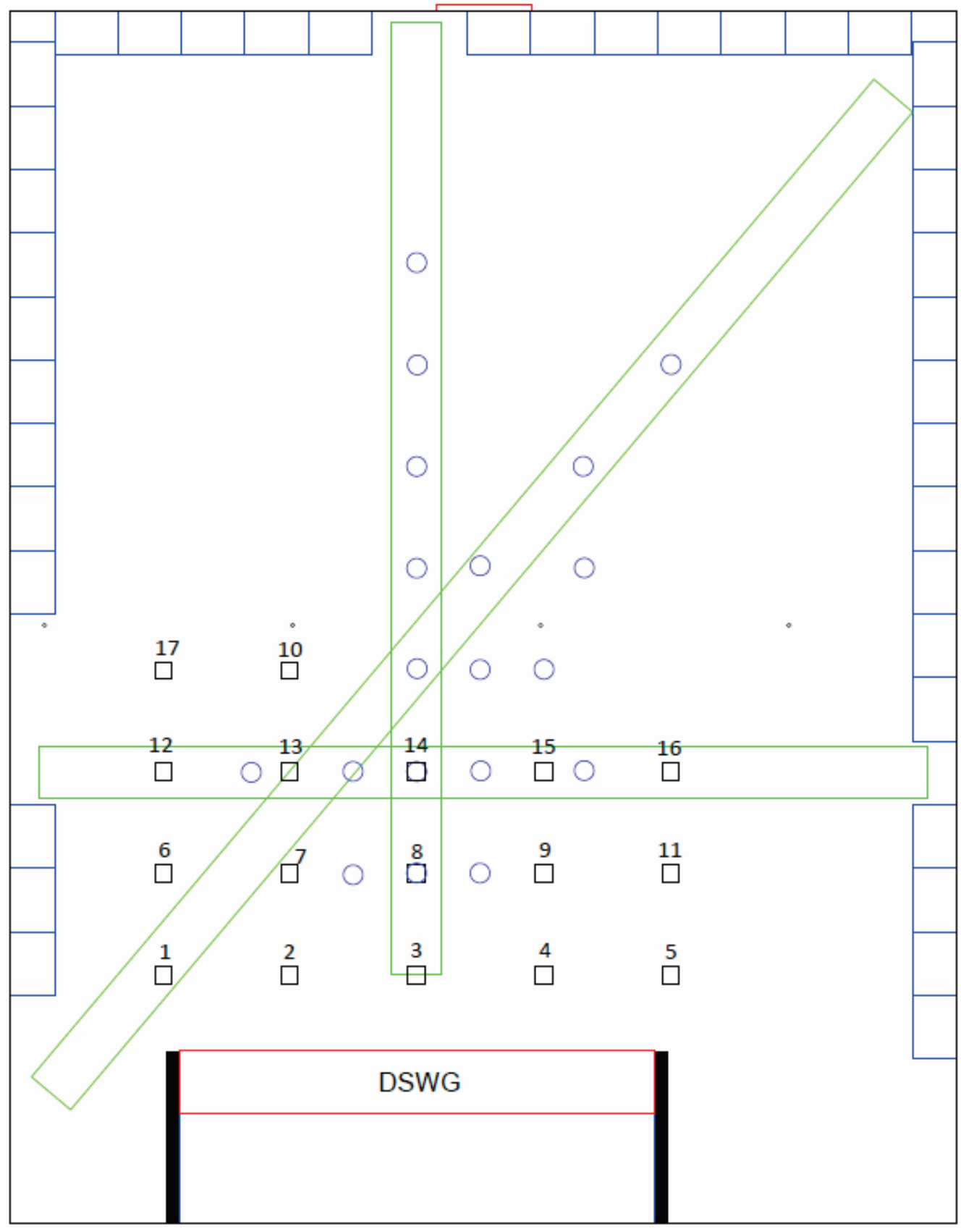


Figure 9. Gage locations for layout 2 wave calibration, shown as circles.

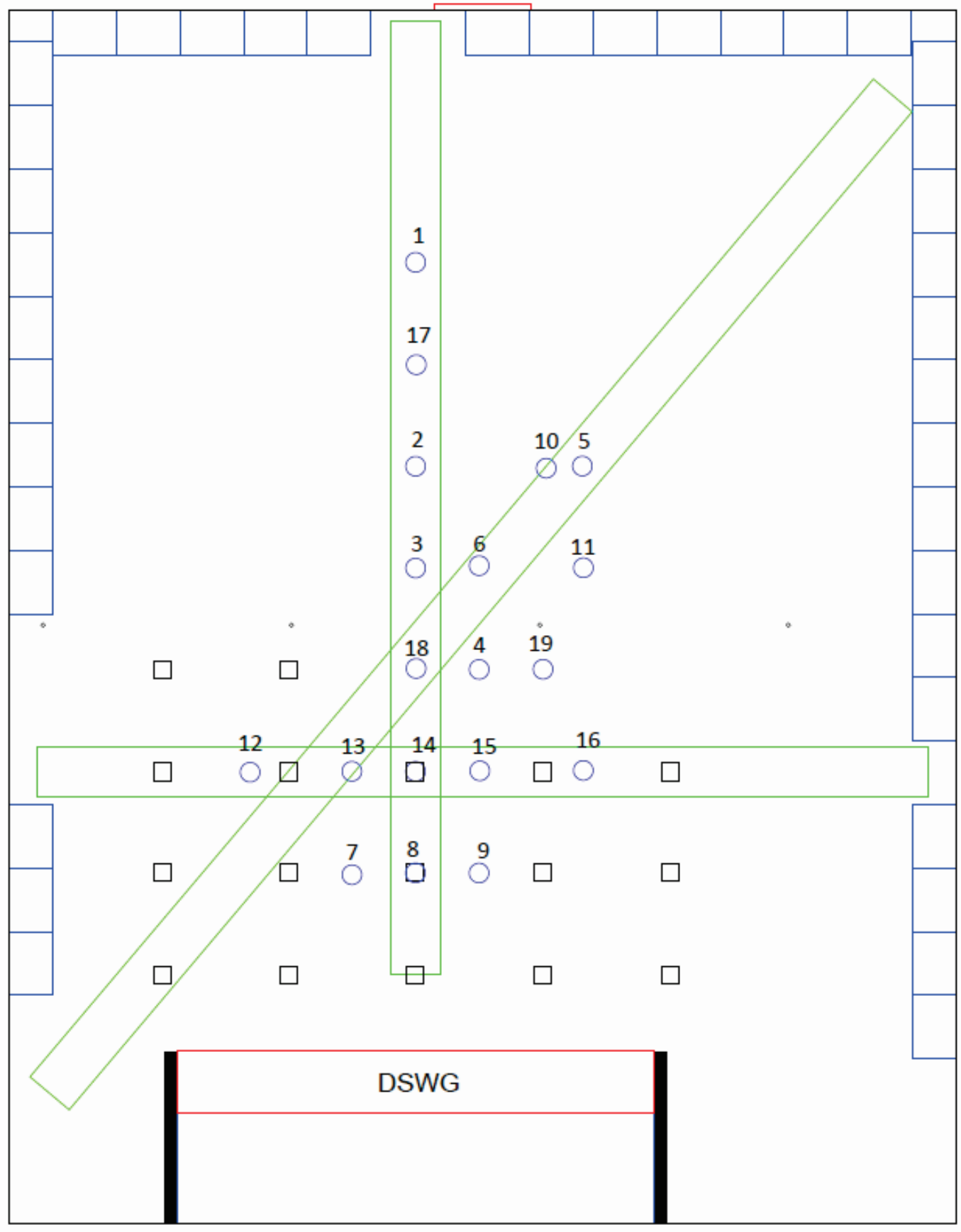


Figure 10. Gage locations during submarine testing, where triangles are Senix gages and circles are Akamina gages.

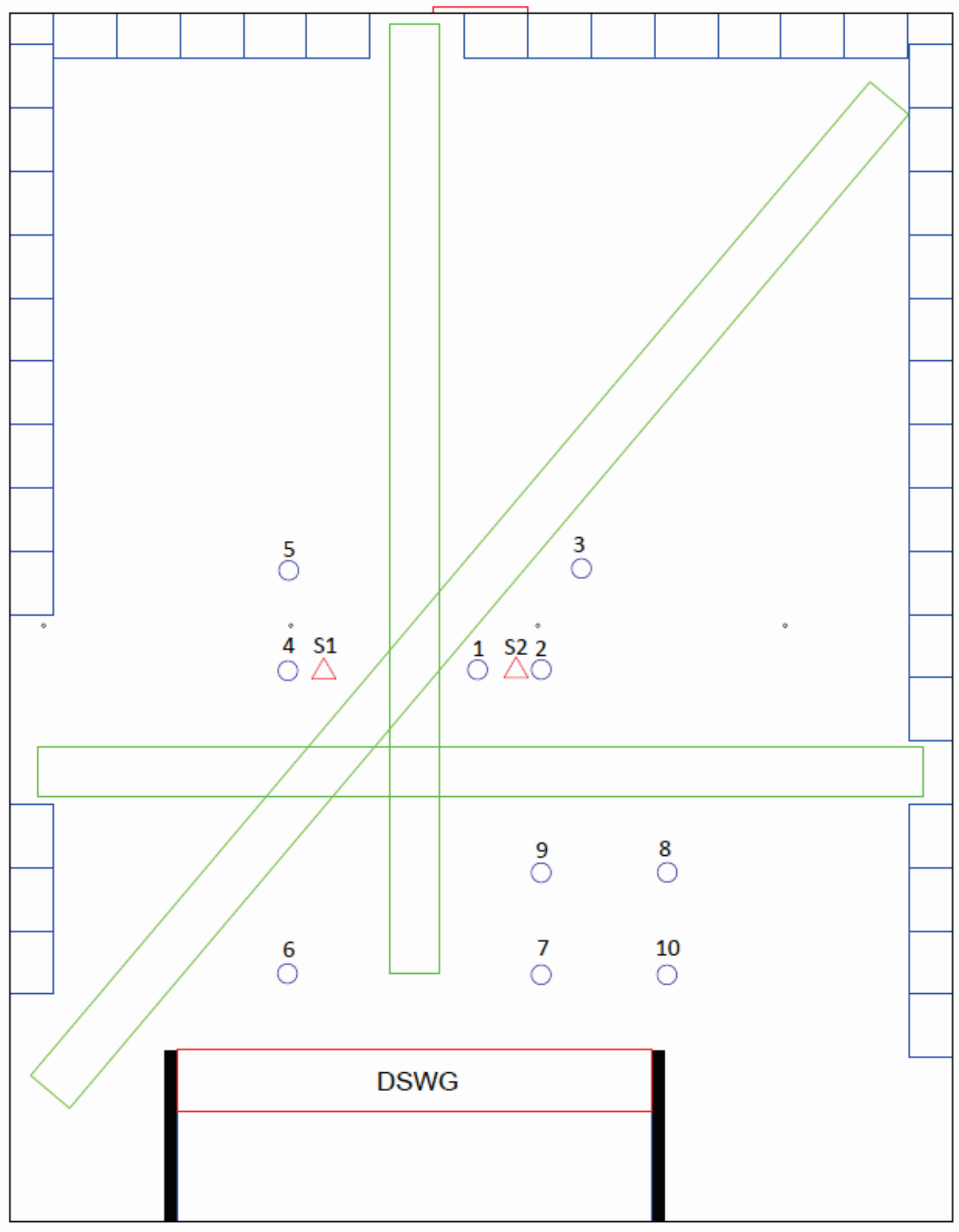




\subsection{Target wave conditions}

The conditions in the basin for the regular waves are described in Table 6 at model scale. Each wave condition was run at zero deg and 5 deg at a $1.927 \mathrm{ft}$ water depth, to fulfill the required wave directions that the submarine encountered with respect to its heading. These wave conditions are similar to those used in Outlaw et al. ${ }^{*}$ and were prescribed by NSWCCD (Temple et al. 2018). The values for the target wave conditions were scaled using Froude similitude, as discussed in Section 2.4, and calibrated to the gages near the transit lanes.

Some wave conditions were modified during testing to reduce the risk of submarine grounding. The wave heights were adjusted during testing if extreme vessel motions were noticed or expected for certain wave frequencies.

Table 6. Target regular wave parameters at a $1.927 \mathrm{ft}$ water depth.

\begin{tabular}{|c|c|c|}
\hline Wave & $\begin{array}{c}\text { Wave Period } \\
\text { T (s) }\end{array}$ & $\begin{array}{c}\text { Wave Height } \\
\text { H (in.) }\end{array}$ \\
\hline M1 & 0.963 & 0.9 \\
\hline M2 & 1.335 & 1.5 \\
\hline M3 & 1.721 & 2.1 \\
\hline M4 & 2.402 & 3.0 \\
\hline M5 & 2.683 & 3.0 \\
\hline M6 & 3.111 & 3.0 \\
\hline M7 & 3.543 & 3.0 \\
\hline M8 & 3.832 & 3.0 \\
\hline M9 & 4.562 & 3.0 \\
\hline
\end{tabular}

The irregular wave conditions are summarized in Table 7 at model scale and a wave angle of $5 \mathrm{deg}$. The NSWCCD requested sea states 3 and 4. The waves were generated with a TMA spectrum with a frequency spreading parameter of 3.3 , recycling period of $15 \mathrm{~min}$, and cutoff

* Outlaw, D. G., D. L. Green, L. A. Barnes, M. J. Briggs, and D. A. Daily. 1988 (unpublished). David Taylor Submarine Seakeeping Study. Miscellaneous Paper CERC-88-nn. Vicksburg, MS: Department of the Army, Waterways Experiment Station, Corps of Engineers, Coastal Engineering Research Facility. 
frequencies of 0.05 and $2.0 \mathrm{~Hz}$. One random number seed was used to create the wave spectrum for the wave calibration. During calibration, 1 min increments were run to ensure fully formed waves were present throughout the testing area. During testing, the wave spectrum was run for approximately 2 to $2.5 \mathrm{~min}$ increments to ensure fully formed waves were present throughout the testing area prior to submarine transit. The increments were concatenated to form the full spectrum to analyze the wave spectral parameters.

Table 7. Irregular wave parameters.

\begin{tabular}{|l|c|c|}
\hline Wave & $\begin{array}{c}\text { Peak Wave Period } \\
T_{p}(\mathrm{sec})\end{array}$ & $\begin{array}{c}\text { Significant Wave Height } \\
\left(H_{\text {mo }}\right)(\text { in. })\end{array}$ \\
\hline SS3 & 1.840 & 1.38 \\
\hline SS4 & 1.517 & 3.324 \\
\hline
\end{tabular}

\subsection{Submarine transit tests}

The submarine was remotely controlled by a model driver positioned on top of the DSWG. The model driver was responsible for diving the model and monitoring it during runs. The data were collected in real time to monitor vessel motions, which were used to make decisions for any onthe-fly adjustments to the test plan, such as modifying the wave height. Three to four submarine handlers were positioned in the basin to ensure safe operation. A punt operator was located at the start of the transit lane to align the model against the alignment poles, set the model up for its zero reading, and position the model in the center of the lane and at the correct heading prior to initiating a transit. The additional handlers were located at the end of transit lane to catch the model as it stopped. These handlers controlled the submarine before and after testing, and re-positioned the submarine at the beginning of the transit lane after each test. A wave generator operator was located in a control room to start and stop wave generation and modify wave conditions based on the submarine operator's decisions.

Within each of the transit lanes, the submarine operational area was limited by the spin-up and stopping distances for the fast and slow transit speeds of 12 and $8 \mathrm{kt}$, full scale. Although the layout of the lanes was designed to produce maximum wave encounters during submarine transit, the operational zone was limited. Multiple iterations of each test were performed to increase wave encounters. 
The submarine transit start times depended on the influence of the waves in the transit lane. Operation began once the wave front was in the transit lane for regular waves; however, care was taken that there were minimal wave re-reflections in the basin and that the model did not outrun the wave field. For the irregular waves, the strategy was to run the full spectrum in short segments to limit the effect of wave re-reflections from basin walls. In this case, the submarine transit started after the slowest wave had reached the west wall, approximately 1 min after the generator started producing waves. The full $15 \mathrm{~min}$ wave spectrum was run in increments of approximately 2 to $2.5 \mathrm{~min}$, where each increment started at the end of the previous increment. Transit time for the submarine lasted approximately $1 \mathrm{~min}$ and began once the basin was fully saturated with the irregular wave. Once the entire signal had been generated, a new one was created using a different random number seed. The increments were concatenated to ensure each seed produced the desired wave conditions. 


\section{Test Results}

The wave conditions during the calibration and testing phases were measured, and an error analysis was completed. The calibration of the zero deg waves were compared with the measurements for the head seas (HS), following seas (FS), and beam seas (BS). The testing for these headings required either a zero deg wave or a 90 deg wave, which was accomplished using waves generated with no obliquity but with different submarine orientations in the vertical and horizontal tracks. The $45 \mathrm{deg}$ heading was accomplished with a combination of 5 deg wave generation obliquity and $40 \mathrm{deg}$ lane angle. The calibration of the $5 \mathrm{deg}$ waves was compared with the measurements for the bow quartering seas (BQ), stern quartering seas (SQ), and the bow quartering sea repeats using M6 and M7 (BQ-R). Testing procedures are detailed in Temple et al. (2018).

During calibration and testing, some of the gages were placed outside of the influence of the generator (to define the wave falloff in the shadow areas), and some were affected by reflections from the roof support poles or from the walls at a 5 deg wave generation obliquity. Additionally, some of the gages were impacted by the submarine wake. Because of these factors, wave analysis focused only on gages where these laboratory effects were minimized. The results from gage location 9 , from calibration setup 1 and during testing, is presented herein for the regular waves because its location was within the influence of the generator to measure fully formed waves and was not heavily impacted by the submarine wake. The results from gage locations 4,8 , and 13 , from calibration setup 2, is presented for the irregular wave calibrations and gage locations 5, 6, 7, and 9, from the testing setup, is presented for the irregular transit test waves. These gages were selected to define the irregular wave characteristics because their locations were within the influence of the generator at a 5 deg wave generation obliquity.

\subsection{Wave calibration}

Wave calibrations were performed prior to submarine testing to ensure that the target wave conditions were being achieved in the basin, specifically in the transit lanes. The complete set of calibration results is found in Appendix C. 
During wave calibrations, it was noticed that the Akamina capacitance gages were not measuring the crest of the regular waves, resulting in a flattened top. The wave heights measured from the Akamina gages were compared to those measured from the Senix gages. The difference between the wave heights measured was within the resolution and accuracy tolerances of the two gages; therefore, the errors from the Akamina measurements were determined to be insignificant.

The M1-M9 regular waves were generated in the zero and 5 deg directions. Two sets of gage arrangements were used to determine the wave field. For each gage, wave height $(H)$ and wave period $(T)$ were determined using a zero-crossing method. The root-mean-square-error (RMSE) ( $H_{R M S E}$ and $\left.T_{R M S E}\right)$, and standard deviation $\left(H_{\text {stdev }}\right)$ were used as metrics for measurement accuracy for each wave condition, where the target conditions from Table 6 were the predicted value for comparison.

During wave calibration, each gage was analyzed; however, some gages were either outside the wave influence or affected by reflected waves. Calibration metrics for gage location 9 is presented due to its location in the influence of waves, shown in Table 8 and Table 9.

Table 8. Accuracy metrics for regular wave heights for gage location 9.

\begin{tabular}{|l|l|c|c|c|c|c|c|c|c|c|}
\hline & & $\mathbf{M} 1$ & $\mathbf{M} 2$ & $\mathbf{M} 3$ & $\mathbf{M} 4$ & $\mathbf{M} 5$ & $\mathbf{M} 6$ & $\mathbf{M} 7$ & $\mathbf{M} 8$ & $\mathbf{M} 9$ \\
\hline $\mathbf{0}^{\circ}$ & $H$ (in.) & 0.86 & 1.37 & 2.19 & 3.63 & 2.86 & 3.36 & 3.44 & 3.28 & 2.56 \\
\hline & $H_{\text {stdev }}$ (in.) & 0.04 & 0.15 & 0.12 & 0.65 & 0.22 & 0.36 & 0.53 & 0.29 & 0.46 \\
\hline & $H_{\text {RMSE }}$ (in.) & 0.02 & 0.07 & 0.09 & 0.14 & 0.17 & 0.08 & 0.28 & 0.04 & 0.14 \\
\hline $\mathbf{5}^{\circ}$ & $H$ (in.) & 0.85 & 1.69 & 2.44 & 3.26 & 3.22 & 2.80 & 2.81 & 2.91 & 2.93 \\
\hline & $H_{\text {stdev }}$ (in.) & 0.06 & 0.21 & 0.35 & 0.27 & 0.24 & 0.20 & 0.22 & 0.10 & 0.13 \\
\hline & $H_{\text {RMSE }}$ (in.) & 0.03 & 0.08 & 0.03 & 0.08 & 0.08 & 0.05 & 0.11 & 0.06 & 0.12 \\
\hline
\end{tabular}

Table 9. Accuracy metrics for regular wave periods for gage location 9.

\begin{tabular}{|l|l|c|c|c|c|c|c|c|c|c|}
\hline & & M1 & M2 & M3 & M4 & M5 & M6 & M7 & M8 & M9 \\
\hline $\mathbf{0}^{\circ}$ & $T(\mathrm{~s})$ & 0.96 & 1.34 & 1.72 & 2.40 & 2.68 & 3.11 & 3.53 & 3.83 & 4.57 \\
\hline & $T_{R M S E}(\mathrm{~s})$ & 0.03 & 0.02 & 0.02 & 0.03 & 0.03 & 0.02 & 0.10 & 0.03 & 0.05 \\
\hline $\mathbf{5}^{\circ}$ & $T(\mathrm{~s})$ & 0.96 & 1.34 & 1.72 & 2.40 & 2.68 & 3.12 & 3.55 & 3.84 & 4.56 \\
\hline & $T_{R M S E}(\mathrm{~s})$ & 0.01 & 0.01 & 0.02 & 0.04 & 0.03 & 0.03 & 0.04 & 0.03 & 0.06 \\
\hline
\end{tabular}


The calibration of the wave heights and periods showed that the DSWG was accurately producing the target regular wave conditions. There was some deviation from the anticipated wave heights in the zero deg wave from M4 to M9, but this remained acceptable. The deviation in wave periods were insignificant. The low RMSE and standard deviations in both the zero and 5 deg wave directions provided confidence that the generator was performing consistently.

The remainder of the gages were analyzed for deviations in both wave height and period. Any deviations from the target regular waves were insignificant or explainable. Significant deviations were due to gage placement outside of the DSWG influence. It was determined that the target regular waves were being produced in the transit lanes and the regular waves were accepted for submarine testing.

The 15 irregular wave calibrations were performed in 1 min increments and were concatenated together to characterize the wave energy density spectrum. The sea state 4 waves were planned to be run at a zero deg heading and were calibrated as such; however, during submarine transit testing, it was decided that sea state 4 waves would provide more valuable results at a quartering heading. This wave condition was not calibrated prior to the submarine testing but was verified during testing.

The second gage layout was used for calibration of irregular waves. Because this gage layout focused on wave characteristics within the lanes, rather than throughout the basin, there were limited gage locations during calibration that overlapped with locations during submarine transit testing. Therefore, gages 4,8 , and 13 were analyzed to characterize the wave spectrum for quartering sea headings during calibration.

A spectral analysis was completed for each gage using concatenated 1 min signals. The results of the spectral analysis were compared to the TMA wave spectrum. Target and measured wave spectra for gage 4 are shown in Figure 11. Here the measured energy in the basin was less than the target TMA energy due to the concatenation.

The statistical analysis for gages 4,8 , and 13 are presented in Table 10. The remaining irregular wave calibration results are found in Appendix $\mathrm{C}$. The energy-based significant wave heights were computed using $H_{m o}=4\left(\mathrm{~m}_{0}\right)^{0.5}$. The irregular wave period $T_{p}$ was computed from the peak frequency as $T_{p}$ 
$=1 / f_{p}$. The standard deviation was computed for the energy-based significant wave height, and the RMSE, with respect to predicted values, were computed for the peak wave period.

Figure 11. Target and measured wave spectra for gage 4 in sea state 3 calibrations.

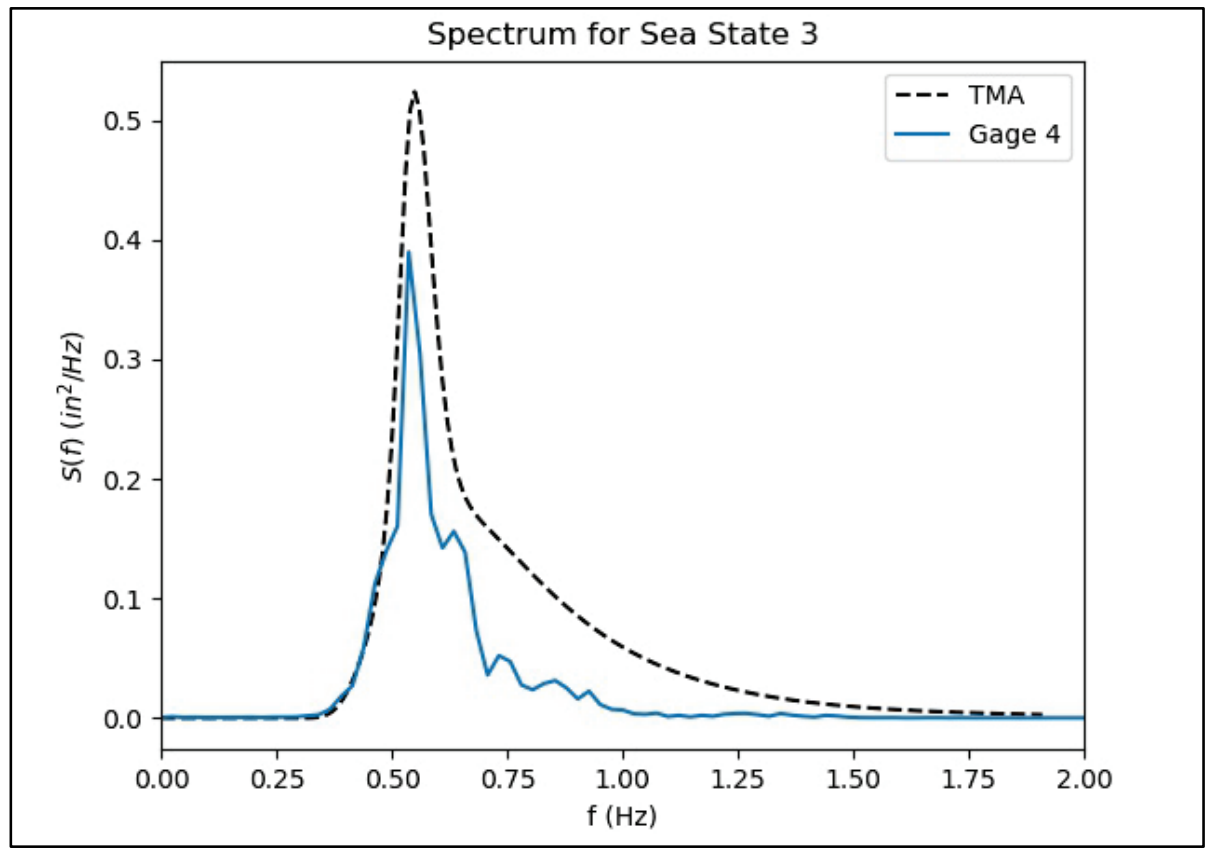

Table 10. Accuracy metrics for capacitance

(C) gages 4, 8, and 13 in sea state 3 calibrations.

\begin{tabular}{|l|c|c|c|c|}
\hline Sensor & C4 & C8 & C13 & Average \\
\hline$H_{m 0}$ (in.) & 0.95 & 1.04 & 0.91 & 0.97 \\
\hline$H_{l / 3}$ (in.) & 1.14 & 1.11 & 1.13 & 1.13 \\
\hline$H_{m 0 \text { stdev }}$ (in.) & 0.02 & 0.02 & 0.02 & 0.02 \\
\hline$T_{p}$ (s) & 1.86 & 1.86 & 1.86 & 1.86 \\
\hline$T_{p R M S E}(\mathrm{~s})$ & 0.02 & 0.02 & 0.02 & 0.02 \\
\hline
\end{tabular}

The energy-based wave heights $\left(H_{m 0}\right)$ for sea state 3 were lower than the target wave conditions. Uncertainty in the $H_{m o}$ statistic was primarily due dispersion and rereflection of the relatively small number of total waves per increment (approximately 30) that influenced the testing area. Thus, the zero upcrossing method was also used to determine the significant wave heights $\left(H_{1 / 3}\right)$ for comparison (Table 10). The $H_{1 / 3}$ statistic was a more reliable measure of the irregular wave heights for this study. However, related studies required $H_{m o}$ to be defined for comparison. 
The zero crossing significant wave heights were similar to the energybased significant wave heights. Although the measured $H_{m o}$ values were lower than the target $H_{m o}$, these wave heights were deemed acceptable in order to reduce the risk of the submarine hitting the bottom of the basin. The $H_{m o}$ values were not spatially uniform; however, the $H_{1 / 3}$ were. The $H_{m o}$ was not reliable so the differences between gages do not necessarily indicate that the waves were spatially non-uniform. The energy-based significant wave height standard deviations for sea state 3 were low, providing confidence in the repeatability of the wave conditions. The peak wave periods were consistent during calibration and had little error.

\subsection{Regular wave tests}

The wave heights and periods from gage 9 are presented in Table 11 through Table 14. Multiple runs were completed for each heading and wave condition, so the values presented are averaged over these runs. The full set of results is in Appendix D.

During the submarine testing, the vessel motions resulted in a small underkeel clearance due to the influence of waves. To limit the submarine motions, the wave height was reduced, denoted in red in Table 11 and Table 12. The wave periods were not adjusted during testing.

Table 11. The zero deg wave heights $H$ (inch) for the HS, FS, and BS.

\begin{tabular}{|c|c|c|c|c|c|c|c|c|c|}
\hline & M1 & M2 & M3 & M4 & M5 & M6 & M7 & M8 & M9 \\
\hline HS & 0.96 & 1.29 & 2.22 & 3.72 & 1.26 & 1.41 & 1.23 & 1.95 & 1.23 \\
\hline FS & 0.96 & 1.49 & 2.47 & 3.61 & 2.94 & 3.29 & 3.36 & 3.26 & 2.64 \\
\hline BS & 0.92 & 1.49 & 2.30 & 2.15 & 1.43 & 1.53 & 3.38 & 3.37 & 2.68 \\
\hline
\end{tabular}

Table 12. The 5 deg wave heights $H$ (inch) for the BQ, SQ, and BQ-R.

\begin{tabular}{|c|c|c|c|c|c|c|c|c|c|}
\hline & M1 & M2 & M3 & M4 & M5 & M6 & M7 & M8 & M9 \\
\hline BQ & 0.82 & 1.71 & 2.28 & 2.81 & 2.39 & 2.14 & 2.32 & 2.48 & 3.55 \\
\hline SQ & 0.83 & 1.67 & 2.24 & 2.29 & 2.16 & 2.14 & 2.36 & 2.44 & 2.93 \\
\hline BQ-R & & & & & & 2.12 & 2.34 & & \\
\hline
\end{tabular}


Table 13. The zero deg wave period $T$ (second) for the HS, FS, and BS.

\begin{tabular}{|c|c|c|c|c|c|c|c|c|c|}
\hline & M1 & M2 & M3 & M4 & M5 & M6 & M7 & M8 & M9 \\
\hline Cal & 0.96 & 1.34 & 1.72 & 2.40 & 2.68 & 3.11 & 3.53 & 3.83 & 4.57 \\
\hline HS & 0.97 & 1.33 & 1.70 & 2.33 & 2.69 & 2.91 & 3.30 & 3.51 & 3.92 \\
\hline FS & 0.96 & 1.34 & 1.72 & 2.39 & 2.67 & 3.12 & 3.54 & 3.81 & 4.54 \\
\hline BS & 0.96 & 1.33 & 1.72 & 2.38 & 2.70 & 3.13 & 3.54 & 3.80 & 4.31 \\
\hline
\end{tabular}

Table 14. The 5 deg wave period $T$ (second) for the BQ, SQ, and BQ-R.

\begin{tabular}{|c|c|c|c|c|c|c|c|c|c|}
\hline & M1 & M2 & M3 & M4 & M5 & M6 & M7 & M8 & M9 \\
\hline Cal & 0.96 & 1.34 & 1.72 & 2.40 & 2.68 & 3.12 & 3.55 & 3.84 & 4.56 \\
\hline BQ & 0.96 & 1.33 & 1.72 & 2.40 & 2.67 & 3.11 & 3.54 & 3.83 & 4.54 \\
\hline SQ & 0.96 & 1.33 & 1.72 & 2.40 & 2.68 & 3.11 & 3.54 & 3.84 & $4.55^{\prime}$ \\
\hline BQ-R & & & & & & 3.11 & 3.54 & & \\
\hline
\end{tabular}

\subsection{Irregular wave tests}

The irregular waves were analyzed using an energy-based spectral analysis. Each heading and sea state required multiple iterations of transit to ensure the submarine encountered enough waves. The BQ waves required 14 iterations for sea state 3 and 15 iterations for sea state 4 . The SQ waves required 18 iterations for sea state 3 and 19 iterations for sea state 4 . The measured water surface oscillations from these increments were concatenated to create the input for the spectral analysis. From the spectral analysis, the wave characteristics were computed.

The results from gage locations 5, 6, 7, and 9 are presented for irregular waves because their locations were within the influence of the 5 deg wave direction. Additionally, the results from these gages were averaged and presented in the last column of each table. The results for influenced gages are found in Appendix D.

The measured significant wave heights for sea state 3 waves were similar to those measured during the wave calibration (Table 15 and Table 16). All tests were run in short bursts to minimize re-reflection impacts, but some were still present during irregular wave tests. The spectral peak wave periods were accurate during the irregular wave testing. 
Table 15. Sea state 3, BQ wave results for the capacitance (C) gages 5, 6, 7, and 9.

\begin{tabular}{|c|c|c|c|c|c|}
\hline & C5 & C6 & C7 & C9 & Average \\
\hline$H_{m 0}$ (in.) & 0.82 & 0.81 & 1.07 & 1.15 & 0.97 \\
\hline$T_{p}(\mathrm{~s})$ & 1.78 & 1.78 & 1.78 & 1.78 & 1.78 \\
\hline
\end{tabular}

Table 16. Sea state 3, SQ wave results for the capacitance (C) gages 5, 6, 7, and 9.

\begin{tabular}{|c|c|c|c|c|c|}
\hline & C5 & C6 & C7 & C9 & Average \\
\hline$H_{m 0}$ (in.) & 0.54 & 0.53 & 0.87 & 0.91 & 0.71 \\
\hline$T_{p}$ (s) & 1.78 & 1.78 & 1.86 & 1.86 & 1.78 \\
\hline
\end{tabular}

The wave condition analysis and statistics for sea state 4 are presented in Table 17 and Table 18. Because a calibration of the 5 deg, sea state 4 wave condition was not completed prior to testing, the statistics were analyzed during the transit testing. The wave conditions were consistent throughout the tests; however, $H_{m o}$ values were smaller than the target TMA wave height. Therefore, the $H_{1 / 3}$ was used as a validation. Although the energy in the basin was lower than the target condition, the wave conditions were deemed acceptable in order to reduce the possibility of the submarine impacting the floor.

Table 17. Sea state 4, BQ wave results for capacitance (C) gages 5, 6, 7, and 9.

\begin{tabular}{|l|c|c|c|c|c|}
\hline & C5 & C6 & C7 & C9 & Average \\
\hline$H_{m 0}$ (in.) & 1.09 & 1.08 & 1.88 & 1.83 & 1.52 \\
\hline$H_{l / 3}$ (in.) & 1.56 & 1.57 & 1.52 & 1.60 & 1.56 \\
\hline$H_{m 0 \text { stdev }}$ (in.) & 0.02 & 0.02 & 0.06 & 0.06 & 0.04 \\
\hline$T_{p}$ (s) & 1.46 & 1.46 & 1.52 & 1.52 & 1.52 \\
\hline$T_{p R M S E}$ (s) & 0.05 & 0.05 & 0.00 & 0.00 & 0.00 \\
\hline
\end{tabular}

Table 18. Sea state 4, SQ wave results for capacitance (C) gages 5, 6, 7, and 9.

\begin{tabular}{|l|c|c|c|c|c|}
\hline & C5 & C6 & C7 & C9 & Average \\
\hline$H_{m 0}$ (in.) & 1.34 & 1.34 & 2.07 & 2.10 & 1.71 \\
\hline$H_{I / 3}$ (in.) & 1.59 & 1.59 & 1.56 & 1.62 & 1.59 \\
\hline$H_{m 0 \text { stdev } \text { (in.) }}$ & 0.04 & 0.04 & 0.07 & 0.08 & 0.06 \\
\hline$T_{p}$ (s) & 1.46 & 1.46 & 1.46 & 1.46 & 1.46 \\
\hline$T_{p R M S E}$ (s) & 0.05 & 0.05 & 0.05 & 0.05 & 0.05 \\
\hline
\end{tabular}




\section{Summary}

The experimental results described in this report are focused on the wave and water level conditions measured during submarine transits. The submarine transits were parallel and perpendicular to the plane of the wave generator and oblique creating following, head, beam, BQ, and SQ headings relative to the waves. The model was tested at $8 \mathrm{kt}$ and $12 \mathrm{kt}$ prototype speeds for nine regular wave sea states at varying frequencies. Tests were conducted in regular and irregular waves of varying height and period. Waves were calibrated within the transit lanes and throughout the constant-depth basin and then measured near the transit lanes and at other locations in the basin during transits. Those measurements are described relative to the target wave conditions in the main report and then listed in detail in appendices. 


\section{References}

Akamina Technologies. 2014. AWP-24-3 Wave Height Gauge User's Guide. Akamina Technologies Inc. Ottawa, ON. https://masde.net/images/PDFS/AWP-24-3-usersguide.pdf

Brougham, Captain William J. 2014. “Ohio Replacement Program System Description.” Sea, Air, and Space Symposium, April 8, 2014.

Jamieson, W., and G. Mogridge. 2000. Model Tests of Upright Wave Absorbers for the ERDC Shallow Water Multidirectional Wave Basin. Technical Report HYDCTR-092. National Research Council Canada, NRC Canadian Hydraulics Centre. Ottawa, ON.

O’Rourke, R. 2018. Navy Columbia (SSBN-826) Class Ballistic Missile Submarine Program: Background and Issues for Congress. Congressional Research Service.

Rexroth Hydraudyne B. V. 2003. System Description, Segmented Wave Generator. Rexroth Bosch Group, Netherlands. https://www.boschrexroth.com/en/xc/industries/machinery-applications-andengineering/hydrodynamic-research/products-and-solutions/wave-generator/index

Senix Corporation. 2015. ToughSonic 14 Level \& Distance Sensor. Senix Distance Measurement. Hinesburg, VT. https://senix.com/wpcontent/uploads/2019/09/toughsonic-14-30mm-data-sheet.pdf

Temple, D., A. Percival, A. Punzi, K. Silva, and R. Thomas. 2018. Deep and Shallow Water Seakeeping Tests for Integration of Columbia into Environmental Monitoring and Operator Guidance System. Naval Surface Warfare Center, Carderock Division. West Bethesda, MD. 


\section{Appendix A: Notation}

$\begin{array}{ll}H & \text { Wave height } \\ H_{\text {err }} & \text { Wave height error } \\ H_{m o} & \text { Energy-based significant wave height } \\ H_{m o e r r} & \text { Significant wave height error } \\ H_{m o \text { RMSE }} & \text { Significant wave height root mean square error } \\ H_{m o s t d e v} & \text { Significant wave height standard deviation } \\ H_{\text {RMSE }} & \text { Wave height root mean square error } \\ H_{\text {stdev }} & \text { Wave height standard deviation } \\ H_{1 / 3} & \text { Explicit significant wave height } \\ T & \text { Period } \\ T_{\text {err }} & \text { Period error } \\ T_{p} & \text { Peak wave period } \\ T_{p \text { err }} & \text { Peak wave period error } \\ T_{p \text { RMSE }} & \text { Peak wave period root mean square error } \\ T_{p \text { stdev }} & \text { Peak wave period standard deviation } \\ T_{\text {RMSE }} & \text { Period root mean square error } \\ T_{\text {stdev }} & \text { Period standard deviation }\end{array}$




\section{Appendix B: Gage Calibration Factors}

Table B-1 presents gage calibration factors.

Table B-1. Gage calibration factors.

\begin{tabular}{|l|c|c|c|c|c|}
\hline Physical Gage & Column & Slope cm/V & Intercept & Bias & RMSE (cm) \\
\hline Akamina 5 & 1 & 5.882 & -22.8 & -0.001 & 0.07 \\
\hline Akamina 21 & 2 & 5.797 & -26.28 & -0.021 & 0.13 \\
\hline Akamina 11 & 3 & 5.929 & -28.23 & 0.000 & 0.05 \\
\hline Akamina 3 & 4 & 5.953 & -27.23 & 0.000 & 0.11 \\
\hline Akamina 4 & 5 & 5.943 & -27.27 & 0.000 & 0.05 \\
\hline Akamina 12 & 6 & 5.892 & -22.82 & 0.000 & 0.04 \\
\hline Akamina 10 & 7 & 5.896 & -22.7 & 0.000 & 0.05 \\
\hline Akamina 16 & 8 & 5.909 & -22.94 & 0.000 & 0.09 \\
\hline Akamina 15 & 9 & 5.91 & -22.86 & 0.000 & 0.05 \\
\hline Senix 1 & 10 & -3.01542 & 0.012345 & & \\
\hline Akamina 22 & 11 & 5.834 & -25.85 & 0.000 & 0.10 \\
\hline Senix 2 & 19 & -3.01542 & 0.012345 & & \\
\hline
\end{tabular}




\section{Appendix C: Calibration Results}

The wave characteristics and statistics measured during the wave calibration are presented in the tables below (Tables $\mathrm{C}-1$ through $\mathrm{C}-26$ ). $\mathrm{M} \#$ refers to the wave conditions, and $\mathrm{C} \#$ refers to the wave gage. Gages measuring outside of the wave influence are not presented. The gage locations for each of the setups is presented in Section 3.1.

\section{C.1 Regular waves}

\section{C.1.1 Setup 1}

The gage locations for setup 1 are presented in Figure 8.

Table C-1. Wave heights (inch) for zero deg waves during wave calibration, setup 1.

\begin{tabular}{|l|l|l|l|l|l|l|l|l|l|l|}
\hline & C2 & C3 & C4 & C7 & C8 & C9 & C10 & C13 & C14 & C15 \\
\hline M1 & 0.924 & 0.892 & 0.859 & 0.860 & 0.873 & 0.861 & 1.042 & 0.828 & 0.778 & 0.820 \\
\hline M2 & 1.409 & 1.340 & 1.513 & 1.352 & 1.519 & 1.367 & 1.658 & 1.626 & 1.272 & 1.579 \\
\hline M3 & 1.991 & 2.151 & 1.982 & 2.346 & 1.873 & 2.189 & 1.653 & 2.327 & 2.235 & 2.264 \\
\hline M4 & 2.687 & 2.513 & 2.824 & 3.606 & 3.005 & 3.632 & 2.970 & 2.797 & 2.006 & 2.845 \\
\hline M5 & 3.355 & 3.162 & 3.412 & 2.755 & 2.217 & 2.861 & 2.960 & 3.343 & 2.632 & 3.156 \\
\hline M6 & 3.248 & 3.180 & 3.365 & 3.522 & 2.088 & 3.356 & 3.712 & 3.193 & 3.100 & 3.265 \\
\hline M7 & 3.045 & 2.417 & 3.279 & 3.699 & 2.426 & 3.441 & 4.042 & 2.676 & 3.533 & 2.767 \\
\hline M8 & 3.256 & 2.160 & 3.189 & 3.374 & 2.564 & 3.285 & 3.626 & 2.147 & 3.794 & 2.613 \\
\hline M9 & 3.410 & 1.826 & 3.379 & 2.571 & 3.093 & 2.563 & 3.626 & 2.252 & 3.846 & 2.286 \\
\hline
\end{tabular}


Table C-2. Wave height RMSE (inch) for zero deg waves during wave calibration, setup 1.

\begin{tabular}{|l|l|l|l|l|l|l|l|l|l|l|}
\hline & C2 & C3 & C4 & C7 & C8 & C9 & C10 & C13 & C14 & C15 \\
\hline M1 & 0.029 & 0.026 & 0.049 & 0.043 & 0.054 & 0.044 & 0.156 & 0.091 & 0.129 & 0.091 \\
\hline M2 & 0.100 & 0.171 & 0.022 & 0.165 & 0.071 & 0.151 & 0.164 & 0.132 & 0.237 & 0.096 \\
\hline M3 & 0.114 & 0.087 & 0.124 & 0.257 & 0.230 & 0.124 & 0.457 & 0.236 & 0.139 & 0.192 \\
\hline M4 & 0.326 & 0.508 & 0.191 & 0.617 & 0.087 & 0.647 & 0.111 & 0.256 & 1.003 & 0.213 \\
\hline M5 & 0.371 & 0.188 & 0.473 & 0.304 & 0.790 & 0.215 & 0.103 & 0.357 & 0.413 & 0.210 \\
\hline M6 & 0.263 & 0.240 & 0.391 & 0.529 & 0.921 & 0.364 & 0.730 & 0.214 & 0.279 & 0.285 \\
\hline M7 & 0.091 & 0.587 & 0.377 & 0.704 & 0.583 & 0.530 & 1.048 & 0.336 & 0.592 & 0.290 \\
\hline M8 & 0.259 & 0.858 & 0.283 & 0.390 & 0.440 & 0.287 & 0.640 & 0.863 & 0.814 & 0.395 \\
\hline M9 & 0.426 & 1.178 & 0.459 & 0.433 & 0.107 & 0.456 & 1.165 & 0.750 & 0.852 & 0.722 \\
\hline
\end{tabular}

Table C-3. Wave height standard deviations (inch) for zero deg waves during wave calibration, setup 1.

\begin{tabular}{|l|l|l|l|l|l|l|l|l|l|l|}
\hline & C2 & C3 & C4 & C7 & C8 & C9 & C10 & C13 & C14 & C15 \\
\hline M1 & 0.017 & 0.025 & 0.028 & 0.017 & 0.048 & 0.022 & 0.066 & 0.056 & 0.041 & 0.043 \\
\hline M2 & 0.042 & 0.058 & 0.018 & 0.075 & 0.068 & 0.073 & 0.043 & 0.039 & 0.066 & 0.055 \\
\hline M3 & 0.036 & 0.072 & 0.039 & 0.077 & 0.036 & 0.087 & 0.096 & 0.066 & 0.034 & 0.102 \\
\hline M4 & 0.092 & 0.147 & 0.077 & 0.118 & 0.089 & 0.142 & 0.109 & 0.159 & 0.140 & 0.150 \\
\hline M5 & 0.110 & 0.099 & 0.209 & 0.186 & 0.111 & 0.169 & 0.097 & 0.103 & 0.195 & 0.140 \\
\hline M6 & 0.090 & 0.162 & 0.145 & 0.087 & 0.136 & 0.077 & 0.167 & 0.094 & 0.269 & 0.106 \\
\hline M7 & 0.082 & 0.071 & 0.225 & 0.090 & 0.101 & 0.278 & 0.122 & 0.089 & 0.237 & 0.179 \\
\hline M8 & 0.038 & 0.160 & 0.175 & 0.117 & 0.063 & 0.039 & 0.141 & 0.133 & 0.191 & 0.086 \\
\hline M9 & 0.121 & 0.097 & 0.266 & 0.064 & 0.054 & 0.136 & 1.028 & 0.054 & 0.113 & 0.108 \\
\hline
\end{tabular}


Table C-4. Wave periods (second) for zero deg waves during wave calibration, setup 1.

\begin{tabular}{|l|l|l|l|l|l|l|l|l|l|l|}
\hline & C2 & C3 & C4 & C7 & C8 & C9 & C10 & C13 & C14 & C15 \\
\hline M1 & 0.962 & 0.963 & 0.963 & 0.963 & 0.962 & 0.963 & 0.963 & 0.961 & 0.962 & 0.963 \\
\hline M2 & 1.335 & 1.334 & 1.334 & 1.336 & 1.336 & 1.338 & 1.337 & 1.336 & 1.338 & 1.334 \\
\hline M3 & 1.721 & 1.721 & 1.721 & 1.721 & 1.721 & 1.721 & 1.717 & 1.720 & 1.721 & 1.720 \\
\hline M4 & 2.399 & 2.404 & 2.400 & 2.400 & 2.396 & 2.401 & 2.408 & 2.400 & 2.398 & 2.398 \\
\hline M5 & 2.679 & 2.682 & 2.670 & 2.681 & 2.678 & 2.680 & 2.679 & 2.685 & 2.682 & 2.678 \\
\hline M6 & 3.113 & 3.106 & 3.114 & 3.109 & 3.114 & 3.112 & 3.110 & 3.110 & 3.109 & 3.111 \\
\hline M7 & 3.549 & 3.551 & 3.521 & 3.543 & 3.532 & 3.526 & 3.543 & 3.540 & 3.528 & 3.538 \\
\hline M8 & 3.836 & 3.842 & 3.838 & 3.819 & 3.836 & 3.832 & 3.818 & 3.844 & 3.831 & 3.836 \\
\hline M9 & 4.559 & 4.573 & 4.562 & 4.567 & 4.551 & 4.571 & 4.112 & 4.571 & 4.559 & 4.559 \\
\hline
\end{tabular}

Table C-5. Wave period RMSE (second) for zero deg waves during wave calibration, setup 1.

\begin{tabular}{|l|l|l|l|l|l|l|l|l|l|l|}
\hline & C2 & C3 & C4 & C7 & C8 & C9 & C10 & C13 & C14 & C15 \\
\hline M1 & 0.021 & 0.026 & 0.031 & 0.024 & 0.021 & 0.026 & 0.067 & 0.028 & 0.023 & 0.027 \\
\hline M2 & 0.022 & 0.028 & 0.018 & 0.023 & 0.028 & 0.022 & 0.050 & 0.020 & 0.019 & 0.016 \\
\hline M3 & 0.028 & 0.024 & 0.025 & 0.019 & 0.020 & 0.024 & 0.054 & 0.022 & 0.021 & 0.015 \\
\hline M4 & 0.025 & 0.031 & 0.037 & 0.033 & 0.046 & 0.033 & 0.062 & 0.036 & 0.031 & 0.032 \\
\hline M5 & 0.032 & 0.028 & 0.070 & 0.032 & 0.046 & 0.027 & 0.092 & 0.045 & 0.054 & 0.033 \\
\hline M6 & 0.032 & 0.027 & 0.032 & 0.028 & 0.029 & 0.024 & 0.048 & 0.024 & 0.037 & 0.028 \\
\hline M7 & 0.048 & 0.037 & 0.141 & 0.047 & 0.055 & 0.104 & 0.048 & 0.049 & 0.086 & 0.040 \\
\hline M8 & 0.043 & 0.030 & 0.058 & 0.052 & 0.022 & 0.031 & 0.047 & 0.016 & 0.045 & 0.035 \\
\hline M9 & 0.059 & 0.071 & 0.040 & 0.039 & 0.059 & 0.049 & 1.219 & 0.047 & 0.037 & 0.063 \\
\hline
\end{tabular}


Table C-6. Wave heights (inch) for 5 deg waves during wave calibration, setup 1.

\begin{tabular}{|l|l|l|l|l|l|l|l|l|l|l|}
\hline & C2 & C3 & C4 & C7 & C8 & C9 & C10 & C13 & C14 & C15 \\
\hline M1 & 0.931 & 0.832 & 1.026 & 0.979 & 0.820 & 0.849 & 0.801 & 1.054 & 1.013 & 1.097 \\
\hline M2 & 1.533 & 1.464 & 1.423 & 1.296 & 1.403 & 1.694 & 1.262 & 1.396 & 1.553 & 1.606 \\
\hline M3 & 1.972 & 1.924 & 1.929 & 1.792 & 2.133 & 2.445 & 2.027 & 2.191 & 1.884 & 2.151 \\
\hline M4 & 2.783 & 2.779 & 3.116 & 3.315 & 2.618 & 3.261 & 2.884 & 3.207 & 2.525 & 2.831 \\
\hline M5 & 2.780 & 2.697 & 3.048 & 2.985 & 2.409 & 3.224 & 2.846 & 3.537 & 2.930 & 2.521 \\
\hline M6 & 3.052 & 2.953 & 3.763 & 3.558 & 2.350 & 2.803 & 3.316 & 3.330 & 2.833 & 2.819 \\
\hline M7 & 3.138 & 2.442 & 3.371 & 3.877 & 2.580 & 2.815 & 3.682 & 2.409 & 3.345 & 2.809 \\
\hline M8 & 3.536 & 2.333 & 2.933 & 3.141 & 2.709 & 2.915 & 3.466 & 2.635 & 3.700 & 2.658 \\
\hline M9 & 3.357 & 1.881 & 3.043 & 2.597 & 2.870 & 2.933 & 3.678 & 2.393 & 3.814 & 1.979 \\
\hline
\end{tabular}

Table C-7. Wave height RMSE (inch) for 5 deg waves during wave calibration, setup 1.

\begin{tabular}{|l|l|l|l|l|l|l|l|l|l|l|}
\hline & C2 & C3 & C4 & C7 & C8 & C9 & C10 & C13 & C14 & C15 \\
\hline M1 & 0.043 & 0.072 & 0.128 & 0.084 & 0.084 & 0.058 & 0.118 & 0.168 & 0.122 & 0.200 \\
\hline M2 & 0.054 & 0.048 & 0.111 & 0.206 & 0.100 & 0.211 & 0.243 & 0.126 & 0.058 & 0.110 \\
\hline M3 & 0.133 & 0.199 & 0.191 & 0.348 & 0.054 & 0.346 & 0.126 & 0.125 & 0.234 & 0.126 \\
\hline M4 & 0.225 & 0.226 & 0.143 & 0.329 & 0.446 & 0.272 & 0.197 & 0.237 & 0.479 & 0.229 \\
\hline M5 & 0.225 & 0.311 & 0.210 & 0.190 & 0.609 & 0.236 & 0.225 & 0.555 & 0.297 & 0.510 \\
\hline M6 & 0.105 & 0.146 & 0.798 & 0.568 & 0.654 & 0.204 & 0.379 & 0.337 & 0.191 & 0.228 \\
\hline M7 & 0.188 & 0.574 & 0.431 & 0.899 & 0.433 & 0.215 & 0.691 & 0.602 & 0.356 & 0.308 \\
\hline M8 & 0.539 & 0.668 & 0.131 & 0.168 & 0.314 & 0.101 & 0.481 & 0.374 & 0.750 & 0.354 \\
\hline M9 & 0.372 & 1.122 & 0.204 & 0.416 & 0.148 & 0.132 & 0.709 & 0.621 & 0.819 & 1.026 \\
\hline
\end{tabular}


Table C-8. Wave height standard deviations (inch) for 5 deg waves during wave calibration, setup 1.

\begin{tabular}{|l|l|l|l|l|l|l|l|l|l|l|}
\hline & C2 & C3 & C4 & C7 & C8 & c9 & C10 & C13 & C14 & C15 \\
\hline M1 & 0.030 & 0.024 & 0.023 & 0.027 & 0.026 & 0.027 & 0.066 & 0.070 & 0.048 & 0.036 \\
\hline M2 & 0.043 & 0.032 & 0.078 & 0.031 & 0.022 & 0.084 & 0.050 & 0.072 & 0.024 & 0.031 \\
\hline M3 & 0.035 & 0.088 & 0.083 & 0.165 & 0.044 & 0.031 & 0.105 & 0.088 & 0.091 & 0.114 \\
\hline M4 & 0.058 & 0.047 & 0.086 & 0.093 & 0.232 & 0.080 & 0.160 & 0.113 & 0.068 & 0.159 \\
\hline M5 & 0.051 & 0.074 & 0.203 & 0.194 & 0.150 & 0.078 & 0.169 & 0.144 & 0.296 & 0.180 \\
\hline M6 & 0.095 & 0.143 & 0.241 & 0.106 & 0.079 & 0.055 & 0.216 & 0.070 & 0.097 & 0.143 \\
\hline M7 & 0.131 & 0.136 & 0.197 & 0.207 & 0.112 & 0.114 & 0.108 & 0.120 & 0.090 & 0.251 \\
\hline M8 & 0.065 & 0.046 & 0.117 & 0.096 & 0.120 & 0.057 & 0.124 & 0.088 & 0.281 & 0.095 \\
\hline M9 & 0.110 & 0.087 & 0.209 & 0.109 & 0.074 & 0.120 & 0.174 & 0.135 & 0.087 & 0.113 \\
\hline
\end{tabular}

Table C-9. Wave periods (second) for 5 deg waves during wave calibration, setup 1.

\begin{tabular}{|l|l|l|l|l|l|l|l|l|l|l|}
\hline & C2 & C3 & C4 & C7 & C8 & C9 & C10 & C13 & C14 & C15 \\
\hline M1 & 0.963 & 0.963 & 0.962 & 0.963 & 0.964 & 0.962 & 0.963 & 0.962 & 0.963 & 0.962 \\
\hline M2 & 1.336 & 1.334 & 1.336 & 1.335 & 1.334 & 1.335 & 1.334 & 1.334 & 1.334 & 1.335 \\
\hline M3 & 1.720 & 1.720 & 1.717 & 1.722 & 1.721 & 1.722 & 1.720 & 1.718 & 1.719 & 1.719 \\
\hline M4 & 2.401 & 2.402 & 2.399 & 2.402 & 2.401 & 2.403 & 2.406 & 2.400 & 2.397 & 2.398 \\
\hline M5 & 2.681 & 2.683 & 2.682 & 2.683 & 2.679 & 2.678 & 2.676 & 2.684 & 2.685 & 2.682 \\
\hline M6 & 3.111 & 3.107 & 3.112 & 3.109 & 3.109 & 3.117 & 3.114 & 3.110 & 3.113 & 3.106 \\
\hline M7 & 3.546 & 3.551 & 3.524 & 3.528 & 3.545 & 3.546 & 3.539 & 3.541 & 3.541 & 3.544 \\
\hline M8 & 3.838 & 3.832 & 3.830 & 3.829 & 3.840 & 3.836 & 3.827 & 3.838 & 3.835 & 3.845 \\
\hline M9 & 4.561 & 4.557 & 4.555 & 4.553 & 4.564 & 4.558 & 4.567 & 4.563 & 4.567 & 4.566 \\
\hline
\end{tabular}


Table C-10. Wave period RMSE (second) for 5 deg waves during wave calibration, setup 1.

\begin{tabular}{|l|l|l|l|l|l|l|l|l|l|l|}
\hline & C2 & C3 & C4 & C7 & C8 & c9 & C10 & C13 & C14 & C15 \\
\hline M1 & 0.014 & 0.019 & 0.020 & 0.027 & 0.021 & 0.013 & 0.034 & 0.017 & 0.008 & 0.020 \\
\hline M2 & 0.012 & 0.026 & 0.016 & 0.024 & 0.020 & 0.012 & 0.037 & 0.016 & 0.020 & 0.018 \\
\hline M3 & 0.024 & 0.024 & 0.043 & 0.018 & 0.044 & 0.021 & 0.052 & 0.024 & 0.022 & 0.032 \\
\hline M4 & 0.038 & 0.026 & 0.034 & 0.025 & 0.024 & 0.039 & 0.071 & 0.031 & 0.036 & 0.023 \\
\hline M5 & 0.033 & 0.031 & 0.024 & 0.025 & 0.041 & 0.035 & 0.047 & 0.035 & 0.034 & 0.032 \\
\hline M6 & 0.035 & 0.041 & 0.021 & 0.033 & 0.030 & 0.032 & 0.060 & 0.024 & 0.031 & 0.039 \\
\hline M7 & 0.060 & 0.045 & 0.118 & 0.071 & 0.055 & 0.037 & 0.074 & 0.045 & 0.042 & 0.046 \\
\hline M8 & 0.026 & 0.040 & 0.046 & 0.033 & 0.028 & 0.032 & 0.045 & 0.039 & 0.025 & 0.043 \\
\hline M9 & 0.045 & 0.055 & 0.034 & 0.051 & 0.062 & 0.056 & 0.091 & 0.040 & 0.034 & 0.035 \\
\hline
\end{tabular}

\section{C.1.2 Setup 2}

The gage locations for setup 2 are presented in Figure 9.

Table C-11. Wave heights (inch) for zero deg waves during wave calibration, setup 2, gages 1-10.

\begin{tabular}{|l|l|l|l|l|l|l|l|l|l|l|}
\hline & C1 & C2 & C3 & C4 & C5 & C6 & C7 & C8 & C9 & C10 \\
\hline M1 & 0.987 & 1.006 & 0.689 & 1.006 & 0.707 & 0.814 & 0.857 & 0.869 & 0.359 & 1.062 \\
\hline M2 & 1.540 & 1.174 & 1.349 & 1.365 & 0.936 & 1.424 & 1.458 & 1.509 & 1.123 & 1.690 \\
\hline M3 & 2.724 & 2.249 & 1.794 & 2.363 & 1.310 & 2.470 & 2.124 & 1.912 & 1.611 & 1.692 \\
\hline M4 & 3.626 & 3.855 & 3.377 & 3.090 & 1.943 & 2.885 & 2.621 & 2.976 & 2.368 & 3.068 \\
\hline M5 & 3.724 & 3.936 & 3.291 & 2.651 & 2.123 & 2.791 & 3.130 & 2.221 & 2.869 & 3.075 \\
\hline M6 & 3.653 & 3.952 & 3.807 & 3.073 & 1.474 & 2.558 & 3.183 & 2.111 & 2.989 & 3.621 \\
\hline M7 & 3.431 & 3.467 & 3.306 & 2.873 & 1.437 & 3.387 & 3.103 & 2.488 & 3.338 & 3.998 \\
\hline M8 & 2.718 & 3.974 & 3.966 & 3.908 & 2.349 & 3.212 & 3.080 & 2.654 & 3.149 & 3.657 \\
\hline M9 & 3.686 & 3.753 & 3.763 & 3.674 & 2.281 & 3.402 & 2.965 & 3.075 & 2.669 & 3.984 \\
\hline
\end{tabular}


Table C-12. Wave heights (inch) for zero deg waves during wave calibration, setup 2, gages 11-19.

\begin{tabular}{|l|l|l|l|l|l|l|l|l|l|}
\hline & C11 & C12 & C13 & C14 & C15 & C16 & C17 & C18 & C19 \\
\hline M1 & 0.509 & 0.732 & 0.830 & 0.777 & 0.792 & 0.802 & 0.966 & 0.859 & 1.007 \\
\hline M2 & 1.018 & 1.245 & 1.346 & 1.327 & 1.362 & 1.181 & 1.326 & 1.470 & 1.437 \\
\hline M3 & 1.474 & 1.841 & 1.975 & 2.197 & 1.862 & 1.756 & 2.261 & 1.779 & 2.465 \\
\hline M4 & 2.329 & 2.269 & 3.442 & 2.050 & 3.419 & 2.223 & 3.854 & 2.372 & 3.096 \\
\hline M5 & 2.092 & 1.972 & 2.931 & 2.637 & 3.119 & 1.977 & 3.214 & 2.115 & 2.713 \\
\hline M6 & 1.840 & 1.860 & 3.192 & 3.197 & 3.117 & 1.932 & 3.314 & 2.344 & 2.639 \\
\hline M7 & 1.106 & 2.226 & 3.115 & 3.552 & 2.997 & 2.329 & 3.727 & 2.311 & 2.194 \\
\hline M8 & 2.030 & 2.461 & 3.297 & 4.013 & 3.069 & 2.675 & 3.132 & 2.626 & 2.384 \\
\hline M9 & 1.975 & 1.845 & 3.155 & 3.855 & 3.002 & 1.975 & 3.802 & 2.785 & 1.610 \\
\hline
\end{tabular}

Table C-13. Wave height RMSE (inch) for zero deg waves during wave calibration, setup 2, gages 1-10.

\begin{tabular}{|l|l|l|l|l|l|l|l|l|l|l|}
\hline & C1 & C2 & C3 & C4 & C5 & C6 & C7 & C8 & C9 & C10 \\
\hline M1 & 0.120 & 0.108 & 0.215 & 0.108 & 0.195 & 0.087 & 0.050 & 0.035 & 0.548 & 0.167 \\
\hline M2 & 0.105 & 0.334 & 0.169 & 0.137 & 0.565 & 0.115 & 0.055 & 0.037 & 0.383 & 0.212 \\
\hline M3 & 0.639 & 0.197 & 0.337 & 0.270 & 0.791 & 0.406 & 0.095 & 0.194 & 0.503 & 0.416 \\
\hline M4 & 0.648 & 0.881 & 0.382 & 0.130 & 1.066 & 0.134 & 0.386 & 0.099 & 0.645 & 0.120 \\
\hline M5 & 0.748 & 0.952 & 0.337 & 0.464 & 0.884 & 0.226 & 0.155 & 0.783 & 0.228 & 0.092 \\
\hline M6 & 0.675 & 0.973 & 0.821 & 0.147 & 1.527 & 0.468 & 0.189 & 0.897 & 0.157 & 0.622 \\
\hline M7 & 0.486 & 0.472 & 0.422 & 0.201 & 1.565 & 0.414 & 0.179 & 0.517 & 0.400 & 1.002 \\
\hline M8 & 0.317 & 1.023 & 1.105 & 1.024 & 0.776 & 0.270 & 0.133 & 0.368 & 0.268 & 0.664 \\
\hline M9 & 0.837 & 0.761 & 0.782 & 0.708 & 0.813 & 0.453 & 0.167 & 0.106 & 0.377 & 0.988 \\
\hline
\end{tabular}


Table C-14. Wave height RMSE (inch) for zero deg waves during wave calibration, setup 2, gages 11-19.

\begin{tabular}{|l|l|l|l|l|l|l|l|l|l|}
\hline & C11 & C12 & C13 & C14 & C15 & C16 & C17 & C18 & C19 \\
\hline M1 & 0.391 & 0.168 & 0.071 & 0.135 & 0.109 & 0.108 & 0.075 & 0.058 & 0.113 \\
\hline M2 & 0.488 & 0.256 & 0.159 & 0.178 & 0.141 & 0.320 & 0.177 & 0.077 & 0.091 \\
\hline M3 & 0.650 & 0.263 & 0.133 & 0.109 & 0.253 & 0.351 & 0.247 & 0.452 & 0.392 \\
\hline M4 & 0.707 & 0.735 & 0.465 & 0.956 & 0.438 & 0.780 & 0.898 & 0.631 & 0.123 \\
\hline M5 & 0.915 & 1.037 & 0.165 & 0.415 & 0.216 & 1.027 & 0.366 & 0.893 & 0.301 \\
\hline M6 & 1.174 & 1.143 & 0.228 & 0.340 & 0.206 & 1.068 & 0.329 & 0.679 & 0.382 \\
\hline M7 & 1.907 & 0.796 & 0.130 & 0.559 & 0.110 & 0.711 & 0.787 & 0.699 & 0.941 \\
\hline M8 & 1.078 & 0.595 & 0.337 & 1.061 & 0.162 & 0.461 & 0.308 & 0.416 & 0.667 \\
\hline M9 & 1.043 & 1.160 & 0.262 & 0.863 & 0.163 & 1.043 & 0.809 & 0.308 & 1.698 \\
\hline
\end{tabular}

Table C-15. Wave height standard deviations (inch) for zero deg waves during wave calibration, setup 2, gages 1-10.

\begin{tabular}{|l|l|l|l|l|l|l|l|l|l|l|}
\hline & C1 & C2 & C3 & C4 & C5 & C6 & C7 & C8 & C9 & C10 \\
\hline M1 & 0.088 & 0.023 & 0.036 & 0.023 & 0.025 & 0.011 & 0.026 & 0.016 & 0.090 & 0.040 \\
\hline M2 & 0.100 & 0.074 & 0.078 & 0.022 & 0.023 & 0.085 & 0.036 & 0.036 & 0.065 & 0.075 \\
\hline M3 & 0.142 & 0.117 & 0.144 & 0.063 & 0.034 & 0.172 & 0.092 & 0.046 & 0.122 & 0.084 \\
\hline M4 & 0.172 & 0.218 & 0.065 & 0.096 & 0.140 & 0.071 & 0.074 & 0.098 & 0.133 & 0.102 \\
\hline M5 & 0.192 & 0.176 & 0.176 & 0.315 & 0.107 & 0.089 & 0.086 & 0.077 & 0.194 & 0.054 \\
\hline M6 & 0.178 & 0.210 & 0.158 & 0.131 & 0.048 & 0.159 & 0.049 & 0.126 & 0.162 & 0.045 \\
\hline M7 & 0.218 & 0.070 & 0.302 & 0.161 & 0.071 & 0.150 & 0.153 & 0.081 & 0.223 & 0.093 \\
\hline M8 & 0.151 & 0.326 & 0.533 & 0.493 & 0.442 & 0.176 & 0.110 & 0.132 & 0.232 & 0.105 \\
\hline M9 & 0.412 & 0.119 & 0.178 & 0.229 & 0.399 & 0.221 & 0.169 & 0.078 & 0.190 & 0.088 \\
\hline
\end{tabular}


Table C-16. Wave height standard deviations (inch) for zero deg waves during wave calibration, setup 2, gages 11-19.

\begin{tabular}{|l|l|l|l|l|l|l|l|l|l|}
\hline & C11 & C12 & C13 & C14 & C15 & C16 & C17 & C18 & C19 \\
\hline M1 & 0.010 & 0.010 & 0.012 & 0.058 & 0.014 & 0.044 & 0.036 & 0.042 & 0.035 \\
\hline M2 & 0.082 & 0.026 & 0.038 & 0.040 & 0.027 & 0.035 & 0.029 & 0.072 & 0.067 \\
\hline M3 & 0.179 & 0.044 & 0.046 & 0.051 & 0.089 & 0.069 & 0.192 & 0.325 & 0.147 \\
\hline M4 & 0.229 & 0.070 & 0.149 & 0.107 & 0.133 & 0.076 & 0.219 & 0.065 & 0.078 \\
\hline M5 & 0.113 & 0.134 & 0.155 & 0.206 & 0.186 & 0.086 & 0.308 & 0.120 & 0.094 \\
\hline M6 & 0.188 & 0.086 & 0.126 & 0.287 & 0.176 & 0.045 & 0.098 & 0.182 & 0.127 \\
\hline M7 & 0.236 & 0.195 & 0.062 & 0.094 & 0.114 & 0.245 & 0.314 & 0.120 & 0.491 \\
\hline M8 & 0.490 & 0.262 & 0.166 & 0.331 & 0.154 & 0.341 & 0.256 & 0.191 & 0.269 \\
\hline M9 & 0.202 & 0.104 & 0.197 & 0.123 & 0.172 & 0.203 & 0.116 & 0.234 & 0.987 \\
\hline
\end{tabular}

Table C-17. Wave periods (second) for zero deg waves during wave calibration, setup 2 , gages 1-10.

\begin{tabular}{|l|l|l|l|l|l|l|l|l|l|l|}
\hline & C1 & C2 & C3 & C4 & C5 & C6 & C7 & C8 & C9 & C10 \\
\hline M1 & 0.955 & 0.962 & 0.961 & 0.962 & 0.960 & 0.963 & 0.963 & 0.963 & 0.963 & 0.967 \\
\hline M2 & 1.329 & 1.331 & 1.333 & 1.337 & 1.337 & 1.336 & 1.335 & 1.335 & 1.335 & 1.332 \\
\hline M3 & 1.721 & 1.715 & 1.720 & 1.722 & 1.720 & 1.720 & 1.716 & 1.722 & 1.722 & 1.720 \\
\hline M4 & 2.401 & 2.405 & 2.396 & 2.399 & 2.396 & 2.402 & 2.405 & 2.399 & 2.408 & 2.399 \\
\hline M5 & 2.685 & 2.683 & 2.682 & 2.682 & 2.680 & 2.683 & 2.681 & 2.678 & 2.679 & 2.679 \\
\hline M6 & 3.121 & 3.105 & 3.111 & 3.107 & 3.106 & 3.112 & 3.111 & 3.113 & 3.111 & 3.107 \\
\hline M7 & 3.526 & 3.554 & 3.542 & 3.543 & 3.576 & 3.542 & 3.547 & 3.538 & 3.542 & 3.544 \\
\hline M8 & 3.847 & 3.825 & 3.808 & 3.835 & 3.818 & 3.827 & 3.833 & 3.840 & 3.840 & 3.835 \\
\hline M9 & 4.526 & 4.563 & 4.560 & 4.571 & 4.540 & 4.569 & 4.569 & 4.552 & 4.566 & 4.569 \\
\hline
\end{tabular}


Table C-18. Wave periods (second) for zero deg waves during wave calibration, setup 2, gages 11-19.

\begin{tabular}{|l|l|l|l|l|l|l|l|l|l|}
\hline & C11 & C12 & C13 & C14 & C15 & C16 & C17 & C18 & C19 \\
\hline M1 & 0.962 & 0.963 & 0.964 & 0.963 & 0.963 & 0.964 & 0.962 & 0.962 & 0.963 \\
\hline M2 & 1.334 & 1.337 & 1.333 & 1.336 & 1.335 & 1.335 & 1.332 & 1.334 & 1.339 \\
\hline M3 & 1.722 & 1.718 & 1.719 & 1.722 & 1.719 & 1.713 & 1.722 & 1.714 & 1.720 \\
\hline M4 & 2.396 & 2.399 & 2.400 & 2.399 & 2.400 & 2.398 & 2.386 & 2.407 & 2.397 \\
\hline M5 & 2.692 & 2.669 & 2.683 & 2.666 & 2.676 & 2.691 & 2.677 & 2.698 & 2.686 \\
\hline M6 & 3.103 & 3.109 & 3.113 & 3.105 & 3.111 & 3.121 & 3.111 & 3.112 & 3.106 \\
\hline M7 & 3.481 & 3.547 & 3.537 & 3.543 & 3.540 & 3.547 & 3.540 & 3.550 & 3.287 \\
\hline M8 & 3.845 & 3.814 & 3.819 & 3.832 & 3.841 & 3.836 & 3.791 & 3.823 & 3.841 \\
\hline M9 & 4.578 & 4.571 & 4.573 & 4.560 & 4.569 & 4.567 & 4.560 & 4.583 & 2.956 \\
\hline
\end{tabular}

Table C-19. Wave period RMSE (second) for zero deg waves during wave calibration, setup 2, gages 1-10.

\begin{tabular}{|l|l|l|l|l|l|l|l|l|l|l|}
\hline & C1 & C2 & C3 & C4 & C5 & C6 & C7 & C8 & c9 & C10 \\
\hline M1 & 0.021 & 0.022 & 0.030 & 0.021 & 0.038 & 0.020 & 0.021 & 0.029 & 0.020 & 0.068 \\
\hline M2 & 0.019 & 0.022 & 0.018 & 0.033 & 0.029 & 0.014 & 0.028 & 0.026 & 0.023 & 0.061 \\
\hline M3 & 0.018 & 0.047 & 0.030 & 0.020 & 0.035 & 0.017 & 0.039 & 0.021 & 0.022 & 0.042 \\
\hline M4 & 0.030 & 0.034 & 0.029 & 0.024 & 0.041 & 0.026 & 0.031 & 0.032 & 0.040 & 0.046 \\
\hline M5 & 0.030 & 0.043 & 0.025 & 0.036 & 0.035 & 0.030 & 0.030 & 0.036 & 0.036 & 0.061 \\
\hline M6 & 0.021 & 0.030 & 0.031 & 0.029 & 0.043 & 0.050 & 0.020 & 0.026 & 0.030 & 0.062 \\
\hline M7 & 0.056 & 0.037 & 0.046 & 0.038 & 0.081 & 0.043 & 0.034 & 0.041 & 0.040 & 0.044 \\
\hline M8 & 0.057 & 0.038 & 0.108 & 0.031 & 0.051 & 0.038 & 0.040 & 0.022 & 0.049 & 0.058 \\
\hline M9 & 0.103 & 0.030 & 0.033 & 0.036 & 0.115 & 0.045 & 0.054 & 0.079 & 0.062 & 0.054 \\
\hline
\end{tabular}


Table C-20. Wave period RMSE (second) for zero deg waves during wave calibration, setup 2, gages 11-19.

\begin{tabular}{|l|l|l|l|l|l|l|l|l|l|}
\hline & C11 & C12 & C13 & C14 & C15 & C16 & C17 & C18 & C19 \\
\hline M1 & 0.027 & 0.020 & 0.030 & 0.014 & 0.013 & 0.017 & 0.009 & 0.050 & 0.051 \\
\hline M2 & 0.028 & 0.028 & 0.030 & 0.018 & 0.020 & 0.026 & 0.042 & 0.067 & 0.027 \\
\hline M3 & 0.037 & 0.029 & 0.031 & 0.022 & 0.026 & 0.051 & 0.019 & 0.040 & 0.075 \\
\hline M4 & 0.065 & 0.031 & 0.028 & 0.029 & 0.026 & 0.027 & 0.056 & 0.052 & 0.072 \\
\hline M5 & 0.037 & 0.088 & 0.033 & 0.104 & 0.045 & 0.026 & 0.035 & 0.076 & 0.060 \\
\hline M6 & 0.062 & 0.033 & 0.025 & 0.049 & 0.019 & 0.031 & 0.028 & 0.108 & 0.061 \\
\hline M7 & 0.250 & 0.059 & 0.040 & 0.040 & 0.041 & 0.038 & 0.057 & 0.060 & 0.769 \\
\hline M8 & 0.042 & 0.098 & 0.068 & 0.023 & 0.019 & 0.048 & 0.139 & 0.092 & 0.071 \\
\hline M9 & 0.072 & 0.067 & 0.042 & 0.041 & 0.039 & 0.076 & 0.023 & 0.135 & 2.012 \\
\hline
\end{tabular}

Table C-21. Wave heights (inch) for 5 deg waves during wave calibration, setup 2.

\begin{tabular}{|l|l|l|l|l|l|l|l|l|l|l|l|}
\hline & C3 & C4 & C6 & C7 & C8 & C9 & C12 & C13 & C14 & C15 & C18 \\
\hline M1 & 0.892 & 0.774 & 1.174 & 0.953 & 0.851 & 0.344 & 0.859 & 0.915 & 0.857 & 0.951 & 0.698 \\
\hline M2 & 1.409 & 1.817 & 1.736 & 1.284 & 1.400 & 1.271 & 1.499 & 1.642 & 1.531 & 1.274 & 1.104 \\
\hline M3 & 2.168 & 2.183 & 2.160 & 2.048 & 2.189 & 1.537 & 2.040 & 1.946 & 1.850 & 2.337 & 1.309 \\
\hline M4 & 3.006 & 3.620 & 2.768 & 2.741 & 2.637 & 2.753 & 2.441 & 2.702 & 2.503 & 3.409 & 1.932 \\
\hline M5 & 2.835 & 2.865 & 2.628 & 2.684 & 2.449 & 2.799 & 2.587 & 2.415 & 2.927 & 3.398 & 1.925 \\
\hline M6 & 3.275 & 2.892 & 1.721 & 2.640 & 2.418 & 3.199 & 2.304 & 2.996 & 2.864 & 3.327 & 1.561 \\
\hline M7 & 3.179 & 2.359 & 2.323 & 2.757 & 2.595 & 3.969 & 2.420 & 3.554 & 3.343 & 3.007 & 1.134 \\
\hline M8 & 3.869 & 3.018 & 2.354 & 3.052 & 2.803 & 3.575 & 2.335 & 3.682 & 3.880 & 2.703 & 1.916 \\
\hline M9 & 3.313 & 2.955 & 2.967 & 3.149 & 2.879 & 2.605 & 2.123 & 3.520 & 3.814 & 2.533 & 2.130 \\
\hline
\end{tabular}


Table C-22. Wave height RMSE (inch) for 5 deg waves during wave calibration, setup 2.

\begin{tabular}{|l|l|l|l|l|l|l|l|l|l|l|l|}
\hline & C3 & C4 & C6 & C7 & C8 & C9 & C12 & C13 & C14 & C15 & C18 \\
\hline M1 & 0.021 & 0.137 & 0.275 & 0.054 & 0.055 & 0.556 & 0.042 & 0.054 & 0.054 & 0.067 & 0.203 \\
\hline M2 & 0.098 & 0.318 & 0.237 & 0.220 & 0.103 & 0.239 & 0.042 & 0.143 & 0.048 & 0.230 & 0.398 \\
\hline M3 & 0.088 & 0.097 & 0.083 & 0.145 & 0.103 & 0.567 & 0.077 & 0.171 & 0.254 & 0.248 & 0.815 \\
\hline M4 & 0.057 & 0.630 & 0.263 & 0.263 & 0.394 & 0.264 & 0.563 & 0.319 & 0.498 & 0.424 & 1.074 \\
\hline M5 & 0.190 & 0.238 & 0.377 & 0.325 & 0.574 & 0.230 & 0.419 & 0.595 & 0.255 & 0.420 & 1.083 \\
\hline M6 & 0.351 & 0.198 & 1.286 & 0.363 & 0.589 & 0.228 & 0.706 & 0.093 & 0.176 & 0.332 & 1.484 \\
\hline M7 & 0.312 & 0.656 & 0.701 & 0.261 & 0.422 & 1.029 & 0.619 & 0.556 & 0.352 & 0.138 & 1.904 \\
\hline M8 & 0.937 & 0.337 & 0.661 & 0.162 & 0.272 & 0.610 & 0.689 & 0.704 & 0.949 & 0.356 & 1.099 \\
\hline M9 & 0.343 & 0.194 & 0.435 & 0.186 & 0.147 & 0.424 & 0.881 & 0.525 & 0.817 & 0.492 & 0.886 \\
\hline
\end{tabular}

Table C-23. Wave height standard deviations (inch) for 5 deg waves during wave calibration, setup 2.

\begin{tabular}{|l|l|l|l|l|l|l|l|l|l|l|l|}
\hline & C3 & C4 & C6 & C7 & C8 & c9 & C12 & C13 & C14 & C15 & C18 \\
\hline M1 & 0.020 & 0.053 & 0.016 & 0.010 & 0.023 & 0.016 & 0.008 & 0.051 & 0.034 & 0.042 & 0.023 \\
\hline M2 & 0.038 & 0.026 & 0.025 & 0.043 & 0.026 & 0.065 & 0.042 & 0.019 & 0.037 & 0.043 & 0.038 \\
\hline M3 & 0.056 & 0.051 & 0.060 & 0.140 & 0.052 & 0.068 & 0.047 & 0.076 & 0.046 & 0.068 & 0.204 \\
\hline M4 & 0.058 & 0.119 & 0.129 & 0.045 & 0.157 & 0.096 & 0.065 & 0.116 & 0.036 & 0.111 & 0.124 \\
\hline M5 & 0.099 & 0.199 & 0.066 & 0.081 & 0.168 & 0.116 & 0.072 & 0.113 & 0.252 & 0.141 & 0.140 \\
\hline M6 & 0.226 & 0.172 & 0.135 & 0.049 & 0.090 & 0.117 & 0.121 & 0.096 & 0.117 & 0.062 & 0.369 \\
\hline M7 & 0.268 & 0.146 & 0.182 & 0.099 & 0.121 & 0.361 & 0.223 & 0.046 & 0.079 & 0.144 & 0.384 \\
\hline M8 & 0.369 & 0.353 & 0.147 & 0.168 & 0.195 & 0.211 & 0.186 & 0.180 & 0.371 & 0.205 & 0.191 \\
\hline M9 & 0.148 & 0.201 & 0.458 & 0.117 & 0.089 & 0.161 & 0.088 & 0.080 & 0.074 & 0.165 & 0.183 \\
\hline
\end{tabular}


Table C-24. Wave periods (second) for 5 deg waves during wave calibration, setup 2.

\begin{tabular}{|l|l|l|l|l|l|l|l|l|l|l|l|}
\hline & C3 & C4 & C6 & C7 & C8 & C9 & C12 & C13 & C14 & C15 & C18 \\
\hline M1 & 0.961 & 0.962 & 0.963 & 0.964 & 0.962 & 0.962 & 0.963 & 0.961 & 0.963 & 0.960 & 0.963 \\
\hline M2 & 1.338 & 1.334 & 1.336 & 1.336 & 1.335 & 1.335 & 1.335 & 1.336 & 1.335 & 1.334 & 1.336 \\
\hline M3 & 1.721 & 1.720 & 1.722 & 1.705 & 1.720 & 1.724 & 1.718 & 1.721 & 1.722 & 1.723 & 1.724 \\
\hline M4 & 2.397 & 2.396 & 2.403 & 2.403 & 2.403 & 2.407 & 2.403 & 2.404 & 2.400 & 2.400 & 2.409 \\
\hline M5 & 2.678 & 2.681 & 2.682 & 2.681 & 2.680 & 2.685 & 2.685 & 2.685 & 2.683 & 2.684 & 2.687 \\
\hline M6 & 3.112 & 3.077 & 3.117 & 3.115 & 3.110 & 3.110 & 3.106 & 3.108 & 3.109 & 3.112 & 2.892 \\
\hline M7 & 3.548 & 3.549 & 3.531 & 3.542 & 3.528 & 3.546 & 3.541 & 3.533 & 3.542 & 3.540 & 3.117 \\
\hline M8 & 3.838 & 3.840 & 3.825 & 3.842 & 3.840 & 3.838 & 3.832 & 3.835 & 3.835 & 3.842 & 3.828 \\
\hline M9 & 4.561 & 4.565 & 4.558 & 4.552 & 4.560 & 4.566 & 4.564 & 4.565 & 4.563 & 4.576 & 4.550 \\
\hline
\end{tabular}

Table C-25. Wave period RMSE (second) for 5 deg waves during wave calibration, setup 2.

\begin{tabular}{|l|l|l|l|l|l|l|l|l|l|l|l|}
\hline & C3 & C4 & C6 & C7 & C8 & C9 & C12 & C13 & C14 & C15 & C18 \\
\hline M1 & 0.012 & 0.012 & 0.021 & 0.016 & 0.021 & 0.010 & 0.015 & 0.023 & 0.008 & 0.022 & 0.041 \\
\hline M2 & 0.017 & 0.018 & 0.028 & 0.021 & 0.030 & 0.029 & 0.017 & 0.020 & 0.026 & 0.016 & 0.045 \\
\hline M3 & 0.028 & 0.014 & 0.030 & 0.062 & 0.027 & 0.018 & 0.027 & 0.021 & 0.017 & 0.023 & 0.039 \\
\hline M4 & 0.026 & 0.034 & 0.030 & 0.033 & 0.030 & 0.033 & 0.033 & 0.030 & 0.032 & 0.025 & 0.046 \\
\hline M5 & 0.036 & 0.034 & 0.029 & 0.041 & 0.035 & 0.037 & 0.046 & 0.036 & 0.033 & 0.026 & 0.067 \\
\hline M6 & 0.033 & 0.120 & 0.076 & 0.020 & 0.024 & 0.029 & 0.030 & 0.042 & 0.044 & 0.028 & 0.636 \\
\hline M7 & 0.039 & 0.027 & 0.049 & 0.051 & 0.071 & 0.036 & 0.040 & 0.045 & 0.043 & 0.037 & 0.943 \\
\hline M8 & 0.026 & 0.039 & 0.046 & 0.045 & 0.018 & 0.030 & 0.047 & 0.030 & 0.019 & 0.030 & 0.072 \\
\hline M9 & 0.033 & 0.040 & 0.054 & 0.024 & 0.063 & 0.047 & 0.050 & 0.031 & 0.052 & 0.058 & 0.203 \\
\hline
\end{tabular}




\section{C.2 Irregular waves}

Irregular wave calibrations were only measured using setup 2. During testing, it was determined beneficial to test both sea state 3 and sea state 4 in quartering seas; therefore, no results for zero deg are presented. The gage locations are presented in Figure 13.

Table C-26. Sea state 3 irregular wave characteristic statistics.

\begin{tabular}{|l|l|l|l|l|l|l|l|l|l|l|l|}
\hline & C3 & C4 & C6 & C7 & C8 & C9 & C12 & C13 & C14 & C15 & C18 \\
\hline$H_{m 0}$ (in.) & 1.08 & 0.95 & 0.53 & 0.95 & 1.04 & 0.92 & 0.85 & 0.91 & 0.76 & 1.25 & 0.30 \\
\hline$H_{m 0 \text { stdev }}$ (in.) & 0.02 & 0.02 & 0.01 & 0.02 & 0.02 & 0.01 & 0.01 & 0.02 & 0.01 & 0.03 & 0.00 \\
\hline$H_{m 0 \text { RMSE }}$ (in.) & 0.30 & 0.43 & 0.85 & 0.43 & 0.34 & 0.46 & 0.54 & 0.48 & 0.62 & 0.14 & 1.09 \\
\hline$T_{p}$ (s) & 1.86 & 1.86 & 1.86 & 1.86 & 1.86 & 1.86 & 1.86 & 1.86 & 1.86 & 1.86 & 1.78 \\
\hline$T_{p R M S E}$ (s) & 0.02 & 0.02 & 0.02 & 0.02 & 0.02 & 0.02 & 0.02 & 0.02 & 0.02 & 0.02 & 0.06 \\
\hline
\end{tabular}




\section{Appendix D: Submarine Testing Results}

The tables presented in this appendix are arranged by heading then wave condition (Tables D-1 through D-22).. For each wave condition, the wave heights and wave period are presented for each run. The results presented are for the gages that are influenced by the waves during the runs. The run numbers are presented as " $\mathrm{R} \#$ " in the left column of each table. The gages are designated as either "C\#" or "S\#", where C gages are Akamina capacitance gages and $\mathrm{S}$ gages are Senix sonar gages. The gage locations for the submarine testing are presented in Figure 10. The average value for each regular wave condition is presented in the last row for each heading. 


\section{D.1 Wave M1}

Table D-1. Wave heights (inch) by heading for wave M1.

\begin{tabular}{|c|c|c|c|c|c|c|c|c|c|c|}
\hline Heading & Run & C1 & $\mathrm{C} 2$ & C4 & C5 & C6 & C7 & $C 9$ & S1 & S2 \\
\hline \multirow[t]{5}{*}{ Following } & R2 & 1.0 & 1.2 & 1.2 & 0.4 & 0.4 & 0.9 & 1.0 & 0.4 & 0.4 \\
\hline & R3 & 1.0 & 1.0 & 1.4 & 0.5 & 0.5 & 0.9 & 0.9 & 0.5 & 0.6 \\
\hline & R4 & 1.0 & 1.0 & 1.2 & 0.4 & 0.4 & 0.8 & 1.0 & 0.3 & 0.4 \\
\hline & R5 & 0.8 & 1.5 & 1.3 & 0.5 & 0.5 & 0.8 & 0.9 & 0.3 & 0.3 \\
\hline & Av & 1.0 & 1.2 & 1.3 & 0.5 & 0.5 & 0.9 & 1.0 & 0.4 & 0.4 \\
\hline \multirow[t]{3}{*}{ Head } & R1 & 1.1 & 0.9 & 1.0 & 0.6 & 0.6 & 0.7 & 0.9 & & \\
\hline & R2 & 0.8 & 1.4 & 1.3 & 0.3 & 0.4 & 0.9 & 1.0 & & \\
\hline & $A v$ & 0.9 & 1.1 & 1.2 & 0.4 & 0.5 & 0.8 & 1.0 & & \\
\hline \multirow[t]{7}{*}{ Beam } & R1 & 0.6 & 0.9 & 0.7 & 0.7 & 0.7 & 0.9 & 0.9 & 0.2 & 0.3 \\
\hline & R2 & 0.8 & 0.9 & 0.9 & 0.5 & 0.5 & 0.9 & 0.9 & 0.2 & 0.3 \\
\hline & R3 & 1.0 & 0.8 & 1.1 & 0.6 & 0.5 & 0.9 & 0.9 & 0.4 & 0.5 \\
\hline & R4 & 0.9 & 0.9 & 1.0 & 0.4 & 0.4 & 0.8 & 0.9 & 0.3 & 0.3 \\
\hline & R5 & 0.9 & 1.1 & 0.9 & 0.5 & 0.5 & 0.9 & 0.9 & 0.4 & 0.3 \\
\hline & R6 & 0.7 & 1.3 & 1.1 & 0.5 & 0.5 & 0.9 & 1.0 & 0.2 & 0.3 \\
\hline & $A v$ & 0.8 & 1.0 & 0.9 & 0.5 & 0.5 & 0.9 & 0.9 & 0.3 & 0.3 \\
\hline \multirow[t]{3}{*}{ SQ } & R1 & & & 0.8 & 0.5 & 0.5 & 0.8 & 0.8 & 0.3 & \\
\hline & R2 & & & 0.7 & 0.6 & 0.5 & 0.9 & 0.9 & 0.3 & \\
\hline & $A v$ & & & 0.8 & 0.5 & 0.5 & 0.9 & 0.8 & 0.3 & \\
\hline \multirow[t]{3}{*}{$B Q$} & R1 & & & 0.8 & 0.4 & 0.4 & 0.9 & 0.8 & & \\
\hline & R2 & & & 0.7 & 0.4 & 0.4 & 0.9 & 0.8 & & \\
\hline & $A v$ & & & 0.8 & 0.4 & 0.4 & 0.9 & 0.8 & & \\
\hline
\end{tabular}


Table D-2. Wave periods (second) by heading for wave M1.

\begin{tabular}{|c|c|c|c|c|c|c|c|c|c|c|}
\hline Heading & Run & C1 & $\mathrm{C} 2$ & C4 & C5 & C6 & C7 & $C 9$ & S1 & S2 \\
\hline \multirow[t]{5}{*}{ Following } & R2 & 1.0 & 1.0 & 1.0 & 1.0 & 1.0 & 1.0 & 1.0 & 0.9 & 0.7 \\
\hline & R3 & 0.9 & 1.0 & 1.0 & 1.0 & 1.0 & 1.0 & 1.0 & 0.9 & 0.9 \\
\hline & R4 & 1.0 & 1.0 & 1.0 & 1.0 & 1.0 & 1.0 & 1.0 & 0.9 & 0.8 \\
\hline & R5 & 1.0 & 1.0 & 1.0 & 1.0 & 1.0 & 1.0 & 1.0 & 0.7 & 0.7 \\
\hline & $A v$ & 1.0 & 1.0 & 1.0 & 1.0 & 1.0 & 1.0 & 1.0 & 0.8 & 0.8 \\
\hline \multirow[t]{3}{*}{ Head } & R1 & 0.9 & 1.0 & 1.0 & 1.0 & 1.0 & 0.9 & 1.0 & & \\
\hline & R2 & 0.9 & 1.0 & 1.0 & 0.8 & 0.9 & 1.0 & 1.0 & & \\
\hline & $A v$ & 0.9 & 1.0 & 1.0 & 0.9 & 0.9 & 1.0 & 1.0 & & \\
\hline \multirow[t]{7}{*}{ Beam } & R1 & 1.0 & 1.0 & 1.0 & 1.0 & 1.0 & 1.0 & 1.0 & 0.7 & 0.7 \\
\hline & R2 & 1.0 & 1.0 & 1.0 & 1.0 & 1.0 & 1.0 & 1.0 & 0.6 & 0.6 \\
\hline & R3 & 1.0 & 1.0 & 1.0 & 1.0 & 1.0 & 1.0 & 1.0 & 0.9 & 0.9 \\
\hline & R4 & 1.0 & 0.9 & 1.0 & 1.0 & 1.0 & 1.0 & 1.0 & 0.7 & 0.7 \\
\hline & R5 & 1.0 & 1.0 & 1.0 & 1.0 & 1.0 & 1.0 & 1.0 & 0.9 & 0.8 \\
\hline & R6 & 0.9 & 0.9 & 1.0 & 1.0 & 1.0 & 1.0 & 1.0 & 0.6 & 0.7 \\
\hline & $A v$ & 1.0 & 1.0 & 1.0 & 1.0 & 1.0 & 1.0 & 1.0 & 0.7 & 0.7 \\
\hline \multirow[t]{3}{*}{ SQ } & R1 & & & 1.0 & 1.0 & 1.0 & 1.0 & 1.0 & 0.7 & \\
\hline & R2 & & & 1.0 & 1.0 & 1.0 & 1.0 & 1.0 & 0.8 & \\
\hline & $A v$ & & & 1.0 & 1.0 & 1.0 & 1.0 & 1.0 & 0.7 & \\
\hline \multirow[t]{3}{*}{$\mathrm{BQ}$} & R1 & & & 1.0 & 1.0 & 1.0 & 1.0 & 1.0 & & \\
\hline & R2 & & & 1.0 & 1.0 & 1.0 & 1.0 & 1.0 & & \\
\hline & $A v$ & & & 1.0 & 1.0 & 1.0 & 1.0 & 1.0 & & \\
\hline
\end{tabular}




\section{D.2 Wave M2}

Table D-3. Wave heights (inch) by heading for wave M2.

\begin{tabular}{|c|c|c|c|c|c|c|c|c|c|c|}
\hline Heading & Run & C1 & C2 & C4 & C5 & C6 & $\mathrm{C7}$ & C9 & S1 & S2 \\
\hline \multirow[t]{8}{*}{ Following } & R1 & 1.5 & 1.5 & 1.8 & 1.3 & 1.3 & 1.5 & 1.3 & 0.5 & 0.7 \\
\hline & R2 & 1.5 & 1.8 & 1.6 & 1.2 & 1.2 & 1.5 & 1.6 & 0.5 & 0.6 \\
\hline & R3 & 1.5 & 1.8 & 1.6 & 1.1 & 1.1 & 1.6 & 1.5 & 0.6 & 0.6 \\
\hline & R4 & 1.4 & 1.7 & 1.7 & 1.1 & 1.1 & 1.6 & 1.4 & 0.5 & 0.6 \\
\hline & R5 & 1.2 & 1.6 & 1.5 & 0.8 & 0.7 & 1.5 & 1.4 & 0.4 & 0.6 \\
\hline & R6 & 1.1 & 1.7 & 1.8 & 1.1 & 0.8 & 1.5 & 1.5 & 0.6 & 0.5 \\
\hline & R7 & 1.3 & 1.9 & 1.7 & 0.8 & 0.8 & 1.6 & 1.7 & 0.6 & 0.6 \\
\hline & Av & 1.4 & 1.7 & 1.7 & 1.1 & 1.0 & 1.5 & 1.5 & 0.5 & 0.6 \\
\hline \multirow[t]{3}{*}{ Head } & R1 & 1.7 & 1.5 & 1.6 & 1.3 & 1.3 & 1.5 & 1.3 & & \\
\hline & R2 & 1.3 & 1.6 & 1.8 & 1.4 & 1.4 & 1.4 & 1.3 & & \\
\hline & $A v$ & 1.5 & 1.5 & 1.7 & 1.3 & 1.3 & 1.5 & 1.3 & & \\
\hline \multirow[t]{7}{*}{ Beam } & R1 & 1.6 & 1.4 & 1.6 & 0.9 & 0.9 & 1.5 & 1.4 & 0.5 & 0.4 \\
\hline & R2 & 1.3 & 1.5 & 1.7 & 1.1 & 1.1 & 1.5 & 1.4 & 0.4 & 0.4 \\
\hline & R3 & 1.6 & 1.4 & 1.6 & 1.2 & 1.2 & 1.5 & 1.6 & 0.6 & 0.5 \\
\hline & R4 & 1.6 & 1.4 & 1.6 & 1.2 & 1.2 & 1.5 & 1.5 & 0.6 & 0.5 \\
\hline & R5 & 1.7 & 1.5 & 1.5 & 1.1 & 1.1 & 1.5 & 1.5 & 0.6 & 0.4 \\
\hline & R6 & 1.3 & 1.5 & 1.3 & 1.2 & 1.2 & 1.5 & 1.5 & 0.4 & 0.5 \\
\hline & $A v$ & 1.5 & 1.5 & 1.5 & 1.1 & 1.1 & 1.5 & 1.5 & 0.5 & 0.5 \\
\hline \multirow[t]{4}{*}{ SQ } & R1 & & & 1.7 & 1.1 & 1.0 & 1.4 & 1.7 & 0.6 & \\
\hline & R2 & & & 1.4 & 1.2 & 1.1 & 1.4 & 1.6 & 0.4 & \\
\hline & R3 & & & 1.6 & 1.1 & 1.1 & 1.4 & 1.7 & 0.6 & \\
\hline & $A v$ & & & 1.6 & 1.1 & 1.1 & 1.4 & 1.7 & 0.5 & \\
\hline \multirow[t]{3}{*}{$\mathrm{BQ}$} & R1 & & & 1.8 & 1.2 & 1.2 & 1.4 & 1.7 & & \\
\hline & R2 & & & 1.5 & 1.2 & 1.1 & 1.4 & 1.7 & & \\
\hline & $A v$ & & & 1.7 & 1.2 & 1.2 & 1.4 & 1.7 & & \\
\hline
\end{tabular}


Table D-4. Wave periods (second) by heading for wave M2.

\begin{tabular}{|c|c|c|c|c|c|c|c|c|c|c|}
\hline Heading & Run & C1 & C2 & C4 & C5 & C6 & C7 & C9 & S1 & S2 \\
\hline \multirow[t]{8}{*}{ Following } & R1 & 1.3 & 1.3 & 1.3 & 1.3 & 1.3 & 1.3 & 1.3 & 1.0 & 1.1 \\
\hline & R2 & 1.3 & 1.3 & 1.3 & 1.3 & 1.3 & 1.3 & 1.3 & 0.9 & 1.0 \\
\hline & R3 & 1.3 & 1.3 & 1.3 & 1.3 & 1.3 & 1.3 & 1.3 & 1.1 & 1.1 \\
\hline & R4 & 1.3 & 1.3 & 1.3 & 1.3 & 1.3 & 1.3 & 1.3 & 1.0 & 1.1 \\
\hline & R5 & 1.3 & 1.3 & 1.3 & 1.3 & 1.3 & 1.3 & 1.3 & 0.9 & 1.1 \\
\hline & R6 & 1.3 & 1.3 & 1.3 & 1.3 & 1.3 & 1.3 & 1.3 & 1.0 & 0.8 \\
\hline & R7 & 1.3 & 1.3 & 1.3 & 1.3 & 1.3 & 1.3 & 1.3 & 1.2 & 1.1 \\
\hline & $A v$ & 1.3 & 1.3 & 1.3 & 1.3 & 1.3 & 1.3 & 1.3 & 1.0 & 1.1 \\
\hline \multirow[t]{3}{*}{ Head } & R1 & 1.3 & 1.3 & 1.3 & 1.3 & 1.3 & 1.3 & 1.3 & & \\
\hline & R2 & 1.3 & 1.3 & 1.3 & 1.3 & 1.3 & 1.3 & 1.3 & & \\
\hline & Av & 1.3 & 1.3 & 1.3 & 1.3 & 1.3 & 1.3 & 1.3 & & \\
\hline \multirow[t]{7}{*}{ Beam } & R1 & 1.3 & 1.3 & 1.3 & 1.3 & 1.3 & 1.3 & 1.3 & 1.2 & 1.0 \\
\hline & $\mathrm{R} 2$ & 1.3 & 1.3 & 1.3 & 1.3 & 1.3 & 1.3 & 1.3 & 1.0 & 0.9 \\
\hline & R3 & 1.3 & 1.3 & 1.3 & 1.3 & 1.3 & 1.3 & 1.3 & 1.2 & 1.1 \\
\hline & R4 & 1.3 & 1.3 & 1.3 & 1.3 & 1.3 & 1.3 & 1.3 & 1.1 & 1.0 \\
\hline & R5 & 1.3 & 1.3 & 1.3 & 1.3 & 1.3 & 1.3 & 1.3 & 1.2 & 1.0 \\
\hline & R6 & 1.3 & 1.3 & 1.3 & 1.3 & 1.3 & 1.3 & 1.3 & 1.0 & 1.1 \\
\hline & $A v$ & 1.3 & 1.3 & 1.3 & 1.3 & 1.3 & 1.3 & 1.3 & 1.1 & 1.0 \\
\hline \multirow[t]{4}{*}{ SQ } & R1 & & & 1.3 & 1.3 & 1.3 & 1.3 & 1.3 & 1.3 & \\
\hline & R2 & & & 1.3 & 1.3 & 1.3 & 1.3 & 1.3 & 0.9 & \\
\hline & R3 & & & 1.3 & 1.3 & 1.3 & 1.3 & 1.3 & 1.1 & \\
\hline & $\mathrm{Av}$ & & & 1.3 & 1.3 & 1.3 & 1.3 & 1.3 & 1.1 & \\
\hline \multirow[t]{3}{*}{$\mathrm{BQ}$} & R1 & & & 1.3 & 1.3 & 1.3 & 1.3 & 1.3 & & \\
\hline & R2 & & & 1.3 & 1.3 & 1.3 & 1.3 & 1.3 & & \\
\hline & $A v$ & & & 1.3 & 1.3 & 1.3 & 1.3 & 1.3 & & \\
\hline
\end{tabular}




\section{D.3 Wave M3}

Table D-5. Wave heights (inch) by heading for wave M3.

\begin{tabular}{|c|c|c|c|c|c|c|c|c|c|c|}
\hline Heading & Run & C1 & C2 & C4 & C5 & C6 & C7 & C9 & S1 & S2 \\
\hline \multirow[t]{5}{*}{ Following } & R1 & 2.4 & 2.6 & 1.9 & 1.7 & 1.7 & 2.0 & 2.5 & 0.8 & 0.9 \\
\hline & R2 & 2.2 & 2.6 & 1.6 & 1.6 & 1.6 & 1.9 & 2.4 & 0.8 & 0.5 \\
\hline & R3 & 2.2 & 2.5 & 1.8 & 1.8 & 1.7 & 1.9 & 2.5 & 0.7 & 0.7 \\
\hline & R4 & 2.2 & 2.4 & 1.8 & 1.7 & 1.7 & 2.0 & 2.5 & 0.6 & 0.8 \\
\hline & $A v$ & 2.2 & 2.5 & 1.8 & 1.7 & 1.7 & 1.9 & 2.5 & 0.7 & 0.7 \\
\hline \multirow[t]{3}{*}{ Head } & R1 & 2.6 & 2.5 & 1.8 & 2.2 & 2.2 & 2.0 & 2.3 & & \\
\hline & R2 & 2.6 & 2.5 & 1.9 & 2.0 & 1.9 & 1.8 & 2.2 & & \\
\hline & $A v$ & 2.6 & 2.5 & 1.8 & 2.1 & 2.0 & 1.9 & 2.2 & & \\
\hline \multirow[t]{4}{*}{ Beam } & R1 & 2.3 & 2.4 & 2.0 & 2.2 & 2.2 & 1.9 & 2.3 & 0.8 & 0.9 \\
\hline & R2 & 2.3 & 2.4 & 2.1 & 2.2 & 2.2 & 1.9 & 2.3 & 0.8 & 0.8 \\
\hline & R3 & 2.5 & 2.5 & 1.9 & 2.2 & 2.2 & 1.9 & 2.3 & 0.7 & 0.8 \\
\hline & $A v$ & 2.4 & 2.4 & 2.0 & 2.2 & 2.2 & 1.9 & 2.3 & 0.8 & 0.8 \\
\hline \multirow[t]{8}{*}{ SQ } & R1 & & & 2.6 & 2.0 & 2.0 & 1.9 & 2.3 & 0.8 & \\
\hline & R2 & & & 2.5 & 2.3 & 2.0 & 2.0 & 2.1 & 0.7 & \\
\hline & R3 & & & 2.3 & 1.7 & 1.8 & 2.0 & 2.1 & 0.9 & \\
\hline & R4 & & & 2.4 & 2.1 & 2.0 & 2.0 & 2.2 & 0.9 & \\
\hline & R5 & & & 2.4 & 1.8 & 2.0 & 2.0 & 2.3 & 0.8 & \\
\hline & R6 & & & 2.3 & 1.9 & 1.9 & 1.9 & 2.4 & 0.9 & \\
\hline & R7 & & & 2.3 & 2.0 & 2.0 & 2.0 & 2.2 & 0.8 & \\
\hline & $A v$ & & & 2.4 & 2.0 & 1.9 & 2.0 & 2.2 & 0.8 & \\
\hline \multirow[t]{3}{*}{$B Q$} & R1 & & & 2.6 & 2.3 & 2.3 & 1.8 & 2.3 & & \\
\hline & R2 & & & 2.4 & 2.3 & 2.3 & 1.8 & 2.3 & & \\
\hline & $A v$ & & & 2.5 & 2.3 & 2.3 & 1.8 & 2.3 & & \\
\hline
\end{tabular}


Table D-6. Wave periods (second) by heading for wave M3.

\begin{tabular}{|c|c|c|c|c|c|c|c|c|c|c|}
\hline Heading & Run & C1 & C2 & C4 & C5 & C6 & C7 & $c 9$ & S1 & S2 \\
\hline \multirow[t]{5}{*}{ Following } & R1 & 1.7 & 1.7 & 1.7 & 1.7 & 1.7 & 1.7 & 1.7 & 1.4 & 1.5 \\
\hline & R2 & 1.7 & 1.7 & 1.7 & 1.7 & 1.7 & 1.7 & 1.7 & 1.4 & 1.0 \\
\hline & R3 & 1.7 & 1.7 & 1.7 & 1.7 & 1.7 & 1.7 & 1.7 & 1.3 & 1.3 \\
\hline & R4 & 1.7 & 1.7 & 1.7 & 1.7 & 1.7 & 1.7 & 1.7 & 1.2 & 1.4 \\
\hline & $\mathrm{Av}$ & 1.7 & 1.7 & 1.7 & 1.7 & 1.7 & 1.7 & 1.7 & 1.3 & 1.3 \\
\hline \multirow[t]{3}{*}{ Head } & R1 & 1.7 & 1.7 & 1.7 & 1.7 & 1.7 & 1.7 & 1.7 & & \\
\hline & R2 & 1.7 & 1.7 & 1.6 & 1.7 & 1.7 & 1.7 & 1.7 & & \\
\hline & Av & 1.7 & 1.7 & 1.7 & 1.7 & 1.7 & 1.7 & 1.7 & & \\
\hline \multirow[t]{4}{*}{ Beam } & R1 & 1.7 & 1.7 & 1.7 & 1.7 & 1.7 & 1.7 & 1.7 & 1.5 & 1.5 \\
\hline & R2 & 1.7 & 1.7 & 1.7 & 1.7 & 1.7 & 1.7 & 1.7 & 1.5 & 1.4 \\
\hline & R3 & 1.7 & 1.7 & 1.7 & 1.7 & 1.7 & 1.7 & 1.7 & 1.1 & 1.3 \\
\hline & $A v$ & 1.7 & 1.7 & 1.7 & 1.7 & 1.7 & 1.7 & 1.7 & 1.4 & 1.4 \\
\hline \multirow[t]{8}{*}{ SQ } & R1 & & & 1.7 & 1.7 & 1.7 & 1.7 & 1.7 & 1.4 & \\
\hline & R2 & & & 1.7 & 1.7 & 1.7 & 1.7 & 1.7 & 1.4 & \\
\hline & R3 & & & 1.7 & 1.7 & 1.7 & 1.7 & 1.7 & 1.6 & \\
\hline & R4 & & & 1.7 & 1.7 & 1.7 & 1.7 & 1.7 & 1.7 & \\
\hline & R5 & & & 1.7 & 1.7 & 1.7 & 1.7 & 1.7 & 1.3 & \\
\hline & R6 & & & 1.7 & 1.7 & 1.7 & 1.7 & 1.7 & 1.5 & \\
\hline & R7 & & & 1.7 & 1.7 & 1.7 & 1.7 & 1.7 & 1.3 & \\
\hline & Av & & & 1.7 & 1.7 & 1.7 & 1.7 & 1.7 & 1.5 & \\
\hline \multirow[t]{3}{*}{$\mathrm{BQ}$} & R1 & & & 1.7 & 1.7 & 1.7 & 1.7 & 1.7 & & \\
\hline & R2 & & & 1.7 & 1.7 & 1.7 & 1.7 & 1.7 & & \\
\hline & $A v$ & & & 1.7 & 1.7 & 1.7 & 1.7 & 1.7 & & \\
\hline
\end{tabular}




\section{D.4 Wave M4}

Table D-7. Wave heights (inch) by heading for wave M4.

\begin{tabular}{|c|c|c|c|c|c|c|c|c|c|c|}
\hline Heading & Run & C1 & $\mathrm{C} 2$ & C4 & C5 & C6 & C7 & C9 & S1 & S2 \\
\hline \multirow[t]{6}{*}{ Following } & R2 & 3.2 & 2.8 & 2.8 & 1.5 & 1.5 & 2.8 & 3.6 & 1.2 & 1.0 \\
\hline & R3 & 3.2 & 2.9 & 2.9 & 1.4 & 1.4 & 2.8 & 3.6 & 1.3 & 0.9 \\
\hline & R4 & 3.2 & 2.9 & 2.9 & 1.3 & 1.3 & 2.8 & 3.6 & 1.1 & 1.0 \\
\hline & R5 & 2.7 & 2.8 & 2.6 & 1.4 & 1.3 & 2.9 & 3.6 & 1.0 & 0.9 \\
\hline & R6 & 3.3 & 2.8 & 2.5 & 1.2 & 1.3 & 2.9 & 3.6 & 1.1 & 0.8 \\
\hline & $A v$ & 3.1 & 2.8 & 2.8 & 1.4 & 1.4 & 2.9 & 3.6 & 1.2 & 1.0 \\
\hline \multirow[t]{3}{*}{ Head } & R1 & 3.3 & 3.3 & 2.9 & 1.4 & 1.4 & 2.7 & 3.8 & & \\
\hline & R2 & 3.1 & 3.2 & 2.6 & 1.3 & 1.3 & 2.3 & 3.6 & & \\
\hline & $A v$ & 3.2 & 3.3 & 2.7 & 1.4 & 1.4 & 2.5 & 3.7 & & \\
\hline \multirow[t]{6}{*}{ Beam } & R1 & 1.5 & 1.5 & 1.3 & 0.7 & 0.7 & 1.4 & 1.8 & 0.6 & 0.5 \\
\hline & R2 & 1.4 & 1.5 & 1.4 & 0.7 & 0.7 & 1.4 & 1.8 & 0.4 & 0.4 \\
\hline & R3 & 1.5 & 1.6 & 1.4 & 0.7 & 0.7 & 1.4 & 1.8 & 0.5 & 0.4 \\
\hline & R4 & 3.1 & 2.9 & 2.8 & 1.3 & 1.3 & 3.0 & 3.6 & 1.2 & 1.2 \\
\hline & R5 & 1.5 & 1.6 & 1.3 & 0.7 & 0.7 & 1.3 & 1.7 & 0.4 & 0.5 \\
\hline & $\mathrm{Av}$ & 1.8 & 1.8 & 1.6 & 0.8 & 0.8 & 1.7 & 2.1 & 0.6 & 0.6 \\
\hline \multirow[t]{8}{*}{ SQ } & R2 & & & 2.1 & 1.0 & 1.0 & 2.2 & 2.3 & 0.9 & \\
\hline & R3 & & & 2.0 & 0.9 & 0.9 & 2.2 & 2.3 & 0.9 & \\
\hline & R4 & & & 2.1 & 1.0 & 1.0 & 2.1 & 2.3 & 0.7 & \\
\hline & R5 & & & 2.0 & 0.9 & 0.9 & 2.1 & 2.2 & 0.7 & \\
\hline & R6 & & & 2.0 & 1.0 & 0.9 & 2.2 & 2.3 & 0.6 & \\
\hline & R7 & & & 1.9 & 0.9 & 0.9 & 2.2 & 2.3 & 0.7 & \\
\hline & R8 & & & 1.9 & 1.0 & 0.9 & 2.2 & 2.3 & 0.6 & \\
\hline & $A v$ & & & 2.0 & 1.0 & 0.9 & 2.2 & 2.3 & 0.7 & \\
\hline \multirow[t]{8}{*}{ BQ } & R2 & & & 2.3 & 1.1 & 1.1 & 2.7 & 2.8 & & \\
\hline & R3 & & & 2.5 & 1.2 & 1.2 & 2.7 & 2.9 & 0.8 & \\
\hline & R4 & & & 2.5 & 1.2 & 1.2 & 2.7 & 2.8 & 0.7 & \\
\hline & R5 & & & 2.4 & 1.2 & 1.2 & 2.7 & 2.7 & 0.8 & \\
\hline & R6 & & & 2.4 & 1.1 & 1.1 & 2.7 & 2.8 & 0.8 & \\
\hline & R7 & & & 2.5 & 1.3 & 1.3 & 2.7 & 2.8 & 0.7 & \\
\hline & R8 & & & 2.3 & 1.1 & 1.1 & 2.7 & 2.8 & 0.8 & \\
\hline & $A v$ & & & 2.4 & 1.2 & 1.2 & 2.7 & 2.8 & 0.8 & \\
\hline
\end{tabular}


Table D-8. Wave periods (second) by heading for wave M4.

\begin{tabular}{|c|c|c|c|c|c|c|c|c|c|c|}
\hline Heading & Run & C1 & $\mathrm{C} 2$ & $\mathrm{C4}$ & C5 & C6 & C7 & $c 9$ & S1 & $S 2$ \\
\hline \multirow[t]{6}{*}{ Following } & R2 & 2.4 & 2.4 & 2.4 & 2.4 & 2.4 & 2.4 & 2.4 & 2.3 & 2.0 \\
\hline & R3 & 2.4 & 2.4 & 2.4 & 2.4 & 2.4 & 2.4 & 2.4 & 2.4 & 1.8 \\
\hline & R4 & 2.4 & 2.4 & 2.4 & 2.4 & 2.3 & 2.4 & 2.4 & 2.0 & 2.0 \\
\hline & R5 & 2.2 & 2.4 & 2.4 & 2.3 & 2.3 & 2.4 & 2.4 & 2.0 & 2.0 \\
\hline & R6 & 2.4 & 2.4 & 2.4 & 2.2 & 2.3 & 2.4 & 2.4 & 2.0 & 1.7 \\
\hline & $A v$ & 2.3 & 2.4 & 2.4 & 2.3 & 2.4 & 2.4 & 2.4 & 2.1 & 1.9 \\
\hline \multirow[t]{3}{*}{ Head } & R1 & 2.4 & 2.4 & 2.4 & 2.4 & 2.4 & 2.4 & 2.4 & & \\
\hline & R2 & 2.4 & 2.4 & 2.4 & 2.3 & 2.4 & 2.3 & 2.3 & & \\
\hline & $A v$ & 2.4 & 2.4 & 2.4 & 2.4 & 2.4 & 2.3 & 2.3 & & \\
\hline \multirow[t]{6}{*}{ Beam } & R1 & 2.4 & 2.4 & 2.4 & 2.4 & 2.3 & 2.4 & 2.4 & 2.3 & 1.6 \\
\hline & R2 & 2.4 & 2.4 & 2.4 & 2.4 & 2.4 & 2.4 & 2.4 & 1.4 & 1.5 \\
\hline & R3 & 2.4 & 2.4 & 2.4 & 2.4 & 2.4 & 2.4 & 2.4 & 1.5 & 1.4 \\
\hline & R4 & 2.4 & 2.4 & 2.4 & 2.4 & 2.4 & 2.4 & 2.4 & 2.2 & 2.2 \\
\hline & R5 & 2.4 & 2.4 & 2.4 & 2.3 & 2.3 & 2.4 & 2.4 & 1.4 & 1.5 \\
\hline & $A v$ & 2.4 & 2.4 & 2.4 & 2.3 & 2.3 & 2.4 & 2.4 & 1.8 & 1.6 \\
\hline \multirow[t]{8}{*}{ SQ } & R2 & & & 2.4 & 2.4 & 2.4 & 2.4 & 2.4 & 1.9 & \\
\hline & R3 & & & 2.4 & 2.2 & 2.2 & 2.4 & 2.4 & 1.9 & \\
\hline & R4 & & & 2.4 & 2.4 & 2.4 & 2.4 & 2.4 & 1.6 & \\
\hline & R5 & & & 2.4 & 2.4 & 2.4 & 2.4 & 2.4 & 1.8 & \\
\hline & R6 & & & 2.4 & 2.4 & 2.4 & 2.4 & 2.4 & 1.7 & \\
\hline & R7 & & & 2.4 & 2.1 & 2.1 & 2.4 & 2.4 & 1.8 & \\
\hline & R8 & & & 2.4 & 2.2 & 2.1 & 2.4 & 2.4 & 1.5 & \\
\hline & $\mathrm{Av}$ & & & 2.4 & 2.3 & 2.3 & 2.4 & 2.4 & 1.8 & \\
\hline \multirow[t]{8}{*}{$\mathrm{BQ}$} & R2 & & & 2.4 & 2.4 & 2.4 & 2.4 & 2.4 & & \\
\hline & R3 & & & 2.4 & 2.4 & 2.3 & 2.4 & 2.4 & 1.9 & \\
\hline & R4 & & & 2.4 & 2.4 & 2.4 & 2.4 & 2.4 & 1.6 & \\
\hline & R5 & & & 2.4 & 2.4 & 2.4 & 2.4 & 2.4 & 2.0 & \\
\hline & R6 & & & 2.4 & 2.4 & 2.4 & 2.4 & 2.4 & 1.7 & \\
\hline & R7 & & & 2.4 & 2.4 & 2.4 & 2.4 & 2.4 & 1.6 & \\
\hline & R8 & & & 2.4 & 2.4 & 2.4 & 2.4 & 2.4 & 1.9 & \\
\hline & $\mathrm{Av}$ & & & 2.4 & 2.4 & 2.4 & 2.4 & 2.4 & 1.8 & \\
\hline
\end{tabular}




\section{D.5 Wave M5}

Table D-9. Wave heights (inch) by heading for wave M5.

\begin{tabular}{|c|c|c|c|c|c|c|c|c|c|c|}
\hline Heading & Run & C1 & $\mathrm{C} 2$ & C4 & C5 & C6 & C7 & C9 & S1 & S2 \\
\hline \multirow[t]{10}{*}{ Following } & R1 & 3.1 & 2.8 & 2.1 & 1.8 & 1.8 & 3.5 & 2.9 & 1.0 & 1.0 \\
\hline & R2 & 2.9 & 2.8 & 2.1 & 1.8 & 1.8 & 3.5 & 2.9 & 0.9 & 0.9 \\
\hline & R3 & 3.0 & 2.6 & 1.8 & 1.7 & 1.7 & 3.6 & 3.1 & 0.8 & 0.8 \\
\hline & R4 & 3.0 & 2.6 & 2.3 & 1.7 & 1.7 & 3.6 & 3.0 & 0.8 & 1.1 \\
\hline & R5 & 3.0 & 2.6 & 2.1 & 1.7 & 1.7 & 3.4 & 3.0 & 0.8 & 1.1 \\
\hline & R6 & 2.8 & 2.6 & 1.9 & 1.8 & 1.8 & 3.4 & 2.9 & 0.7 & 0.9 \\
\hline & R7 & 3.1 & 2.6 & 2.0 & 1.8 & 1.8 & 3.5 & 2.9 & 0.8 & 0.9 \\
\hline & R8 & 2.9 & 2.7 & 2.4 & 1.8 & 1.8 & 3.6 & 2.9 & 0.8 & 1.0 \\
\hline & R9 & 2.7 & 2.8 & 2.4 & 1.8 & 1.8 & 3.6 & 2.9 & 0.9 & 1.1 \\
\hline & $A v$ & 2.9 & 2.7 & 2.1 & 1.8 & 1.8 & 3.5 & 2.9 & 0.8 & 1.0 \\
\hline \multirow[t]{9}{*}{ Head } & R1 & 1.6 & 1.5 & 1.3 & 1.0 & 1.0 & 1.5 & 1.3 & & \\
\hline & R2 & 1.6 & 1.4 & 1.4 & 1.0 & 1.0 & 1.7 & 1.4 & & \\
\hline & R3 & 1.3 & 1.2 & 1.1 & 0.8 & 0.8 & 1.5 & 1.1 & 0.3 & 0.3 \\
\hline & R4 & 1.1 & 1.2 & 1.0 & 0.9 & 0.9 & 1.4 & 1.1 & 0.3 & 0.3 \\
\hline & R5 & 1.3 & 1.2 & 1.0 & 0.8 & 0.9 & 1.4 & 1.1 & 0.4 & 0.3 \\
\hline & R6 & 1.2 & 1.2 & 1.0 & 0.8 & 0.8 & 1.2 & 1.2 & 0.3 & 0.3 \\
\hline & R7 & 1.6 & 1.6 & 1.3 & 1.0 & 0.9 & 1.7 & 1.4 & 0.6 & 0.3 \\
\hline & R8 & 1.5 & 1.6 & 1.3 & 1.0 & 0.9 & 1.6 & 1.4 & 0.5 & 0.3 \\
\hline & $A v$ & 1.4 & 1.4 & 1.2 & 0.9 & 0.9 & 1.5 & 1.3 & 0.4 & 0.3 \\
\hline \multirow[t]{6}{*}{ Beam } & R1 & 1.4 & 1.3 & 1.1 & 1.0 & 1.0 & 1.6 & 1.4 & 0.4 & 0.4 \\
\hline & R2 & 1.3 & 1.3 & 1.2 & 1.0 & 1.0 & 1.6 & 1.4 & 0.4 & 0.4 \\
\hline & R3 & 1.3 & 1.3 & 1.2 & 0.9 & 0.9 & 1.6 & 1.4 & 0.4 & 0.4 \\
\hline & R4 & 1.3 & 1.3 & 1.2 & 1.0 & 0.9 & 1.6 & 1.5 & 0.4 & 0.3 \\
\hline & R5 & 1.3 & 1.3 & 1.2 & 0.9 & 0.9 & 1.6 & 1.4 & 0.4 & 0.4 \\
\hline & $A v$ & 1.3 & 1.3 & 1.1 & 1.0 & 0.9 & 1.6 & 1.4 & 0.4 & 0.4 \\
\hline \multirow[t]{4}{*}{ SQ } & R1 & & & 1.9 & 0.9 & 0.9 & 2.1 & 2.2 & 0.5 & \\
\hline & R2 & & & 1.9 & 1.0 & 1.0 & 2.1 & 2.1 & 0.6 & \\
\hline & R3 & & & 1.9 & 1.0 & 1.0 & 2.1 & 2.2 & 0.4 & \\
\hline & $A v$ & & & 1.9 & 1.0 & 1.0 & 2.1 & 2.2 & 0.5 & \\
\hline
\end{tabular}




\begin{tabular}{|l|l|l|l|l|l|l|l|l|l|l|}
\hline Heading & Run & C1 & C2 & C4 & C5 & C6 & C7 & C9 & S1 & S2 \\
\hline BQ & R2 & & & 2.1 & 1.2 & 1.2 & 2.4 & 2.4 & & \\
\hline & R3 & & & 2.0 & 1.1 & 1.1 & 2.4 & 2.4 & & \\
\hline & R4 & & & 2.1 & 1.1 & 1.1 & 2.4 & 2.4 & & \\
\hline & R5 & & & 2.2 & 1.2 & 1.2 & 2.4 & 2.4 & 0.6 & \\
\hline & R6 & & & 2.2 & 1.2 & 1.2 & 2.4 & 2.4 & 0.7 & \\
\hline & R7 & & & 2.0 & 1.3 & 1.3 & 2.4 & 2.4 & 0.6 & \\
\hline & R8 & & & 2.1 & 1.2 & 1.2 & 2.4 & 2.4 & 0.7 & \\
\hline & R9 & & & 2.1 & 1.2 & 1.2 & 2.4 & 2.4 & 0.8 & \\
\hline & R10 & & & 2.1 & 1.2 & 1.2 & 2.5 & 2.4 & 0.7 & \\
\hline & Av & & & 2.1 & 1.2 & 1.2 & 2.4 & 2.4 & 0.7 & \\
\hline
\end{tabular}

Table D-10. Wave periods (second) by heading for wave M5.

\begin{tabular}{|l|l|l|l|l|l|l|l|l|l|l|}
\hline Heading & Run & C1 & C2 & C4 & C5 & C6 & C7 & C9 & S1 & S2 \\
\hline Following & R1 & 2.7 & 2.7 & 2.5 & 2.7 & 2.7 & 2.7 & 2.7 & 2.3 & 2.2 \\
\hline & R2 & 2.7 & 2.7 & 2.5 & 2.7 & 2.7 & 2.7 & 2.7 & 2.1 & 1.9 \\
\hline & R3 & 2.7 & 2.7 & 2.3 & 2.7 & 2.7 & 2.7 & 2.7 & 1.9 & 1.9 \\
\hline & R4 & 2.7 & 2.7 & 2.7 & 2.7 & 2.8 & 2.7 & 2.7 & 1.9 & 2.3 \\
\hline & R5 & 2.7 & 2.7 & 2.3 & 2.8 & 2.8 & 2.7 & 2.7 & 1.9 & 2.3 \\
\hline & R6 & 2.6 & 2.7 & 2.3 & 2.7 & 2.7 & 2.7 & 2.7 & 1.7 & 2.2 \\
\hline & R7 & 2.7 & 2.6 & 2.7 & 2.7 & 2.7 & 2.7 & 2.5 & 1.8 & 1.9 \\
\hline & R8 & 2.7 & 2.7 & 2.7 & 2.7 & 2.7 & 2.7 & 2.7 & 1.8 & 2.2 \\
\hline & R9 & 2.7 & 2.7 & 2.7 & 2.7 & 2.7 & 2.7 & 2.7 & 2.1 & 2.3 \\
\hline & Av & 2.7 & 2.7 & 2.5 & 2.7 & 2.7 & 2.7 & 2.7 & 1.9 & 2.2 \\
\hline Head & R1 & 2.0 & 2.7 & 2.7 & 2.7 & 2.8 & 2.7 & 2.7 & & \\
\hline & R2 & 2.5 & 2.7 & 2.7 & 2.7 & 2.7 & 2.6 & 2.7 & & \\
\hline & R3 & 2.7 & 2.7 & 2.8 & 2.7 & 2.7 & 2.7 & 2.7 & 1.6 & 1.8 \\
\hline & R4 & 2.6 & 2.7 & 2.7 & 2.7 & 2.7 & 2.7 & 2.7 & 1.4 & 1.4 \\
\hline & R5 & 2.7 & 2.7 & 2.7 & 2.7 & 2.7 & 2.7 & 2.7 & 1.8 & 1.4 \\
\hline & R6 & 2.7 & 2.7 & 2.8 & 2.7 & 2.7 & 2.7 & 2.7 & 1.7 & 1.4 \\
\hline & R7 & 2.7 & 2.7 & 2.7 & 2.7 & 2.7 & 2.7 & 2.6 & 2.4 & 1.2 \\
\hline & R8 & 2.2 & 2.7 & 2.7 & 2.7 & 2.6 & 2.7 & 2.7 & 2.0 & 1.2 \\
\hline & 2.5 & 2.7 & 2.7 & 2.7 & 2.7 & 2.7 & 2.7 & 1.8 & 1.4 \\
\hline & & & & & & \\
\hline & & &
\end{tabular}




\begin{tabular}{|c|c|c|c|c|c|c|c|c|c|c|}
\hline Heading & Run & C1 & C2 & C4 & C5 & C6 & C7 & C9 & S1 & S2 \\
\hline \multirow[t]{6}{*}{ Beam } & R1 & 2.7 & 2.7 & 2.7 & 2.7 & 2.6 & 2.7 & 2.7 & 1.9 & 1.8 \\
\hline & R2 & 2.7 & 2.7 & 2.7 & 2.7 & 2.7 & 2.7 & 2.7 & 1.6 & 1.9 \\
\hline & R3 & 2.7 & 2.7 & 2.7 & 2.7 & 2.7 & 2.7 & 2.7 & 2.2 & 1.6 \\
\hline & R4 & 2.7 & 2.7 & 2.7 & 2.8 & 2.8 & 2.7 & 2.7 & 1.7 & 1.3 \\
\hline & R5 & 2.7 & 2.8 & 2.7 & 2.8 & 2.8 & 2.7 & 2.7 & 2.1 & 1.7 \\
\hline & $A v$ & 2.7 & 2.7 & 2.7 & 2.7 & 2.7 & 2.7 & 2.7 & 1.9 & 1.6 \\
\hline \multirow[t]{4}{*}{ SQ } & R1 & & & 2.7 & 2.5 & 2.5 & 2.7 & 2.7 & 1.8 & \\
\hline & R2 & & & 2.7 & 2.7 & 2.7 & 2.7 & 2.7 & 2.1 & \\
\hline & R3 & & & 2.7 & 2.5 & 2.5 & 2.7 & 2.7 & 1.2 & \\
\hline & $A v$ & & & 2.7 & 2.6 & 2.6 & 2.7 & 2.7 & 1.7 & \\
\hline \multirow[t]{10}{*}{$\mathrm{BQ}$} & R2 & & & 2.7 & 2.7 & 2.7 & 2.7 & 2.7 & & \\
\hline & R3 & & & 2.7 & 2.7 & 2.7 & 2.7 & 2.7 & & \\
\hline & R4 & & & 2.7 & 2.7 & 2.7 & 2.7 & 2.7 & & \\
\hline & R5 & & & 2.7 & 2.7 & 2.7 & 2.7 & 2.7 & 1.9 & \\
\hline & R6 & & & 2.7 & 2.7 & 2.7 & 2.7 & 2.7 & 2.2 & \\
\hline & R7 & & & 2.7 & 2.7 & 2.7 & 2.7 & 2.7 & 2.0 & \\
\hline & R8 & & & 2.7 & 2.7 & 2.7 & 2.7 & 2.7 & 2.2 & \\
\hline & R9 & & & 2.7 & 2.7 & 2.7 & 2.7 & 2.7 & 2.4 & \\
\hline & R10 & & & 2.7 & 2.7 & 2.7 & 2.7 & 2.7 & 2.3 & \\
\hline & $A v$ & & & 2.7 & 2.7 & 2.7 & 2.7 & 2.7 & 2.2 & \\
\hline
\end{tabular}




\section{D.6 Wave M6}

Table D-11. Wave heights (inch) by heading for wave M6.

\begin{tabular}{|c|c|c|c|c|c|c|c|c|c|c|}
\hline Heading & Run & C1 & C2 & C4 & C5 & C6 & C7 & C9 & S1 & S2 \\
\hline \multirow[t]{10}{*}{ Following } & R1 & 3.1 & 2.5 & 1.7 & 2.8 & 2.8 & 3.3 & 3.3 & 0.7 & 0.7 \\
\hline & R2 & 3.0 & 2.4 & 1.7 & 2.8 & 2.8 & 3.3 & 3.3 & 0.7 & 0.7 \\
\hline & R3 & 3.0 & 2.5 & 1.7 & 2.8 & 2.8 & 3.3 & 3.3 & 0.7 & 0.7 \\
\hline & R4 & 3.1 & 2.5 & 1.7 & 2.7 & 2.8 & 3.3 & 3.1 & 0.9 & 0.7 \\
\hline & R5 & 3.1 & 2.5 & 1.9 & 2.8 & 2.8 & 3.3 & 3.3 & 0.8 & 0.5 \\
\hline & R6 & 3.1 & 2.2 & 2.0 & 2.9 & 2.8 & 3.4 & 3.3 & 0.7 & 1.0 \\
\hline & R7 & 2.7 & 2.4 & 2.1 & 2.7 & 2.8 & 3.3 & 3.3 & 0.8 & 0.7 \\
\hline & R8 & 2.8 & 2.7 & 1.7 & 2.7 & 2.7 & 3.4 & 3.4 & 0.6 & 0.7 \\
\hline & R9 & 2.9 & 2.6 & 1.9 & 2.8 & 2.7 & 3.3 & 3.4 & 0.6 & 0.8 \\
\hline & $A v$ & 3.0 & 2.5 & 1.8 & 2.8 & 2.8 & 3.3 & 3.3 & 0.7 & 0.7 \\
\hline \multirow[t]{10}{*}{ Head } & R1 & 1.4 & 1.3 & 1.1 & 1.2 & 1.2 & 1.4 & 1.4 & & \\
\hline & R2 & 1.4 & 1.1 & 1.0 & 1.3 & 1.3 & 1.4 & 1.5 & & \\
\hline & R3 & 1.5 & 1.2 & 0.9 & 1.2 & 1.2 & 1.6 & 1.5 & & \\
\hline & R4 & 1.2 & 1.3 & 0.7 & 1.4 & 1.3 & 1.5 & 1.5 & 0.3 & 0.3 \\
\hline & R5 & 1.3 & 1.2 & 0.8 & 1.2 & 1.2 & 1.5 & 1.4 & 0.2 & 0.3 \\
\hline & R6 & 1.3 & 1.2 & 0.8 & 1.3 & 1.3 & 1.5 & 1.6 & 0.3 & 0.3 \\
\hline & R7 & 1.2 & 1.3 & 0.6 & 1.1 & 1.1 & 1.5 & 1.4 & 0.4 & 0.3 \\
\hline & R8 & 1.3 & 1.2 & 0.8 & 1.3 & 1.1 & 1.3 & 1.2 & 0.3 & 0.3 \\
\hline & R9 & 1.2 & 1.3 & 0.8 & 1.2 & 1.2 & 1.2 & 1.2 & 0.3 & 0.3 \\
\hline & $A v$ & 1.3 & 1.2 & 0.8 & 1.2 & 1.2 & 1.4 & 1.4 & 0.3 & 0.3 \\
\hline \multirow[t]{9}{*}{ Beam } & R1 & 1.2 & 1.2 & 0.9 & 1.3 & 1.3 & 1.5 & 1.5 & 0.3 & 0.3 \\
\hline & R2 & 1.2 & 1.1 & 0.9 & 1.3 & 1.3 & 1.5 & 1.6 & 0.3 & 0.3 \\
\hline & R3 & 1.2 & 1.2 & 0.9 & 1.3 & 1.3 & 1.5 & 1.6 & 0.3 & 0.3 \\
\hline & R4 & 1.3 & 1.2 & 0.9 & 1.2 & 1.3 & 1.5 & 1.5 & 0.3 & 0.2 \\
\hline & R5 & 1.2 & 1.2 & 0.9 & 1.3 & 1.3 & 1.5 & 1.5 & 0.3 & 0.2 \\
\hline & R6 & 1.2 & 1.2 & 1.0 & 1.2 & 1.2 & 1.5 & 1.5 & 0.3 & 0.2 \\
\hline & R7 & 1.2 & 1.1 & 1.0 & 1.3 & 1.3 & 1.5 & 1.5 & 0.3 & 0.2 \\
\hline & R8 & 1.2 & 1.2 & 0.9 & 1.3 & 1.3 & 1.5 & 1.5 & 0.3 & 0.2 \\
\hline & $A v$ & 1.2 & 1.2 & 0.9 & 1.3 & 1.3 & 1.5 & 1.5 & 0.3 & 0.3 \\
\hline
\end{tabular}




\begin{tabular}{|c|c|c|c|c|c|c|c|c|c|c|}
\hline Heading & Run & C1 & C2 & C4 & C5 & C6 & C7 & C9 & S1 & S2 \\
\hline \multirow[t]{5}{*}{ SQ } & R1 & & & 1.7 & 2.1 & 2.1 & 2.8 & 2.1 & 0.7 & \\
\hline & R2 & & & 1.8 & 2.1 & 2.1 & 2.8 & 2.2 & 0.5 & \\
\hline & R3 & & & 1.9 & 2.1 & 2.1 & 2.8 & 2.1 & 0.7 & \\
\hline & R4 & & & 1.8 & 2.1 & 2.1 & 2.8 & 2.1 & 0.7 & \\
\hline & $A v$ & & & 1.8 & 2.1 & 2.1 & 2.8 & 2.1 & 0.6 & \\
\hline \multirow[t]{4}{*}{$B Q$} & R1 & & & 2.1 & 2.0 & 2.0 & 2.8 & 2.1 & & \\
\hline & R2 & & & 2.0 & 2.0 & 2.0 & 2.8 & 2.1 & & \\
\hline & R3 & & & 1.9 & 2.1 & 2.1 & 2.8 & 2.1 & & \\
\hline & $A v$ & & & 2.0 & 2.1 & 2.0 & 2.8 & 2.1 & & \\
\hline \multirow[t]{21}{*}{ BQ Repeats } & R1 & & & 1.9 & 2.2 & 2.1 & 2.8 & 2.1 & 0.7 & \\
\hline & R2 & & & 1.9 & 2.1 & 2.1 & 2.7 & 2.1 & 0.5 & \\
\hline & R3 & & & 1.8 & 2.1 & 2.1 & 2.8 & 2.1 & 0.6 & \\
\hline & R4 & & & 1.9 & 2.2 & 2.1 & 2.8 & 2.1 & 0.5 & \\
\hline & R5 & & & 2.0 & 2.1 & 2.1 & 2.7 & 2.1 & 0.7 & \\
\hline & R6 & & & 1.9 & 2.1 & 2.1 & 2.7 & 2.1 & 0.6 & \\
\hline & R7 & & & 1.9 & 2.1 & 2.1 & 2.7 & 2.1 & 0.6 & \\
\hline & R8 & & & 1.8 & 2.1 & 2.0 & 2.7 & 2.1 & 0.6 & \\
\hline & R9 & & & 1.9 & 2.1 & 2.1 & 2.7 & 2.1 & 0.6 & \\
\hline & R10 & & & 1.9 & 2.1 & 2.1 & 2.7 & 2.2 & 0.6 & \\
\hline & R11 & & & 2.1 & 2.1 & 2.1 & 2.7 & 2.2 & 0.6 & \\
\hline & R12 & & & 2.0 & 2.1 & 2.1 & 2.7 & 2.1 & 0.7 & \\
\hline & R13 & & & 2.0 & 2.1 & 2.1 & 2.8 & 2.1 & 0.5 & \\
\hline & R14 & & & 2.0 & 2.1 & 2.0 & 2.8 & 2.2 & 0.4 & \\
\hline & R15 & & & 1.9 & 2.1 & 2.0 & 2.8 & 2.1 & 0.7 & \\
\hline & R16 & & & 1.8 & 2.0 & 2.0 & 2.7 & 2.1 & 0.7 & \\
\hline & R17 & & & 1.9 & 2.1 & 2.0 & 2.7 & 2.1 & 0.6 & \\
\hline & R18 & & & 1.9 & 2.1 & 2.0 & 2.8 & 2.1 & 0.8 & \\
\hline & R19 & & & 1.9 & 2.1 & 2.1 & 2.8 & 2.1 & 0.5 & \\
\hline & R2O & & & 1.9 & 2.0 & 2.0 & 2.7 & 2.1 & 0.6 & \\
\hline & $A v$ & & & 1.9 & 2.1 & 2.1 & 2.7 & 2.1 & 0.6 & \\
\hline
\end{tabular}


Table D-12. Wave periods (second) by heading for wave M6.

\begin{tabular}{|c|c|c|c|c|c|c|c|c|c|c|}
\hline Heading & Run & C1 & $\mathrm{C} 2$ & C4 & C5 & C6 & $\mathrm{C7}$ & C9 & S1 & S2 \\
\hline \multirow[t]{10}{*}{ Following } & R1 & 3.1 & 3.1 & 3.1 & 3.1 & 3.1 & 3.1 & 3.1 & 2.1 & 2.1 \\
\hline & $\mathrm{R} 2$ & 3.1 & 3.1 & 3.1 & 3.1 & 3.1 & 3.1 & 3.1 & 2.1 & 2.0 \\
\hline & R3 & 3.1 & 3.1 & 3.1 & 3.1 & 3.1 & 3.1 & 3.1 & 2.1 & 2.0 \\
\hline & $\mathrm{R} 4$ & 3.1 & 3.1 & 2.7 & 3.0 & 3.1 & 3.1 & 3.1 & 2.3 & 1.7 \\
\hline & R5 & 3.1 & 3.1 & 3.2 & 3.1 & 3.1 & 3.1 & 3.1 & 2.2 & 1.5 \\
\hline & R6 & 3.1 & 2.4 & 3.1 & 3.1 & 3.1 & 3.1 & 3.1 & 1.8 & 2.7 \\
\hline & R7 & 2.7 & 2.7 & 3.1 & 3.1 & 3.1 & 3.1 & 3.1 & 2.3 & 1.9 \\
\hline & R8 & 3.1 & 3.1 & 2.8 & 3.1 & 3.1 & 3.1 & 3.1 & 1.8 & 2.1 \\
\hline & R9 & 3.1 & 3.1 & 3.0 & 3.1 & 3.1 & 3.1 & 3.1 & 1.7 & 2.4 \\
\hline & Av & 3.1 & 3.0 & 3.0 & 3.1 & 3.1 & 3.1 & 3.1 & 2.0 & 2.0 \\
\hline \multirow[t]{10}{*}{ Head } & R1 & 2.3 & 3.1 & 3.1 & 3.1 & 3.1 & 3.1 & 3.1 & & \\
\hline & $\mathrm{R} 2$ & 2.3 & 2.6 & 3.1 & 3.1 & 3.1 & 3.1 & 3.1 & & \\
\hline & R3 & 2.5 & 3.1 & 2.7 & 3.1 & 3.1 & 3.1 & 3.1 & & \\
\hline & R4 & 3.1 & 3.1 & 3.0 & 3.1 & 3.1 & 3.1 & 3.1 & 1.8 & 1.6 \\
\hline & R5 & 3.0 & 3.1 & 3.1 & 3.1 & 3.1 & 3.1 & 2.9 & 1.3 & 1.6 \\
\hline & R6 & 3.1 & 3.1 & 3.1 & 3.1 & 3.1 & 3.1 & 3.1 & 1.6 & 1.6 \\
\hline & R7 & 2.8 & 3.1 & 1.9 & 2.9 & 2.8 & 3.1 & 2.8 & 2.0 & 1.5 \\
\hline & R8 & 3.0 & 3.1 & 2.5 & 3.1 & 2.9 & 3.1 & 2.3 & 1.4 & 1.6 \\
\hline & R9 & 2.3 & 3.1 & 2.3 & 3.1 & 3.1 & 3.1 & 2.5 & 1.9 & 1.5 \\
\hline & Av & 2.7 & 3.0 & 2.8 & 3.1 & 3.1 & 3.1 & 2.9 & 1.7 & 1.6 \\
\hline \multirow[t]{9}{*}{ Beam } & R1 & 3.1 & 3.1 & 3.1 & 3.1 & 3.1 & 3.1 & 3.1 & 2.1 & 1.7 \\
\hline & R2 & 3.1 & 2.9 & 3.1 & 3.1 & 3.1 & 3.1 & 3.1 & 1.7 & 1.8 \\
\hline & R3 & 3.1 & 3.2 & 3.1 & 3.1 & 3.1 & 3.1 & 3.1 & 1.6 & 1.8 \\
\hline & R4 & 3.1 & 3.1 & 3.1 & 3.1 & 3.1 & 3.1 & 3.1 & 1.6 & 1.5 \\
\hline & R5 & 3.0 & 3.1 & 3.1 & 3.1 & 3.1 & 3.1 & 3.1 & 1.8 & 1.4 \\
\hline & R6 & 3.1 & 3.2 & 3.1 & 3.1 & 3.1 & 3.1 & 3.1 & 2.1 & 1.5 \\
\hline & R7 & 3.2 & 3.1 & 3.1 & 3.1 & 3.1 & 3.1 & 3.1 & 1.6 & 1.5 \\
\hline & R8 & 3.1 & 3.1 & 3.1 & 3.1 & 3.1 & 3.1 & 3.1 & 1.8 & 1.3 \\
\hline & Av & 3.1 & 3.1 & 3.1 & 3.1 & 3.1 & 3.1 & 3.1 & 1.8 & 1.6 \\
\hline SQ & R1 & & & 3.1 & 3.1 & 3.1 & 3.1 & 3.1 & 2.3 & \\
\hline
\end{tabular}




\begin{tabular}{|c|c|c|c|c|c|c|c|c|c|c|}
\hline \multirow[t]{5}{*}{ Heading } & Run & C1 & C2 & C4 & C5 & C6 & $\mathrm{C7}$ & $C 9$ & S1 & S2 \\
\hline & R2 & & & 3.1 & 3.1 & 3.1 & 3.1 & 3.1 & 1.5 & \\
\hline & R3 & & & 3.1 & 3.1 & 3.1 & 3.1 & 3.1 & 2.2 & \\
\hline & R4 & & & 3.1 & 3.1 & 3.1 & 3.1 & 3.1 & 2.3 & \\
\hline & Av & & & 3.1 & 3.1 & 3.1 & 3.1 & 3.1 & 2.1 & \\
\hline \multirow[t]{4}{*}{$\mathrm{BQ}$} & R1 & & & 3.1 & 3.1 & 3.1 & 3.1 & 3.1 & & \\
\hline & R2 & & & 3.1 & 3.1 & 3.1 & 3.1 & 3.1 & & \\
\hline & R3 & & & 3.1 & 3.1 & 3.1 & 3.1 & 3.1 & & \\
\hline & Av & & & 3.1 & 3.1 & 3.1 & 3.1 & 3.1 & & \\
\hline \multirow[t]{21}{*}{ BQ Repeats } & R1 & & & 3.1 & 3.1 & 3.1 & 3.1 & 3.1 & 2.4 & \\
\hline & $\mathrm{R} 2$ & & & 3.1 & 3.1 & 3.1 & 3.1 & 3.1 & 1.8 & \\
\hline & R3 & & & 3.1 & 3.1 & 3.1 & 3.1 & 3.1 & 2.2 & \\
\hline & R4 & & & 3.1 & 3.1 & 3.1 & 3.1 & 3.1 & 1.8 & \\
\hline & R5 & & & 3.1 & 3.1 & 3.1 & 3.1 & 3.1 & 2.4 & \\
\hline & R6 & & & 3.1 & 3.1 & 3.1 & 3.1 & 3.1 & 2.2 & \\
\hline & R7 & & & 3.1 & 3.1 & 3.1 & 3.1 & 3.1 & 2.0 & \\
\hline & R8 & & & 3.1 & 3.1 & 3.1 & 3.1 & 3.1 & 2.2 & \\
\hline & R9 & & & 3.1 & 3.1 & 3.1 & 3.1 & 3.1 & 2.0 & \\
\hline & R10 & & & 3.1 & 3.1 & 3.1 & 3.1 & 3.1 & 2.2 & \\
\hline & R11 & & & 3.1 & 3.1 & 3.1 & 3.1 & 3.1 & 2.1 & \\
\hline & R12 & & & 3.1 & 3.1 & 3.1 & 3.1 & 3.1 & 2.4 & \\
\hline & R13 & & & 3.1 & 3.1 & 3.1 & 3.1 & 3.1 & 1.9 & \\
\hline & R14 & & & 3.1 & 3.1 & 3.1 & 3.1 & 3.1 & 1.6 & \\
\hline & R15 & & & 3.1 & 3.1 & 3.1 & 3.1 & 3.1 & 2.4 & \\
\hline & R16 & & & 3.1 & 3.1 & 3.1 & 3.1 & 3.1 & 2.7 & \\
\hline & R17 & & & 3.1 & 3.1 & 3.1 & 3.1 & 3.1 & 2.3 & \\
\hline & R18 & & & 3.1 & 3.1 & 3.1 & 3.1 & 3.1 & 3.1 & \\
\hline & R19 & & & 3.1 & 3.1 & 3.1 & 3.1 & 3.1 & 1.9 & \\
\hline & R20 & & & 3.1 & 3.1 & 3.1 & 3.1 & 3.1 & 2.1 & \\
\hline & Av & & & 3.1 & 3.1 & 3.1 & 3.1 & 3.1 & 2.2 & \\
\hline
\end{tabular}




\section{D.7 Wave M7}

Table D-13. Wave heights (inch) by heading for wave M7.

\begin{tabular}{|c|c|c|c|c|c|c|c|c|c|c|}
\hline Heading & Run & C1 & $\mathrm{C} 2$ & C4 & C5 & $\mathrm{C} 6$ & $\mathrm{C7}$ & C9 & S1 & S2 \\
\hline \multirow[t]{8}{*}{ Following } & $\mathrm{R} 1$ & 3.1 & 2.4 & 2.6 & 1.7 & 1.7 & 3.4 & 3.4 & 0.7 & 0.6 \\
\hline & $\mathrm{R} 2$ & 3.1 & 2.3 & 2.6 & 1.7 & 1.7 & 3.4 & 3.4 & 0.7 & 0.6 \\
\hline & R3 & 3.3 & 2.2 & 2.3 & 1.4 & 1.4 & 3.3 & 3.4 & 0.9 & 0.4 \\
\hline & R4 & 3.1 & 2.2 & 2.2 & 1.4 & 1.5 & 3.4 & 3.3 & 0.7 & 0.6 \\
\hline & R5 & 3.3 & 2.3 & 2.3 & 1.7 & 1.7 & 3.3 & 3.4 & 0.8 & 0.8 \\
\hline & R6 & 3.1 & 2.1 & 2.6 & 1.7 & 1.7 & 3.3 & 3.3 & 0.6 & 0.6 \\
\hline & $\mathrm{R} 7$ & 3.1 & 2.3 & 2.5 & 1.7 & 1.6 & 3.3 & 3.3 & 0.8 & 0.6 \\
\hline & Av & 3.2 & 2.2 & 2.4 & 1.6 & 1.6 & 3.4 & 3.4 & 0.8 & 0.6 \\
\hline \multirow[t]{10}{*}{ Head } & R1 & 1.4 & 0.8 & 0.9 & 0.7 & 0.7 & 1.2 & 1.3 & & \\
\hline & R2 & 1.3 & 0.7 & 1.0 & 0.7 & 0.6 & 1.2 & 1.0 & & \\
\hline & R3 & 1.5 & 0.7 & 0.9 & 0.6 & 0.6 & 1.3 & 1.3 & & \\
\hline & R4 & 1.0 & 0.7 & 0.8 & 0.6 & 0.6 & 1.3 & 1.3 & 0.2 & 0.1 \\
\hline & R5 & 1.1 & 0.7 & 0.8 & 0.6 & 0.6 & 1.3 & 1.3 & 0.2 & 0.1 \\
\hline & R6 & 1.2 & 0.7 & 0.9 & 0.6 & 0.6 & 1.3 & 1.4 & 0.2 & 0.1 \\
\hline & $\mathrm{R} 7$ & 0.9 & 0.7 & 0.8 & 0.6 & 0.6 & 1.0 & 1.2 & 0.2 & 0.1 \\
\hline & R8 & 1.1 & 0.7 & 0.9 & 0.5 & 0.6 & 1.2 & 1.1 & 0.1 & 0.1 \\
\hline & R9 & 1.0 & 0.8 & 0.7 & 0.5 & 0.5 & 0.9 & 1.1 & 0.2 & 0.1 \\
\hline & Av & 1.2 & 0.7 & 0.9 & 0.6 & 0.6 & 1.2 & 1.2 & 0.2 & 0.1 \\
\hline \multirow[t]{7}{*}{ Beam } & R1 & 2.9 & 2.3 & 2.3 & 1.3 & 1.4 & 3.4 & 3.4 & 1.0 & 0.5 \\
\hline & $\mathrm{R} 2$ & 3.0 & 2.3 & 2.3 & 1.6 & 1.6 & 3.3 & 3.3 & 0.8 & 0.5 \\
\hline & R3 & 2.9 & 2.3 & 2.2 & 1.5 & 1.4 & 3.4 & 3.3 & 0.7 & 0.7 \\
\hline & R4 & 3.0 & 2.1 & 2.3 & 1.6 & 1.6 & 3.4 & 3.6 & 0.8 & 0.7 \\
\hline & R5 & 2.9 & 2.3 & 2.3 & 1.7 & 1.6 & 3.3 & 3.4 & 0.8 & 0.6 \\
\hline & R6 & 3.0 & 2.1 & 2.2 & 1.6 & 1.6 & 3.3 & 3.3 & 0.6 & 0.6 \\
\hline & Av & 3.0 & 2.2 & 2.3 & 1.5 & 1.6 & 3.3 & 3.4 & 0.8 & 0.6 \\
\hline \multirow[t]{4}{*}{ SQ } & R1 & & & 2.5 & 1.6 & 1.6 & 2.8 & 2.3 & 0.4 & \\
\hline & $\mathrm{R} 2$ & & & 2.6 & 1.6 & 1.4 & 2.8 & 2.3 & 0.4 & \\
\hline & R3 & & & 2.5 & 1.7 & 1.6 & 2.8 & 2.3 & 0.3 & \\
\hline & R4 & & & 2.4 & 1.6 & 1.6 & 2.8 & 2.4 & 0.5 & \\
\hline
\end{tabular}




\begin{tabular}{|c|c|c|c|c|c|c|c|c|c|c|}
\hline Heading & Run & C1 & $\mathrm{C2}$ & C4 & C5 & C6 & $\mathrm{C7}$ & $c 9$ & S1 & S2 \\
\hline & R5 & & & 2.5 & 1.6 & 1.6 & 2.8 & 2.4 & 0.4 & \\
\hline & $\mathrm{R} 6$ & & & 2.4 & 1.6 & 1.6 & 2.9 & 2.4 & 0.6 & \\
\hline & Av & & & 2.5 & 1.6 & 1.6 & 2.8 & 2.4 & 0.4 & \\
\hline \multirow[t]{5}{*}{$\mathrm{BQ}$} & R1 & & & 2.5 & 1.7 & 1.7 & 2.8 & 2.3 & & \\
\hline & $\mathrm{R} 2$ & & & 2.6 & 1.6 & 1.6 & 2.8 & 2.3 & & \\
\hline & R3 & & & 2.4 & 1.6 & 1.6 & 2.8 & 2.3 & & \\
\hline & R4 & & & 2.5 & 1.7 & 1.6 & 2.8 & 2.3 & & \\
\hline & $A v$ & & & 2.5 & 1.7 & 1.6 & 2.8 & 2.3 & & \\
\hline \multirow[t]{21}{*}{ BQ Repeat } & $\mathrm{R} 1$ & & & 2.6 & 1.6 & 1.6 & 2.8 & 2.3 & 0.4 & \\
\hline & $\mathrm{R} 2$ & & & 2.5 & 1.7 & 1.7 & 2.8 & 2.3 & 0.5 & \\
\hline & R3 & & & 2.5 & 1.6 & 1.5 & 2.8 & 2.4 & 0.5 & \\
\hline & $\mathrm{R} 4$ & & & 2.5 & 1.5 & 1.5 & 2.8 & 2.3 & 0.4 & \\
\hline & R5 & & & 2.4 & 1.5 & 1.5 & 2.7 & 2.4 & 0.5 & \\
\hline & $\mathrm{R} 6$ & & & 2.5 & 1.6 & 1.5 & 2.8 & 2.3 & 0.4 & \\
\hline & $\mathrm{R} 7$ & & & 2.3 & 1.5 & 1.5 & 2.8 & 2.4 & 0.6 & \\
\hline & $\mathrm{R} 8$ & & & 2.5 & 1.6 & 1.6 & 2.8 & 2.4 & 0.5 & \\
\hline & R9 & & & 2.5 & 1.6 & 1.6 & 2.8 & 2.3 & 0.5 & \\
\hline & R10 & & & 2.5 & 1.6 & 1.6 & 2.8 & 2.3 & 0.4 & \\
\hline & R11 & & & 2.5 & 1.6 & 1.6 & 2.8 & 2.3 & 0.4 & \\
\hline & R12 & & & 2.5 & 1.6 & 1.6 & 2.8 & 2.4 & 0.5 & \\
\hline & R13 & & & 2.6 & 1.6 & 1.6 & 2.8 & 2.4 & 0.4 & \\
\hline & R14 & & & 2.6 & 1.6 & 1.6 & 2.8 & 2.4 & 0.4 & \\
\hline & R15 & & & 2.6 & 1.6 & 1.6 & 2.8 & 2.3 & 0.4 & \\
\hline & R16 & & & 2.6 & 1.6 & 1.6 & 2.8 & 2.4 & 0.4 & \\
\hline & R17 & & & 2.5 & 1.6 & 1.6 & 2.7 & 2.3 & 0.5 & \\
\hline & R18 & & & 2.5 & 1.6 & 1.6 & 2.8 & 2.3 & 0.4 & \\
\hline & R19 & & & 2.4 & 1.6 & 1.6 & 2.7 & 2.3 & 0.4 & \\
\hline & R20 & & & 2.4 & 1.5 & 1.5 & 2.7 & 2.3 & 0.5 & \\
\hline & Av & & & 2.5 & 1.6 & 1.6 & 2.8 & 2.3 & 0.5 & \\
\hline
\end{tabular}


Table D-14. Wave periods (second) by heading for wave M7.

\begin{tabular}{|c|c|c|c|c|c|c|c|c|c|c|}
\hline Heading & Run & C1 & $\mathrm{C} 2$ & $\mathrm{C4}$ & C5 & C6 & C7 & $C 9$ & S1 & S2 \\
\hline \multirow[t]{8}{*}{ Following } & R1 & 3.5 & 3.5 & 3.6 & 3.5 & 3.5 & 3.5 & 3.5 & 2.4 & 2.6 \\
\hline & R2 & 3.5 & 3.5 & 3.5 & 3.5 & 3.5 & 3.6 & 3.5 & 2.3 & 2.2 \\
\hline & R3 & 3.5 & 3.5 & 2.9 & 2.8 & 2.8 & 3.5 & 3.5 & 3.1 & 1.7 \\
\hline & R4 & 3.5 & 3.5 & 2.9 & 2.6 & 3.0 & 3.5 & 3.5 & 2.3 & 2.2 \\
\hline & R5 & 3.5 & 3.5 & 3.0 & 3.5 & 3.5 & 3.5 & 3.5 & 2.7 & 3.0 \\
\hline & R6 & 3.5 & 3.5 & 3.5 & 3.4 & 3.5 & 3.6 & 3.5 & 2.0 & 2.3 \\
\hline & R7 & 3.5 & 3.5 & 3.5 & 3.5 & 3.5 & 3.6 & 3.5 & 2.7 & 2.7 \\
\hline & $A v$ & 3.5 & 3.5 & 3.3 & 3.3 & 3.3 & 3.5 & 3.5 & 2.5 & 2.4 \\
\hline \multirow[t]{10}{*}{ Head } & R1 & 3.5 & 3.6 & 2.3 & 3.6 & 3.6 & 3.6 & 3.5 & & \\
\hline & R2 & 2.8 & 2.8 & 2.9 & 3.5 & 3.5 & 3.5 & 2.7 & & \\
\hline & R3 & 3.6 & 3.1 & 3.5 & 3.1 & 3.1 & 3.6 & 3.6 & & \\
\hline & R4 & 3.2 & 3.1 & 3.0 & 3.6 & 3.5 & 3.6 & 3.5 & 1.4 & 1.0 \\
\hline & R5 & 3.6 & 3.6 & 3.5 & 3.3 & 3.5 & 3.6 & 3.6 & 1.7 & 1.4 \\
\hline & R6 & 3.5 & 3.5 & 3.0 & 3.4 & 3.4 & 3.6 & 3.6 & 1.9 & 1.3 \\
\hline & R7 & 2.5 & 2.7 & 2.8 & 3.0 & 3.2 & 2.9 & 3.3 & 1.3 & 0.9 \\
\hline & R8 & 2.7 & 3.4 & 3.5 & 3.4 & 3.5 & 3.5 & 2.9 & 1.0 & 1.0 \\
\hline & R9 & 2.5 & 2.7 & 2.6 & 2.6 & 2.6 & 2.6 & 3.1 & 1.3 & 0.8 \\
\hline & $A v$ & 3.1 & 3.2 & 3.0 & 3.3 & 3.3 & 3.4 & 3.3 & 1.4 & 1.1 \\
\hline \multirow[t]{7}{*}{ Beam } & R1 & 3.6 & 3.5 & 3.5 & 2.6 & 3.0 & 3.6 & 3.5 & 3.6 & 2.4 \\
\hline & R2 & 3.6 & 3.5 & 3.5 & 3.5 & 3.5 & 3.6 & 3.5 & 2.8 & 2.3 \\
\hline & R3 & 3.6 & 3.6 & 3.5 & 3.0 & 3.0 & 3.5 & 3.6 & 2.3 & 2.8 \\
\hline & R4 & 3.6 & 3.6 & 3.5 & 3.5 & 3.5 & 3.6 & 3.5 & 2.7 & 2.5 \\
\hline & R5 & 3.5 & 3.6 & 3.6 & 3.5 & 3.5 & 3.5 & 3.5 & 2.8 & 2.5 \\
\hline & R6 & 3.5 & 3.2 & 3.5 & 3.4 & 3.4 & 3.5 & 3.5 & 2.1 & 2.3 \\
\hline & $A v$ & 3.6 & 3.5 & 3.5 & 3.3 & 3.3 & 3.5 & 3.5 & 2.7 & 2.5 \\
\hline \multirow[t]{5}{*}{ SQ } & R1 & & & 3.5 & 3.5 & 3.6 & 3.5 & 3.5 & 1.6 & \\
\hline & R2 & & & 3.5 & 3.1 & 2.9 & 3.5 & 3.5 & 1.5 & \\
\hline & R3 & & & 3.5 & 3.5 & 3.5 & 3.5 & 3.5 & 1.3 & \\
\hline & R4 & & & 3.5 & 3.5 & 3.5 & 3.5 & 3.5 & 2.0 & \\
\hline & R5 & & & 3.5 & 3.5 & 3.5 & 3.5 & 3.5 & 1.7 & \\
\hline
\end{tabular}




\begin{tabular}{|c|c|c|c|c|c|c|c|c|c|c|}
\hline Heading & Run & C1 & $\mathrm{C} 2$ & C4 & C5 & C6 & C7 & C9 & S1 & S2 \\
\hline & R6 & & & 3.5 & 3.5 & 3.5 & 3.6 & 3.6 & 2.6 & \\
\hline & $A v$ & & & 3.5 & 3.4 & 3.4 & 3.5 & 3.5 & 1.8 & \\
\hline \multirow[t]{5}{*}{$\mathrm{BQ}$} & R1 & & & 3.5 & 3.5 & 3.5 & 3.5 & 3.5 & & \\
\hline & R2 & & & 3.5 & 3.5 & 3.5 & 3.5 & 3.5 & & \\
\hline & R3 & & & 3.5 & 3.5 & 3.5 & 3.5 & 3.5 & & \\
\hline & R4 & & & 3.5 & 3.5 & 3.5 & 3.6 & 3.5 & & \\
\hline & $A v$ & & & 3.5 & 3.5 & 3.5 & 3.5 & 3.5 & & \\
\hline \multirow[t]{21}{*}{ BQ Repeat } & R1 & & & 3.5 & 3.5 & 3.5 & 3.5 & 3.5 & 1.7 & \\
\hline & R2 & & & 3.5 & 3.5 & 3.5 & 3.5 & 3.5 & 2.3 & \\
\hline & R3 & & & 3.5 & 3.5 & 3.5 & 3.5 & 3.5 & 2.5 & \\
\hline & R4 & & & 3.5 & 3.5 & 3.5 & 3.5 & 3.5 & 1.6 & \\
\hline & R5 & & & 3.5 & 3.5 & 3.5 & 3.5 & 3.5 & 2.1 & \\
\hline & R6 & & & 3.5 & 3.5 & 3.5 & 3.5 & 3.5 & 1.9 & \\
\hline & R7 & & & 3.5 & 3.5 & 3.5 & 3.5 & 3.5 & 2.8 & \\
\hline & R8 & & & 3.5 & 3.5 & 3.5 & 3.5 & 3.5 & 2.7 & \\
\hline & R9 & & & 3.5 & 3.5 & 3.5 & 3.5 & 3.5 & 2.3 & \\
\hline & R10 & & & 3.5 & 3.5 & 3.5 & 3.5 & 3.5 & 2.1 & \\
\hline & R11 & & & 3.5 & 3.5 & 3.5 & 3.5 & 3.5 & 1.9 & \\
\hline & R12 & & & 3.5 & 3.5 & 3.5 & 3.5 & 3.5 & 2.6 & \\
\hline & R13 & & & 3.5 & 3.5 & 3.5 & 3.5 & 3.5 & 1.9 & \\
\hline & R14 & & & 3.5 & 3.5 & 3.5 & 3.5 & 3.5 & 1.8 & \\
\hline & R15 & & & 3.5 & 3.5 & 3.5 & 3.5 & 3.5 & 2.2 & \\
\hline & R16 & & & 3.5 & 3.5 & 3.5 & 3.5 & 3.5 & 2.2 & \\
\hline & R17 & & & 3.6 & 3.5 & 3.5 & 3.5 & 3.5 & 2.6 & \\
\hline & R18 & & & 3.5 & 3.5 & 3.5 & 3.5 & 3.6 & 2.1 & \\
\hline & R19 & & & 3.5 & 3.4 & 3.5 & 3.5 & 3.5 & 1.8 & \\
\hline & R20 & & & 3.5 & 3.5 & 3.3 & 3.5 & 3.5 & 2.5 & \\
\hline & $A v$ & & & 3.5 & 3.5 & 3.5 & 3.5 & 3.5 & 2.2 & \\
\hline
\end{tabular}




\section{D.8 Wave M8}

Table D-15. Wave heights (inch) by heading for wave M8.

\begin{tabular}{|c|c|c|c|c|c|c|c|c|c|c|}
\hline Heading & Run & C1 & $\mathrm{C} 2$ & C4 & C5 & c6 & C7 & C9 & S1 & $S 2$ \\
\hline \multirow[t]{12}{*}{ Following } & R1 & 3.8 & 2.2 & 2.4 & 0.9 & 0.9 & 3.2 & 3.2 & 1.1 & 0.6 \\
\hline & R2 & 3.7 & 2.0 & 2.4 & 1.1 & 0.9 & 3.3 & 3.1 & 1.0 & 0.6 \\
\hline & R3 & 3.5 & 2.1 & 2.5 & 0.9 & 0.9 & 3.2 & 3.3 & 0.9 & 0.5 \\
\hline & R4 & 3.5 & 2.1 & 1.9 & 1.0 & 1.2 & 3.4 & 3.2 & 0.6 & 0.8 \\
\hline & R5 & 3.4 & 2.0 & 2.5 & 1.0 & 1.0 & 3.3 & 3.2 & 1.0 & 0.7 \\
\hline & R6 & 3.5 & 2.1 & 2.1 & 1.2 & 1.1 & 3.3 & 3.3 & 0.7 & 0.7 \\
\hline & R7 & 3.5 & 1.8 & 2.4 & 1.1 & 1.1 & 3.4 & 3.3 & 0.7 & 0.6 \\
\hline & R8 & 3.3 & 2.1 & 2.2 & 1.0 & 1.1 & 3.3 & 3.2 & 0.6 & 0.7 \\
\hline & R9 & 3.2 & 2.1 & 2.3 & 1.1 & 1.1 & 3.3 & 3.5 & 0.6 & 0.5 \\
\hline & R10 & 3.1 & 2.3 & 2.6 & 0.7 & 0.9 & 3.2 & 3.2 & 0.9 & 1.0 \\
\hline & R11 & 3.5 & 2.0 & 2.4 & 0.9 & 0.9 & 3.2 & 3.3 & 0.5 & 0.7 \\
\hline & $A v$ & 3.5 & 2.1 & 2.3 & 1.0 & 1.0 & 3.3 & 3.3 & 0.8 & 0.7 \\
\hline \multirow[t]{8}{*}{ Head } & R1 & 1.6 & 0.7 & 0.6 & 0.4 & 0.4 & 0.9 & 0.9 & 0.0 & 0.0 \\
\hline & R2 & 1.7 & 0.6 & 0.8 & 0.3 & 0.3 & 0.9 & 0.9 & 0.0 & 0.0 \\
\hline & R3 & 1.7 & 0.8 & 0.7 & 0.4 & 0.3 & 1.2 & 1.1 & 0.0 & 0.0 \\
\hline & R4 & 1.5 & 0.8 & 0.7 & 0.4 & 0.3 & 1.2 & 1.1 & 0.0 & 0.0 \\
\hline & R5 & 3.4 & 1.9 & 1.9 & 1.0 & 1.0 & 3.1 & 3.0 & 0.9 & 0.8 \\
\hline & R6 & 4.0 & 2.3 & 2.7 & 0.6 & 0.8 & 2.9 & 3.0 & 1.0 & 0.9 \\
\hline & R7 & 4.0 & 2.5 & 2.2 & 0.8 & 0.9 & 3.3 & 3.7 & 0.9 & 1.0 \\
\hline & $A v$ & 2.5 & 1.4 & 1.4 & 0.6 & 0.6 & 1.9 & 2.0 & 0.4 & 0.4 \\
\hline \multirow[t]{9}{*}{ Beam } & R1 & 3.4 & 2.1 & 2.2 & 1.3 & 1.3 & 3.2 & 3.3 & 0.8 & 0.8 \\
\hline & R2 & 3.4 & 2.2 & 2.1 & 1.0 & 1.0 & 3.3 & 3.4 & 0.6 & 0.7 \\
\hline & R3 & 3.6 & 2.1 & 2.2 & 1.0 & 1.1 & 3.3 & 3.4 & 0.8 & 0.6 \\
\hline & R4 & 3.1 & 2.2 & 2.1 & 1.0 & 1.1 & 3.3 & 3.2 & 0.8 & 0.6 \\
\hline & R5 & 3.2 & 2.2 & 2.3 & 1.1 & 1.3 & 3.3 & 3.4 & 0.8 & 0.5 \\
\hline & R6 & 3.3 & 2.3 & 2.3 & 1.3 & 1.3 & 3.3 & 3.4 & 0.9 & 0.8 \\
\hline & R7 & 3.4 & 2.3 & 2.3 & 1.1 & 1.1 & 3.3 & 3.4 & 0.8 & 0.6 \\
\hline & R8 & 3.3 & 2.3 & 2.2 & 1.1 & 1.1 & 3.3 & 3.5 & 0.6 & 0.6 \\
\hline & $\mathrm{Av}$ & 3.3 & 2.2 & 2.2 & 1.1 & 1.2 & 3.3 & 3.4 & 0.8 & 0.7 \\
\hline
\end{tabular}




\begin{tabular}{|l|l|l|l|l|l|l|l|l|l|l|}
\hline Heading & Run & C1 & C2 & C4 & C5 & C6 & C7 & C9 & S1 & S2 \\
\hline SQ & R1 & & & 2.7 & 0.6 & 0.7 & 2.5 & 2.4 & 0.5 & \\
\hline & R2 & & 2.7 & 0.5 & 0.6 & 2.5 & 2.4 & 0.5 & \\
\hline & R3 & & & 2.7 & 0.8 & 0.8 & 2.5 & 2.4 & 0.6 & \\
\hline & R4 & & 2.6 & 0.6 & 0.6 & 2.5 & 2.4 & 0.4 & \\
\hline & R5 & & & 2.7 & 0.6 & 0.7 & 2.5 & 2.4 & 0.6 & \\
\hline & R6 & & 2.6 & 0.6 & 0.6 & 2.5 & 2.4 & 0.6 & \\
\hline & R7 & & & 2.4 & 0.6 & 0.6 & 2.5 & 2.5 & 0.4 & \\
\hline & R8 & & & 2.7 & 0.7 & 0.7 & 2.5 & 2.6 & 0.5 & \\
\hline & R9 & & & 2.7 & 0.7 & 0.7 & 2.5 & 2.5 & 0.4 & \\
\hline & R10 & & & 2.7 & 0.8 & 0.7 & 2.5 & 2.5 & 0.5 & \\
\hline & Av & & & 2.6 & 0.7 & 0.7 & 2.5 & 2.4 & 0.5 & \\
\hline & R1 & & & 2.4 & 0.7 & 0.8 & 2.5 & 2.5 & & \\
\hline BQ & R2 & & & 2.4 & 0.7 & 0.9 & 2.5 & 2.5 & & \\
\hline & R3 & & 2.5 & 0.5 & 0.6 & 2.5 & 2.5 & & \\
\hline & R5 & & 2.5 & 0.6 & 0.7 & 2.5 & 2.5 & & \\
\hline & Av & & 2.4 & 0.6 & 0.7 & 2.5 & 2.5 & & \\
\hline
\end{tabular}

Table D-16. Wave periods (second) by heading for wave M8.

\begin{tabular}{|l|l|l|l|l|l|l|l|l|l|l|}
\hline Heading & Run & C1 & C2 & C4 & C5 & C6 & C7 & C9 & S1 & S2 \\
\hline Following & R1 & 3.8 & 3.8 & 3.8 & 2.4 & 2.4 & 3.8 & 3.8 & 3.0 & 2.2 \\
\hline & R2 & 3.8 & 3.8 & 3.8 & 3.0 & 2.5 & 3.8 & 3.8 & 2.7 & 2.1 \\
\hline & R3 & 3.8 & 3.8 & 3.8 & 2.4 & 2.4 & 3.8 & 3.8 & 2.5 & 1.7 \\
\hline & R4 & 3.8 & 3.9 & 2.8 & 2.3 & 3.1 & 3.8 & 3.8 & 1.9 & 2.8 \\
\hline & R5 & 3.8 & 3.8 & 3.8 & 2.7 & 2.7 & 3.8 & 3.8 & 2.9 & 2.6 \\
\hline & R6 & 3.8 & 3.8 & 2.8 & 3.3 & 3.1 & 3.8 & 3.8 & 2.1 & 2.6 \\
\hline & R7 & 3.8 & 3.3 & 3.8 & 2.9 & 2.8 & 3.8 & 3.8 & 2.4 & 2.1 \\
\hline & R8 & 3.8 & 3.8 & 3.8 & 2.8 & 2.9 & 3.8 & 3.8 & 2.0 & 2.4 \\
\hline & R9 & 3.8 & 3.8 & 3.8 & 3.1 & 3.1 & 3.8 & 3.8 & 2.3 & 1.6 \\
\hline & R10 & 3.3 & 3.9 & 3.9 & 1.7 & 2.3 & 3.7 & 3.7 & 2.8 & 2.9 \\
\hline & R11 & 3.8 & 3.8 & 3.8 & 2.5 & 2.5 & 3.8 & 3.8 & 1.6 & 2.4 \\
\hline & Av & 3.8 & 3.8 & 3.6 & 2.6 & 2.7 & 3.8 & 3.8 & 2.4 & 2.3 \\
\hline Head & R1 & 3.9 & 3.7 & 2.5 & 3.2 & 3.8 & 3.2 & 3.2 & 0.1 & 0.1 \\
\hline
\end{tabular}




\begin{tabular}{|c|c|c|c|c|c|c|c|c|c|c|}
\hline Heading & Run & C1 & C2 & C4 & C5 & C6 & C7 & C9 & S1 & S2 \\
\hline & R2 & 3.8 & 3.1 & 2.4 & 2.2 & 2.5 & 3.4 & 2.7 & 0.1 & 0.1 \\
\hline & R3 & 3.9 & 3.4 & 2.9 & 3.0 & 2.4 & 3.9 & 3.6 & 0.1 & 0.1 \\
\hline & R4 & 3.3 & 3.4 & 2.9 & 2.9 & 2.6 & 3.8 & 3.7 & 0.1 & 0.1 \\
\hline & R5 & 3.9 & 3.5 & 3.3 & 2.9 & 2.9 & 3.8 & 3.9 & 3.3 & 2.7 \\
\hline & R6 & 3.8 & 3.8 & 3.8 & 1.9 & 2.4 & 3.6 & 3.5 & 2.9 & 2.8 \\
\hline & R7 & 3.8 & 3.8 & 3.3 & 2.4 & 2.9 & 3.8 & 3.8 & 2.7 & 3.3 \\
\hline & $A v$ & 3.8 & 3.5 & 3.0 & 2.6 & 2.8 & 3.6 & 3.5 & 1.3 & 1.3 \\
\hline \multirow[t]{9}{*}{ Beam } & R1 & 3.8 & 3.8 & 3.8 & 3.9 & 3.9 & 3.8 & 3.8 & 2.5 & 2.9 \\
\hline & R2 & 3.8 & 3.8 & 3.8 & 2.9 & 2.9 & 3.8 & 3.8 & 2.0 & 2.3 \\
\hline & R3 & 3.8 & 3.8 & 3.8 & 2.8 & 3.0 & 3.8 & 3.8 & 2.8 & 2.3 \\
\hline & R4 & 3.8 & 3.8 & 3.8 & 2.8 & 3.3 & 3.9 & 3.8 & 2.9 & 2.4 \\
\hline & R5 & 3.8 & 3.8 & 3.8 & 3.1 & 3.8 & 3.9 & 3.8 & 2.6 & 1.8 \\
\hline & R6 & 3.8 & 3.8 & 3.8 & 3.8 & 3.8 & 3.8 & 3.8 & 3.1 & 3.0 \\
\hline & R7 & 3.8 & 3.8 & 3.8 & 2.9 & 3.1 & 3.8 & 3.8 & 2.7 & 2.2 \\
\hline & R8 & 3.8 & 3.8 & 3.8 & 3.2 & 3.1 & 3.8 & 3.8 & 2.1 & 2.1 \\
\hline & $A v$ & 3.8 & 3.8 & 3.8 & 3.2 & 3.4 & 3.8 & 3.8 & 2.6 & 2.4 \\
\hline \multirow[t]{11}{*}{ SQ } & R1 & & & 3.8 & 2.0 & 2.1 & 3.8 & 3.8 & 2.0 & 2.8 \\
\hline & R2 & & & 3.8 & 1.6 & 1.8 & 3.8 & 3.9 & 1.8 & \\
\hline & R3 & & & 3.8 & 2.1 & 2.2 & 3.8 & 3.8 & 2.3 & \\
\hline & R4 & & & 3.8 & 1.8 & 1.8 & 3.8 & 3.8 & 2.0 & \\
\hline & R5 & & & 3.8 & 1.7 & 1.9 & 3.8 & 3.8 & 2.4 & \\
\hline & R6 & & & 3.8 & 1.6 & 1.7 & 3.8 & 3.8 & 2.4 & \\
\hline & R7 & & & 3.8 & 2.1 & 2.2 & 3.8 & 3.8 & 2.2 & \\
\hline & R8 & & & 3.8 & 2.1 & 2.2 & 3.8 & 3.9 & 2.2 & \\
\hline & R9 & & & 3.8 & 2.1 & 2.1 & 3.8 & 3.8 & 1.9 & \\
\hline & R10 & & & 3.8 & 2.2 & 1.8 & 3.8 & 3.8 & 2.0 & \\
\hline & $A v$ & & & 3.8 & 1.9 & 2.0 & 3.8 & 3.8 & 2.1 & \\
\hline \multirow[t]{5}{*}{$\mathrm{BQ}$} & R1 & & & 3.8 & 2.4 & 2.8 & 3.8 & 3.8 & & \\
\hline & R2 & & & 3.8 & 2.4 & 3.0 & 3.8 & 3.8 & & \\
\hline & R3 & & & 3.8 & 1.6 & 1.9 & 3.8 & 3.8 & & \\
\hline & R5 & & & 3.8 & 1.7 & 2.2 & 3.8 & 3.8 & & \\
\hline & $A v$ & & & 3.8 & 2.0 & 2.5 & 3.8 & 3.8 & & \\
\hline
\end{tabular}




\section{D.9 Wave M9}

Table D-17. Wave heights (inch) by heading for wave M9.

\begin{tabular}{|c|c|c|c|c|c|c|c|c|c|c|}
\hline Heading & Run & C1 & $\mathrm{C} 2$ & C4 & C5 & C6 & C7 & C9 & S1 & S2 \\
\hline \multirow[t]{10}{*}{ Following } & R1 & 3.2 & 2.1 & 3.0 & 1.1 & 1.1 & 3.5 & 2.6 & 0.5 & 0.4 \\
\hline & R2 & 3.2 & 1.8 & 2.7 & 1.3 & 1.3 & 3.6 & 2.6 & 0.8 & 0.5 \\
\hline & R3 & 3.3 & 2.2 & 2.6 & 1.2 & 1.0 & 3.5 & 2.6 & 0.7 & 0.5 \\
\hline & R4 & 3.0 & 2.3 & 2.6 & 1.4 & 1.2 & 3.6 & 2.6 & 0.5 & 0.7 \\
\hline & R5 & 3.0 & 2.1 & 2.5 & 1.5 & 1.2 & 3.6 & 2.7 & 0.6 & 0.6 \\
\hline & R6 & 3.0 & 1.9 & 2.1 & 1.4 & 1.4 & 3.5 & 2.6 & 0.6 & 0.5 \\
\hline & R7 & 3.6 & 2.2 & 2.7 & 1.4 & 1.2 & 3.7 & 2.7 & 0.5 & 0.5 \\
\hline & R8 & 2.7 & 1.6 & 2.1 & 1.4 & 1.4 & 3.4 & 2.7 & 0.6 & 0.6 \\
\hline & R9 & 3.5 & 2.0 & 2.9 & 1.4 & 1.4 & 3.4 & 2.7 & 0.4 & 0.4 \\
\hline & Av & 3.2 & 2.0 & 2.6 & 1.3 & 1.3 & 3.5 & 2.6 & 0.6 & 0.5 \\
\hline \multirow[t]{8}{*}{ Head } & R1 & 0.7 & 0.5 & 0.9 & 0.4 & 0.5 & 0.9 & 0.8 & 0.0 & 0.0 \\
\hline & R2 & 1.2 & 0.4 & 0.8 & 0.3 & 0.4 & 0.8 & 0.9 & 0.0 & 0.0 \\
\hline & R3 & 1.1 & 0.6 & 0.9 & 0.3 & 0.2 & 0.9 & 0.7 & 0.0 & 0.0 \\
\hline & R4 & 1.5 & 0.6 & 0.8 & 0.3 & 0.3 & 1.0 & 0.8 & 0.0 & 0.0 \\
\hline & R5 & 1.4 & 0.6 & 0.9 & 0.2 & 0.3 & 1.0 & 0.8 & 0.0 & 0.0 \\
\hline & R6 & 3.1 & 2.2 & 2.5 & 1.2 & 1.2 & 3.0 & 2.1 & 0.7 & 0.5 \\
\hline & R7 & 3.5 & 2.7 & 2.9 & 1.4 & 1.4 & 2.9 & 2.5 & 0.6 & 0.6 \\
\hline & $A v$ & 1.8 & 1.1 & 1.4 & 0.6 & 0.6 & 1.5 & 1.2 & 0.2 & 0.2 \\
\hline \multirow[t]{9}{*}{ Beam } & R1 & 3.3 & 2.3 & 2.7 & 1.4 & 1.4 & 3.5 & 2.6 & 0.7 & 0.7 \\
\hline & R2 & 3.3 & 1.8 & 2.7 & 1.4 & 1.3 & 3.4 & 2.7 & 0.4 & 0.6 \\
\hline & R3 & 3.3 & 2.4 & 2.7 & 1.4 & 1.4 & 3.5 & 2.6 & 0.5 & 0.7 \\
\hline & R4 & 2.5 & 1.9 & 2.7 & 1.4 & 1.4 & 3.5 & 2.2 & 0.7 & 0.6 \\
\hline & R5 & 2.9 & 1.7 & 2.7 & 1.5 & 1.5 & 3.4 & 2.9 & 0.5 & 0.7 \\
\hline & R6 & 3.5 & 1.5 & 2.6 & 1.5 & 1.4 & 3.6 & 2.9 & 0.6 & 0.4 \\
\hline & R7 & 3.4 & 1.6 & 2.7 & 1.4 & 1.4 & 3.4 & 2.9 & 0.4 & 0.5 \\
\hline & R8 & 3.0 & 2.1 & 2.7 & 1.4 & 1.4 & 3.4 & 2.4 & 0.4 & 0.5 \\
\hline & Av & 3.1 & 1.9 & 2.7 & 1.4 & 1.4 & 3.5 & 2.7 & 0.5 & 0.6 \\
\hline \multirow[t]{2}{*}{ SQ } & R1 & & & 3.7 & 1.6 & 1.6 & 3.1 & 2.9 & 0.5 & \\
\hline & R2 & & & 3.8 & 1.6 & 1.6 & 3.1 & 3.0 & 0.4 & \\
\hline
\end{tabular}




\begin{tabular}{|c|c|c|c|c|c|c|c|c|c|c|}
\hline Heading & Run & C1 & C2 & C4 & C5 & C6 & $\mathrm{C7}$ & C9 & S1 & S2 \\
\hline & R3 & & & 3.7 & 1.6 & 1.6 & 3.0 & 3.0 & 0.3 & \\
\hline & R4 & & & 3.9 & 1.6 & 1.4 & 3.0 & 3.0 & 0.6 & \\
\hline & R5 & & & 3.8 & 1.3 & 1.3 & 3.1 & 3.0 & 0.5 & \\
\hline & R6 & & & 3.6 & 1.2 & 1.2 & 3.1 & 2.9 & 0.4 & \\
\hline & R7 & & & 3.7 & 1.6 & 1.6 & 3.2 & 2.9 & 0.6 & \\
\hline & R8 & & & 3.6 & 1.2 & 1.1 & 3.0 & 2.9 & 0.4 & \\
\hline & R9 & & & 3.8 & 1.3 & 1.4 & 3.1 & 2.9 & 0.4 & \\
\hline & R10 & & & 3.6 & 1.5 & 1.5 & 3.2 & 2.9 & 0.4 & \\
\hline & R11 & & & 3.6 & 1.6 & 1.4 & 3.2 & 2.8 & 0.3 & \\
\hline & R12 & & & 3.5 & 1.6 & 1.5 & 3.1 & 2.8 & 0.3 & \\
\hline & R13 & & & 3.8 & 1.5 & 1.7 & 3.2 & 3.0 & 0.4 & \\
\hline & R14 & & & 3.7 & 1.4 & 1.5 & 3.2 & 3.0 & 0.4 & \\
\hline & R15 & & & 3.7 & 1.5 & 1.4 & 3.2 & 2.9 & 0.5 & \\
\hline & Av & & & 3.7 & 1.5 & 1.5 & 3.1 & 2.9 & 0.4 & \\
\hline$B Q$ & R1 & & & 3.0 & 1.3 & 1.3 & 2.7 & 2.4 & & \\
\hline & R2 & & & 3.0 & 1.2 & 1.2 & 2.7 & 2.4 & & \\
\hline & R3 & & & 3.0 & 1.2 & 1.2 & 2.6 & 2.4 & & \\
\hline & R4 & & & 3.1 & 1.3 & 1.2 & 2.7 & 2.4 & & \\
\hline & R5 & & & 3.0 & 1.3 & 1.3 & 2.6 & 2.4 & & \\
\hline & R6 & & & 3.1 & 1.3 & 1.3 & 2.7 & 2.4 & & \\
\hline & Av & & & 3.0 & 1.3 & 1.2 & 2.7 & 2.4 & & \\
\hline & & & & & & & & & & \\
\hline
\end{tabular}

Table D-18. Wave periods (second) by heading for wave M9.

\begin{tabular}{|l|l|l|l|l|l|l|l|l|l|l|}
\hline Heading & Run & C1 & C2 & C4 & C5 & C6 & C7 & C9 & S1 & S2 \\
\hline Following & R1 & 3.9 & 3.9 & 4.5 & 4.0 & 4.0 & 4.6 & 4.6 & 1.8 & 1.7 \\
\hline & R2 & 3.9 & 3.4 & 3.9 & 4.7 & 4.7 & 4.6 & 4.5 & 2.8 & 1.8 \\
\hline & R3 & 3.9 & 4.5 & 3.9 & 4.1 & 3.6 & 4.5 & 4.5 & 2.4 & 2.1 \\
\hline & R4 & 3.6 & 4.5 & 3.4 & 4.4 & 4.3 & 4.6 & 4.5 & 1.9 & 2.8 \\
\hline & R5 & 3.6 & 4.2 & 3.8 & 4.6 & 3.8 & 4.6 & 4.6 & 2.0 & 2.0 \\
\hline & R6 & 3.6 & 3.8 & 2.9 & 4.7 & 4.5 & 4.6 & 4.5 & 2.2 & 1.9 \\
\hline & R7 & 4.5 & 4.6 & 3.9 & 4.6 & 3.8 & 4.5 & 4.6 & 1.6 & 2.1 \\
\hline
\end{tabular}




\begin{tabular}{|c|c|c|c|c|c|c|c|c|c|c|}
\hline Heading & Run & C1 & $\mathrm{C2}$ & C4 & C5 & C6 & C7 & $c 9$ & S1 & S2 \\
\hline & R8 & 3.2 & 3.0 & 3.2 & 4.8 & 4.6 & 4.5 & 4.6 & 2.3 & 2.6 \\
\hline & R9 & 4.5 & 3.8 & 4.5 & 4.6 & 4.7 & 4.5 & 4.5 & 1.5 & 1.9 \\
\hline & $A v$ & 3.9 & 4.0 & 3.8 & 4.5 & 4.2 & 4.6 & 4.5 & 2.1 & 2.1 \\
\hline \multirow[t]{8}{*}{ Head } & R1 & 1.8 & 2.3 & 3.1 & 3.6 & 4.5 & 3.6 & 3.9 & 0.1 & 0.1 \\
\hline & $\mathrm{R} 2$ & 3.4 & 1.7 & 3.1 & 2.3 & 2.8 & 3.4 & 3.9 & 0.1 & 0.1 \\
\hline & R3 & 3.8 & 3.0 & 3.0 & 1.7 & 1.8 & 3.6 & 2.9 & 0.1 & 0.1 \\
\hline & R4 & 4.6 & 3.3 & 3.9 & 2.7 & 2.5 & 4.5 & 4.4 & 0.1 & 0.1 \\
\hline & R5 & 4.5 & 3.3 & 4.5 & 2.5 & 2.9 & 4.5 & 3.9 & 0.1 & 0.1 \\
\hline & R6 & 4.3 & 3.6 & 3.6 & 4.2 & 4.3 & 4.3 & 3.9 & 2.3 & 2.0 \\
\hline & R7 & 4.5 & 4.6 & 4.6 & 4.6 & 4.6 & 4.3 & 4.5 & 2.2 & 2.3 \\
\hline & $A v$ & 3.8 & 3.1 & 3.7 & 3.1 & 3.3 & 4.0 & 3.9 & 0.7 & 0.7 \\
\hline \multirow[t]{9}{*}{ Beam } & R1 & 4.6 & 4.6 & 4.6 & 4.6 & 4.6 & 4.5 & 4.6 & 2.6 & 2.8 \\
\hline & R2 & 4.5 & 3.6 & 4.6 & 4.7 & 4.7 & 4.5 & 4.6 & 1.4 & 2.4 \\
\hline & R3 & 4.5 & 4.6 & 4.6 & 4.7 & 4.7 & 4.5 & 4.5 & 2.1 & 2.6 \\
\hline & R4 & 3.1 & 3.4 & 4.6 & 4.6 & 4.7 & 4.5 & 3.4 & 2.3 & 2.5 \\
\hline & R5 & 3.7 & 2.7 & 4.6 & 4.6 & 4.6 & 4.5 & 4.5 & 2.1 & 2.8 \\
\hline & R6 & 4.6 & 2.3 & 4.6 & 4.6 & 4.5 & 4.6 & 4.5 & 2.1 & 1.4 \\
\hline & R7 & 4.6 & 2.7 & 4.6 & 4.5 & 4.5 & 4.4 & 4.6 & 1.4 & 2.3 \\
\hline & R8 & 3.8 & 3.7 & 4.6 & 4.4 & 4.6 & 4.5 & 3.8 & 1.2 & 2.0 \\
\hline & $A v$ & 4.2 & 3.4 & 4.6 & 4.6 & 4.6 & 4.5 & 4.3 & 1.9 & 2.4 \\
\hline \multirow[t]{12}{*}{$\mathrm{SQ}$} & R1 & & & 4.6 & 4.6 & 4.6 & 4.6 & 4.5 & 2.1 & \\
\hline & R2 & & & 4.6 & 4.7 & 4.7 & 4.6 & 4.6 & 1.5 & \\
\hline & R3 & & & 4.6 & 4.6 & 4.7 & 4.5 & 4.5 & 1.3 & \\
\hline & R4 & & & 4.5 & 4.6 & 4.5 & 4.6 & 4.5 & 2.5 & \\
\hline & R5 & & & 4.5 & 3.7 & 3.7 & 4.5 & 4.6 & 2.0 & \\
\hline & R6 & & & 4.5 & 3.1 & 3.1 & 4.5 & 4.6 & 1.5 & \\
\hline & R7 & & & 4.6 & 4.6 & 4.6 & 4.6 & 4.6 & 2.4 & \\
\hline & R8 & & & 4.6 & 3.6 & 3.6 & 4.5 & 4.5 & 1.7 & \\
\hline & R9 & & & 4.5 & 3.7 & 4.2 & 4.6 & 4.5 & 1.4 & \\
\hline & R10 & & & 4.6 & 4.5 & 4.5 & 4.6 & 4.6 & 1.4 & \\
\hline & R11 & & & 4.6 & 4.7 & 4.0 & 4.6 & 4.6 & 1.4 & \\
\hline & R12 & & & 4.6 & 4.6 & 4.3 & 4.5 & 4.6 & 1.3 & \\
\hline
\end{tabular}




\begin{tabular}{|l|l|l|l|l|l|l|l|l|l|l|}
\hline Heading & Run & C1 & C2 & C4 & C5 & C6 & C7 & C9 & S1 & S2 \\
\hline & R13 & & & 4.6 & 3.9 & 4.7 & 4.6 & 4.5 & 1.5 & \\
\hline & R14 & & & 4.6 & 4.0 & 4.5 & 4.6 & 4.6 & 1.7 & \\
\hline & R15 & & & 4.5 & 4.1 & 4.1 & 4.6 & 4.5 & 1.6 & \\
\hline & Av & & & 4.6 & 4.2 & 4.3 & 4.5 & 4.6 & 1.7 & \\
\hline BQ & R1 & & & 4.5 & 4.7 & 4.7 & 4.5 & 4.5 & & \\
\hline & R2 & & & 4.5 & 4.5 & 4.7 & 4.6 & 4.5 & & \\
\hline & R3 & & & 4.6 & 4.6 & 4.6 & 4.6 & 4.6 & & \\
\hline & R4 & & & 4.6 & 4.7 & 4.1 & 4.6 & 4.5 & & \\
\hline & R5 & & & 4.5 & 4.7 & 4.7 & 4.6 & 4.5 & & \\
\hline & R6 & & & 4.6 & 4.7 & 4.7 & 4.6 & 4.6 & & \\
\hline & Av & & & 4.6 & 4.6 & 4.6 & 4.6 & 4.5 & & \\
\hline
\end{tabular}

\section{D.10 Irregular seas - SQ}

Table D-19. Irregular wave condition statistics for sea state 3 for SQ.

\begin{tabular}{|l|l|l|l|l|l|l|l|}
\hline & C4 & C5 & C6 & C7 & C9 & S1 & Average \\
\hline$H_{m 0}$ (in.) & 0.57 & 0.54 & 0.53 & 0.87 & 0.91 & 0.44 & 0.64 \\
\hline$T_{p}(\mathrm{~s})$ & 1.86 & 1.78 & 1.78 & 1.86 & 1.86 & 1.78 & 1.82 \\
\hline
\end{tabular}

Table D-20. Irregular wave condition statistics for sea state 4 for SQ.

\begin{tabular}{|l|l|l|l|l|l|l|l|}
\hline & C4 & C5 & C6 & C7 & C9 & S1 & Average \\
\hline$H_{m 0}$ (in.) & 1.08 & 1.34 & 1.34 & 2.07 & 2.10 & 1.44 & 1.56 \\
\hline$T_{p}$ (s) & 1.52 & 1.46 & 1.46 & 1.46 & 1.46 & 1.46 & 1.47 \\
\hline
\end{tabular}

\section{D.11 Irregular seas - BQ}

Table D-21. Irregular wave condition statistics for sea state 3 for BQ.

\begin{tabular}{|l|l|l|l|l|l|l|l|}
\hline & C4 & C5 & C6 & C7 & C9 & S1 & Average \\
\hline$H_{m 0}$ (in.) & 0.83 & 0.82 & 0.81 & 1.07 & 1.15 & 0.62 & 0.88 \\
\hline$T_{p}$ (s) & 1.86 & 1.78 & 1.78 & 1.78 & 1.78 & 1.78 & 1.79 \\
\hline
\end{tabular}

Table D-22. Irregular wave condition statistics for sea state $\mathbf{4}$ for BQ.

\begin{tabular}{|l|l|l|l|l|l|l|l|}
\hline & C4 & C5 & C6 & C7 & C9 & S1 & Average \\
\hline$H_{m 0}$ (in.) & 1.19 & 1.09 & 1.08 & 1.88 & 1.83 & 1.71 & 1.46 \\
\hline$T_{p}$ (s) & 1.64 & 1.46 & 1.46 & 1.52 & 1.52 & 1.52 & 1.52 \\
\hline
\end{tabular}




\section{Unit Conversion Factors}

A sponsor requirement for this study was the use of English Customary units of measurement. Most measurements and calculations were done in International System (SI) units and then converted to English Customary. The following table can be used to convert back to SI units.

\begin{tabular}{|l|l|l|}
\hline Multiply & By & To Obtain \\
\hline feet & 0.3048 & meters \\
\hline cubic feet & 0.02831685 & cubic meters \\
\hline pounds (force) & 4.448222 & Newtons \\
\hline square feet & 0.09290304 & square meters \\
\hline knots & 1.6878099 & feet per second \\
\hline knots & 0.5144444 & meters per second \\
\hline
\end{tabular}




\section{Acronyms and Abbreviations}

$\begin{array}{ll}\text { BQ } & \text { bow quartering seas } \\ \text { BQ-R } & \text { bow quartering sea repeats } \\ \text { BS } & \text { beam seas } \\ \text { CHL } & \text { Coastal and Hydraulics Laboratory } \\ \text { DAQ } & \text { data acquisition } \\ \text { DSWG } & \text { Directional Spectral Wave Generator } \\ \text { EMOGS } & \text { Environmental Monitoring and Operator Guidance System } \\ \text { ERDC } & \text { US Army Engineer Research and Development Center } \\ \text { FS } & \text { following seas } \\ \text { HES } & \text { Harbors, Entrances, and Structures } \\ \text { HS } & \text { head seas } \\ \text { LabVIEW } & \text { Laboratory Virtual Instrumentation Engineering Workbench } \\ \text { LAMP } & \text { Large Amplitude Motion Program } \\ \text { LIDAR } & \text { Light Detection and Ranging } \\ \text { MASK } & \text { Maneuvering and Seakeeping Basin } \\ \text { NSB } & \text { Naval Submarine Base } \\ \text { NSWCCD } & \text { Naval Surface Warfare Center, Carderock Division } \\ \text { RMSE } & \text { root-mean-square-error } \\ \text { SI } & \text { International System } \\ \text { SQ } & \text { stern quartering } \\ \text { TMA } & \text { Texel, Marsen, and Arsole Spectrum }\end{array}$




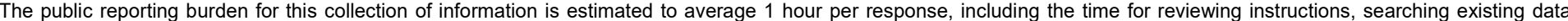

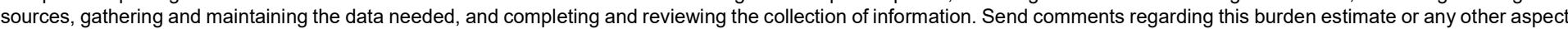

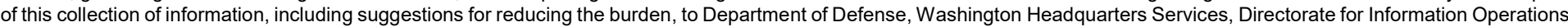

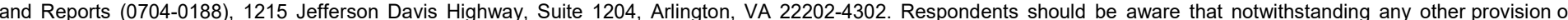
law, no person shall be subject to any penalty for failing to comply with a collection of information if it does not display a currently valid OMB control number.

PLEASE DO NOT RETURN YOUR FORM TO THE ABOVE ADDRESS.

\begin{tabular}{l|l|l}
\hline $\begin{array}{l}\text { 1. REPORT DATE } \\
\text { August } 2020\end{array}$ & $\begin{array}{l}\text { 2. REPORT TYPE } \\
\text { Final Report }\end{array}$ & 3. DATES COVERED (From - To)
\end{tabular}

\section{TITLE AND SUBTITLE}

Shallow Water Seakeeping Tests with Columbia Class Submarine for Integration into the

Environmental Monitoring and Operator Guidance System 5a. CONTRACT NUMBER

5b. GRANT NUMBER

5c. PROGRAM ELEMENT NUMBER

6. AUTHOR(S)

Abigail L. Stehno and Jeffrey A. Melby

\section{5d. PROJECT NUMBER}

5e. TASK NUMBER

5f. WORK UNIT NUMBER

\section{PERFORMING ORGANIZATION NAME(S) AND ADDRESS(ES)}

Coastal and Hydraulics Laboratory

US Army Engineer Research and Development Center

3909 Halls Ferry Road

Vicksburg, MS 39180-6199

\section{SPONSORING/MONITORING AGENCY NAME(S) AND ADDRESS(ES)}

US Naval Surface Warfare Center

Carderock Division

West Bethesda, MD 20817-5700
8. PERFORMING ORGANIZATION REPORT NUMBER

ERDC/CHL TR-20-18

10. SPONSOR/MONITOR'S ACRONYM(S) NSWCCD

11. SPONSOR/MONITOR'S REPORT NUMBER(S)

\section{DISTRIBUTION/AVAILABILITY STATEMENT}

Approved for public release; distribution is unlimited.

\section{SUPPLEMENTARY NOTES}

MIPR N0002418MP00414

\section{ABSTRACT}

The Environmental Monitoring and Operation Guidance System (EMOGS) tool was developed in 1989 to provide a real-time risk analysis for underkeel clearance for the Ohio class submarine while in transit to the Naval Submarine Base at Kings Bay, Georgia. The program computes expected submarine response for input water level, depth, speed, wave, and other input conditions using shallowwater motion transfer functions generated by the strip theory tool, Large Amplitude Motion Program (LAMP). The integration of the new Columbia class submarine into EMOGS required that new transfer functions be developed using LAMP. The LAMP results are to be validated using measured motions from physical model laboratory testing. This report summarizes a laboratory study of the Columbia class submarine response in shallow-water waves. The study was conducted at the US Army Engineer Research and Development Center, Coastal and Hydraulics Laboratory, and was done in direct support of the Naval Surface Warfare Center, Carderock Division. These seakeeping tests were performed in a shallow basin with a multi-directional wave generator, with measured still water vessel motions and measured vessel motion in regular and irregular waves of varying height, period, and direction.

\section{SUBJECT TERMS}

Columbia Class (Submarines), Hydrodynamics, Kings Bay (Ga.), Navigation, Water waves

\section{SECURITY CLASSIFICATION OF:}

\begin{tabular}{|l|c|l|}
\hline a. REPORT & b. ABSTRACT & c. THIS PAGE \\
Unclassified & Unclassified & Unclassified \\
& & \\
\hline
\end{tabular}

17. LIMITATION OF ABSTRACT

SAR
18. NUMBER OF PAGES

84 19a. NAME OF RESPONSIBLE PERSON

Abigail L. Stehno

19b. TELEPHONE NUMBER (Include area code)

601-634-2062 